OAK RIDGE

ORNL/TM-2014/539

NATIONAL LABORATORY

MANAGED BY UT-BATTELLE FOR THE DEPARTMENT OF ENERGY

\title{
Variable Speed Heat Pump Sizing Guide for Mixed-Humid Climates
}
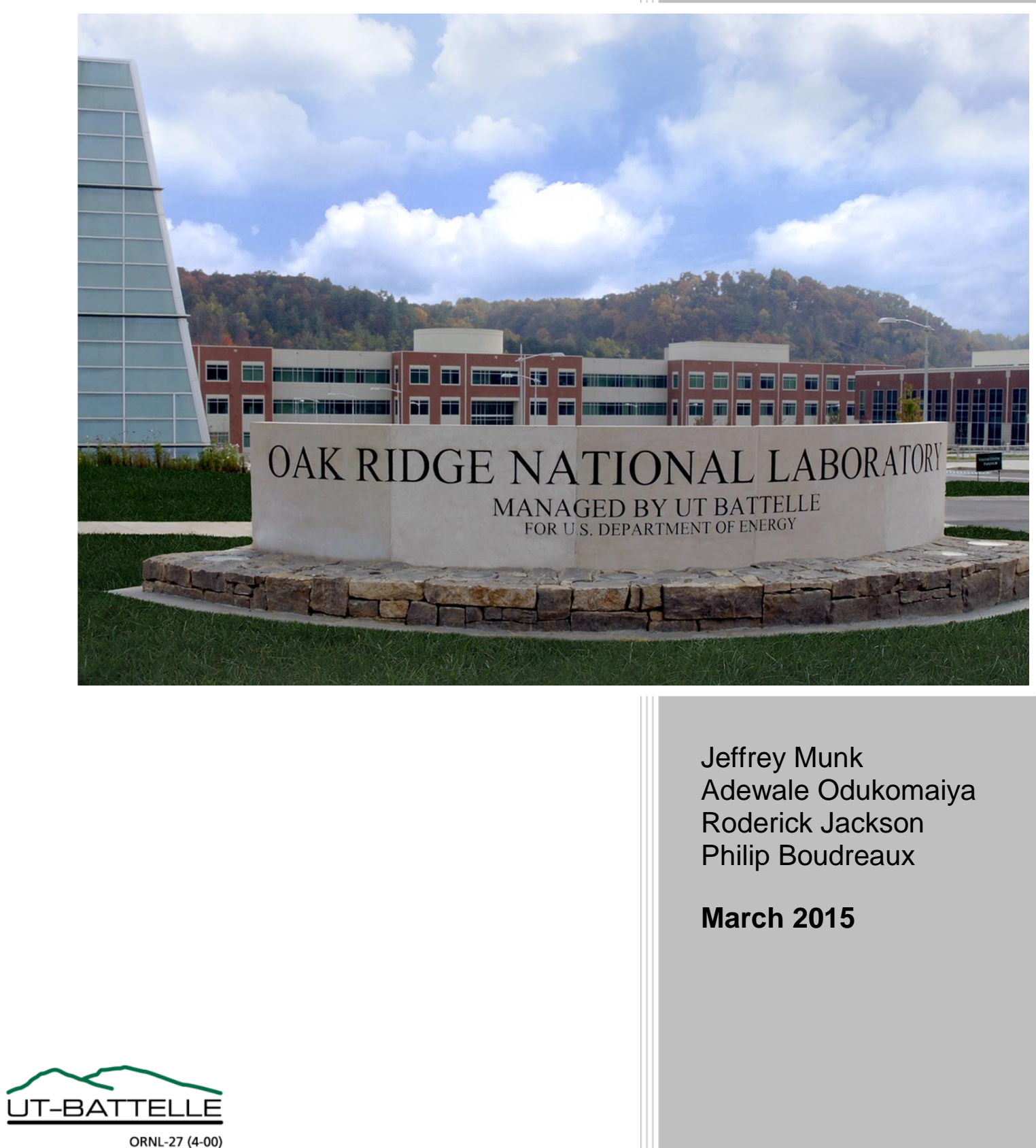

Jeffrey Munk Adewale Odukomaiya Roderick Jackson Philip Boudreaux

March 2015 


\section{DOCUMENT AVAILABILITY}

Reports produced after January 1, 1996, are generally available free via US Department of Energy (DOE) SciTech Connect.

Website http://www.osti.gov/scitech/

Reports produced before January 1, 1996, may be purchased by members of the public from the following source:

National Technical Information Service

5285 Port Royal Road

Springfield, VA 22161

Telephone 703-605-6000 (1-800-553-6847)

TDD 703-487-4639

Fax 703-605-6900

E-mail info@ntis.gov

Website http://www.ntis.gov/help/ordermethods.aspx

Reports are available to DOE employees, DOE contractors, Energy Technology Data Exchange representatives, and International Nuclear Information System representatives from the following source:

Office of Scientific and Technical Information

PO Box 62

Oak Ridge, TN 37831

Telephone 865-576-8401

Fax 865-576-5728

E-mail reports@osti.gov

Website http://www.osti.gov/contact.html

This report was prepared as an account of work sponsored by an agency of the United States Government. Neither the United States Government nor any agency thereof, nor any of their employees, makes any warranty, express or implied, or assumes any legal liability or responsibility for the accuracy, completeness, or usefulness of any information, apparatus, product, or process disclosed, or represents that its use would not infringe privately owned rights. Reference herein to any specific commercial product, process, or service by trade name, trademark, manufacturer, or otherwise, does not necessarily constitute or imply its endorsement, recommendation, or favoring by the United States Government or any agency thereof. The views and opinions of authors expressed herein do not necessarily state or reflect those of the United States Government or any agency thereof. 
ORNL/TM-2014/539

Buildings Technologies Research and Integration Center

\title{
Variable Speed Heat Pump Sizing Guide for Mixed-Humid Climates
}

\author{
Jeffrey Munk \\ Adewale Odukomaiya \\ Roderick Jackson \\ Philip Boudreaux
}

March 2015

Prepared by

OAK RIDGE NATIONAL LABORATORY

Oak Ridge, Tennessee 37831-6283

managed by

UT-BATTELLE, LLC

for the

US DEPARTMENT OF ENERGY

under contract DE-AC05-00OR22725 



\section{CONTENTS}

Page

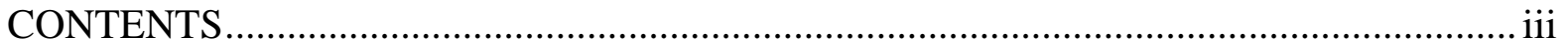

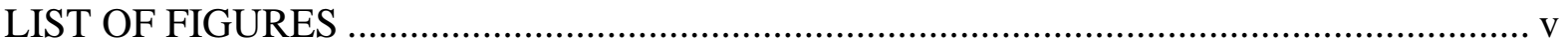

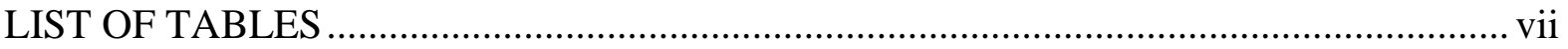

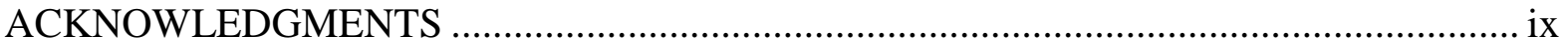

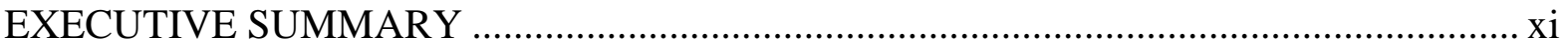

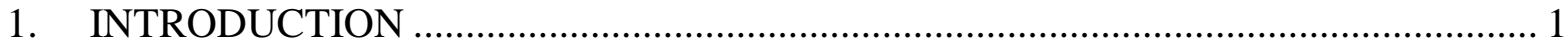

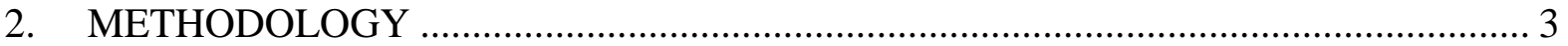

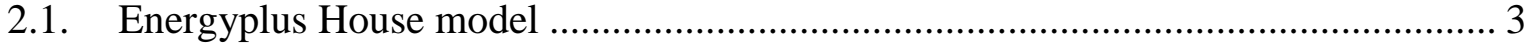

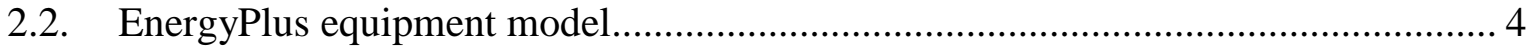

2.2.1. Cooling Performance Curves ....................................................................... 5

2.2.2. Heating Performance Curves ……………................................................... 10

2.2.3. Equipment Model Validation..................................................................... 15

3. INTERPRETATION OF RESULTS …………...................................................... 17

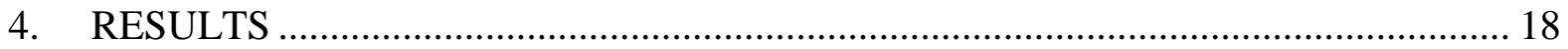

4.1. Mixed-Humid Climate …………………………....................................... 18

4.1.1. Charlotte, North Carolina.............................................................................. 18

4.1.2. Little Rock, Arkansas................................................................................ 22

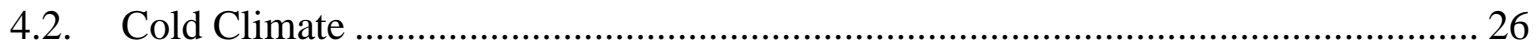

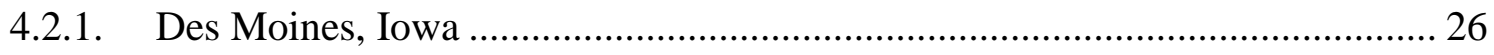

4.2.2. Pittsburgh, Pennsylvania .............................................................................. 32

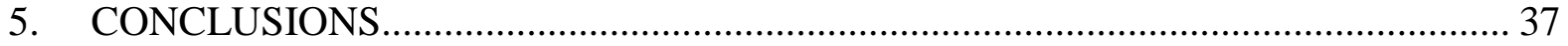

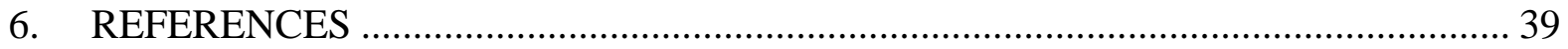

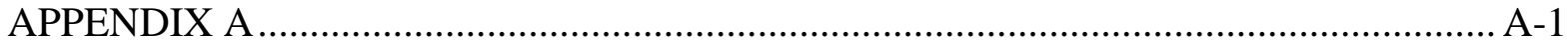

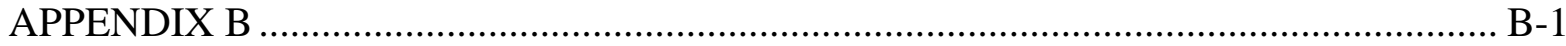

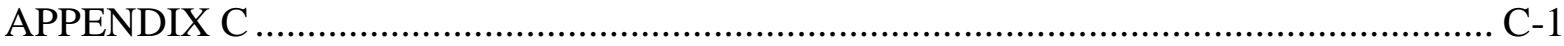





\section{LIST OF FIGURES}

\section{Figure}

Figure 1: Climate zones in the United States (Office of Energy Efficiency and Renewable

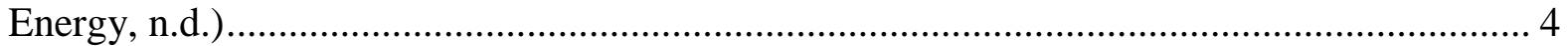

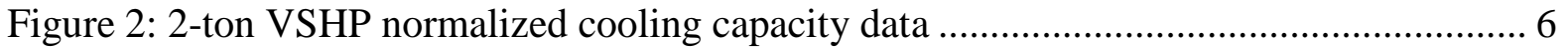

Figure $3:$ 3-ton VSHP normalized cooling capacity data ............................................ 7

Figure 4: 2 -ton normalized cooling efficiency data .................................................... 8

Figure 5: 3-ton normalized cooling efficiency data ..................................................... 9

Figure 6: Normalized cooling efficiency curves for 22 SEER VSHP option in BEopt .......... 9 Figure 7: Laboratory cooling efficiency comparison of a VSHP to a single speed heat pump taken from (Hunt, et al, 2013) ................................................................................ 10

Figure 8: Heating capacity ratio vs. OAT from manufacturer's expanded product data for all

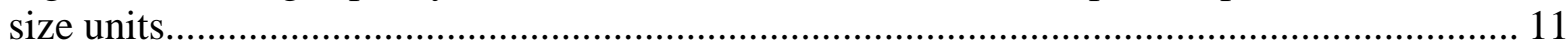

Figure 9: 2-ton VSHP normalized heating capacity data.................................................. 12

Figure 10: 3-ton VSHP normalized heating capacity data................................................... 13

Figure 11: 2-ton VSHP normalized heating efficiency data ........................................... 14

Figure 12: 3-ton VSHP normalized efficiency data........................................................ 15

Figure 13: Comfort, energy savings, and peak power reduction plots for Charlotte, North Carolina, with 15\% duct leakage and R-4 duct insulation............................................. 20

Figure 14: Supplemental resistance heat use in Charlotte, North Carolina, with $15 \%$ duct

leakage and R-4 duct insulation ............................................................................... 21

Figure 15: Comfort, energy savings, and peak power reduction plots for Charlotte, North

Carolina, with ducts in the conditioned space (no duct losses) ......................................... 22

Figure 16: Comfort, energy savings, and peak power reduction plots for Little Rock,

Arkansas, with 15\% duct leakage and R-4 duct insulation................................................. 24

Figure 17: Supplemental resistance heat use for Little Rock, Arkansas, with 15\% duct

leakage and R-4 duct insulation ................................................................................. 25

Figure 18: Comfort, energy savings, and peak power reduction plots for Little Rock,

Arkansas, with ducts in the conditioned space (no duct losses) ........................................ 26

Figure 19: Comfort, energy savings and peak power reduction plots for Des Moines, Iowa,

with $15 \%$ duct leakage and R-4 duct insulation......................................................... 28

Figure 20: Peak heating power reduction at $3{ }^{\circ} \mathrm{F}$ (left) and $-2^{\circ} \mathrm{F}$ (right) outdoor air temperature for Des Moines, Iowa, with 15\% duct leakage and R-4 duct insulation............................. 29

Figure 21: Supplemental resistance heat use for Des Moines, IA with 15\% duct leakage and

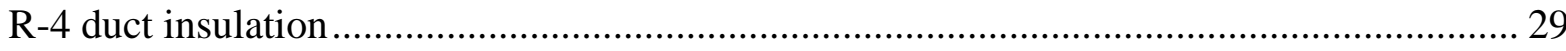

Figure 22: Comfort, energy savings, and peak power reduction plots for Des Moines, Iowa, with ducts in the conditioned space (no duct losses) .................................................... 31

Figure 23: Peak heating power reduction at $3^{\circ} \mathrm{F}$ (left) and $-2^{\circ} \mathrm{F}$ (right) outdoor air temperature for Des Moines, Iowa, with ducts in the conditioned space (no duct losses) ..... 32

Figure 24: Supplemental resistance heat use for Des Moines, Iowa, with ducts in the conditioned space (no duct losses)................................................................................ 32

Figure 25: Comfort, energy savings, and peak power reduction for Pittsburgh, Pennsylvania, with $15 \%$ duct leakage and R-4 duct insulation. 33

Figure 26: Supplemental resistance heat use for Pittsburgh, Pennsylvania, with $15 \%$ duct 
leakage and R-4 duct insulation.

Figure 27: Comfort, energy savings, and peak power reduction for Pittsburgh, Pennsylvania, with ducts in the conditioned space (no duct losses) .............................................................. 35

Figure 28: Supplemental resistance heat use for Pittsburgh, Pennsylvania, with ducts in the conditioned space (no duct losses)

Figure 29: Comparison of sensible heating delivered between field test measurements and model verification simulation for 2-ton field test VSHP

Figure 30: Comparison of sensible cooling delivered between field test measurements and model verification simulation for 2-ton field test VSHP C-1 Figure 31: Comparison of return air temperature (RAT) between field test measurements and model verification simulation for 2-ton field test VSHP C-2

Figure 32: Comparison of return air humidity ratio between field test measurements and model verification simulation for 2-ton field test VSHP

Figure 33: Comparison of latent cooling delivered between field test measurements and model verification simulation for 2-ton field test VSHP

Figure 34: Comparison of heat pump system energy consumption between field test measurements and model verification simulation for 2-ton field test VSHP

Figure 35: Comparison of sensible heating delivered between field test measurements and model verification simulation for 3-ton field test VSHP C-4

Figure 36: Comparison of sensible cooling delivered between field test measurements and model verification simulation for 3-ton field test VSHP C-4 Figure 37: Comparison of return air temperature (RAT) between field test measurements and model verification simulation for 3-ton field test VSHP C-5 Figure 38: Comparison of return air humidity ratio between field test measurements and model verification simulation for 3-ton field test VSHP C-5

Figure 39: Comparison of latent cooling delivered between field test measurements and model verification simulation for 3-ton field test VSHP C-6 Figure 40: Comparison of heat pump system energy consumption between field test measurements and model verification simulation for 3-ton field test VSHP C-6 


\section{LIST OF TABLES}

\section{Table}

Table 1: Matrix of simulations run for each city

Table 2: BEopt inputs for each city's baseline case

Table 3: EnergyPlus cooling and heating rated values for the field test VSHP for the model matching the measured data from the test house and the corrected models used for simulations .....

Table 4: EnergyPlus biquadratic constants for cooling capacity and cooling energy input ratio

Table 5: EnergyPlus biquadratic constants for heating capacity and heating energy input ratio 


\section{ACKNOWLEDGMENTS}

The authors would like to thank David Dinse of Tennessee Valley Authority who sponsored the Campbell Creek homes where some of this research was completed. The authors would also like to thank Jon Winkler of National Renewable Energy Laboratory for providing an in-house version of BEopt and EnergyPlus with improved moisture modeling and details on lab test results of some variable speed heat pumps. Thanks to Keith Rice and Bo Shen for general guidance on modeling variable speed heat pumps. 


\section{EXECUTIVE SUMMARY}

Traditionally, heat pumps are sized to the cooling load of a home and any deficit in heating capacity is compensated for by the use of electric resistance heating elements. This limits the impact of part-load efficiency and latent removal degradation while cooling and improves indoor comfort. However, in homes and/or climates that experience higher heating loads than cooling loads, sizing to the cooling load can result in a significant amount of resistance heat use in the winter and higher heating energy use.

The ability of variable-speed heat pumps (VSHPs) to provide enhanced dehumidification via indoor blower speed control potentially mitigates the risks of oversizing with respect to the cooling load. The VSHP could then be sized to the larger heating load and significantly reduce the use of supplemental resistance heating elements, decreasing heating season energy use and winter peak power consumption.

Performance data on two VSHPs with different capacities, but from the same manufacturer were collected from an unoccupied house installation. This data was used to develop performance curves for modeling the units in EnergyPlus. The performance curves were then validated with the measured data to ensure accuracy.

Simulations were then run for four cities located along the southern edge of the mixed-humid and cold climate zones. These locations were selected in order to bracket the performance over the range of the mixed-humid climate. For comparison, simulations were also run using the 13 SEER single speed heat pump and VSHP models from BEopt. The capacity of the VSHPs was adjusted between 2- and 5-tons in 1-ton increments at each location in order to evaluate the impact that sizing has on comfort, energy savings, and peak power use. Two different duct configurations were modeled for each simulation, one with ducts having $15 \%$ leakage and R-4 duct insulation and the other with ducts located in the conditioned space (no duct losses).

The simulation results indicate that energy savings up to $10 \%$ are achievable in the cold climate by sizing VSHPs with a focus on the heating load instead of the cooling load. Energy savings will diminish in warmer climates and the simulations showed no energy savings for homes along the southern edge of the mixed-humid climate.

Peak power use in the heating season can be greatly reduced, up to $35 \%$ in the mixed-humid climate and $26 \%$ in the cold climate. In cold climates, it is important to know the lowest ambient temperature at which the heat pump will still operate. The VSHP in BEopt had a minimum operating temperature of $0^{\circ} \mathrm{F}$, while the field test VSHP had a minimum operating temperature of $-15^{\circ} \mathrm{F}$, based on the manufacturer's documentation. At temperatures below these limits, the VSHPs will not run and the home will be heated entirely with the backup heating source, usually electric resistance heat.

Reductions in peak power use during the cooling season were not consistent between the two VSHPs modeled. The BEopt VSHP model showed up to a $17 \%$ reduction in peak cooling power use, while the field test VSHP showed an increase in peak power use. 
The duct losses did not have a major impact on the optimal cooling size ratio with respect to annual energy savings in any of the cases. However, it did make a significant impact on the energy savings when compared to the baseline single speed heat pump. The longer runtimes of the VSHPs increased the duct losses when compared to a single speed heat pump that cycled more often. This makes it important to ensure that ducts are evaluated and improved if needed in order to ensure maximum savings when upgrading to a VSHP.

The way in which a manufacturer achieves the different rated capacity units in any model family also has an impact on what size unit is going to provide the highest energy savings. The field test VSHPs were rated at 2- and 3-tons of cooling. The actual outdoor units used the same model compressor though and had the same size coil. The additional capacity of the 3-ton unit is achieved by running the compressor at higher speeds. Both units also had the same minimum operating compressor speed, and therefore similar minimum capacities and performance at low loads. In a situation like this, it is likely always better, on the basis of performance, to choose the 3-ton unit even if your load only requires the 2-ton unit. This is illustrated in the energy savings plots in the mixed-humid climate. There is little need for the added capacity of the 3-ton unit in these homes, but the 3-ton unit provides similar levels of comfort and energy savings. The 3-ton unit will run at the same minimum speed, but will have additional capacity to cope with off-design conditions and thereby provide additional comfort in the cooling season or additional savings by minimizing resistance heat use in the winter. In addition, the unit will be able to use the extra capacity to respond to changes in the thermostat temperature set point more quickly, which can also reduce the use of resistance heat during temperature setups.

Some VSHPs run at higher compressor speeds in the heating mode than the cooling mode, providing additional heating capacity at low temperatures and reducing the benefits of oversizing relative to the cooling load. The field test VSHPs have rated low temperature $\left(17^{\circ} \mathrm{F}\right)$ heating capacity to rated cooling capacity ratios of 0.87 to 1.05 per the manufacturer's data as compared to the VSHP in BEopt that has a ratio of 0.64. This is a significant difference and will impact how much the cooling capacity must be oversized in order to meet the heating capacity.

The similarities and differences between different capacity units in a model family will vary depending on the manufacturer. These unit specific details are critical to choosing the VSHP capacity that will yield the highest energy savings without compromising comfort. In addition, the house construction, climate, and occupant behavior will influence the balance of the heating and cooling load on the house as well as the sensible and latent cooling demand. All of these factors need to be considered when trying to select the proper unit for the highest energy savings. Based on the simulations performed in this study, it is likely that VSHPs with an enhanced dehumidification mode can be sized to two times the cooling load of the house without any reduction in comfort when compared to a single speed heat pump assuming a typical home and occupant behavior in the mixed-humid and cold climates. 


\section{INTRODUCTION}

Space conditioning is the largest energy consuming end use in residential buildings (U.S. EIA, 2009), and is a major focus for energy saving efforts. In the past few years, manufacturers in the U.S. have been designing heat pumps utilizing inverter-driven, variable speed compressors that allow new levels of efficiency to be achieved. These variable speed heat pumps (VSHPs) are capable of modulating their output capacity in order to meet the building load thereby reducing cycling losses and increasing steady-state efficiency levels. In addition to a variable speed compressor, VSHPs also have variable speed indoor blowers. This allows the manufacturers the ability to program the indoor blower to adjust its speed in response to the indoor humidity. As fan speed is decreased, the heat pump's sensible heat ratio (SHR) decreases thereby removing more moisture from the home for a given sensible load. This strategy gives VSHPs the capability to better control indoor humidity for improved occupant comfort.

Traditionally, heat pumps are sized to the cooling load of a home and any deficit in heating capacity is compensated for by the use of electric resistance heating elements. This limits the impact of part-load efficiency and latent removal degradation while cooling and improves indoor comfort. However, in homes and/or climates that experience higher heating loads than cooling loads, sizing to the cooling load can result in a significant amount of resistance heat use in the winter and higher heating energy use. A similar concept is applied to northern climate two-capacity heat pumps with variable-speed indoor blowers where the high-capacity mode is locked out for the cooling mode.

The ability of VSHPs to provide enhanced dehumidification via indoor blower speed control potentially mitigates the risks of oversizing with respect to the cooling load. The VSHP could then be sized to the larger heating load and significantly reduce the use of supplemental resistance heating elements, decreasing heating season energy use and winter peak power consumption.

Oak Ridge National Laboratory (ORNL) has collected heating and cooling performance data on two VSHPs installed in a single residential home located in Knoxville, Tennessee (Munk, et al., 2014). One of these heat pumps was a 2-ton unit conditioning the lower level, and the other was a 3-ton unit conditioning the second story. The data from these two units was used to generate heating and cooling performance curves for use in EnergyPlus, a building energy simulation program. The rated capacities were then scaled up for 4- and 5-ton units.

In addition to the VSHP performance curves generated from the field data, the default VSHP performance curves in BEopt were also used in the simulations as another point for comparison.

The EnergyPlus simulations were structured to simulate a retrofit installation. A baseline home for each of the four cities was generated and equipped with a 13 SEER 7.7 HSPF heat pump and ducts with typical leakage and R-4 insulation. VSHPs of various sizes were then modeled with no improvements to the duct work and in a best-case scenario where the ducts 
are brought inside the envelope. This allows the interaction between heat pump sizing and duct losses to be analyzed. 


\section{METHODOLOGY}

\subsection{ENERGYPLUS HOUSE MODEL}

The houses used for the EnergyPlus simulations were based on the Building America Benchmark (Hendron, 2008) specifications for the climate where they were located. Two exceptions to the benchmark are as follows. The ductwork was assumed to have R-4 insulation instead of R-8 insulation. This was done in order to facilitate the study on how staged improvements to the duct work and HVAC system can impact energy use. Also no dehumidifiers were used in the simulations in order to see how the HVAC equipment handled the latent cooling load.

The size of the homes was adjusted in order to obtain a 2.5-ton cooling load for each location. Since VSHPs are only sold in integer capacities from 2- to 5-tons, this cooling load will allow a reasonable range of cooling capacity to cooling load ratios of 0.8 to 2.0 to be studied. Details on the different homes can be found in Appendix A.

VSHPs are also equipped with variable speed indoor blower motors. These motors are typically programmed to deliver the desired airflow regardless of the external static pressure of the duct system. This results in higher energy consumption for ducts that are more restrictive. Since the intention of this study is to evaluate the impact of the retrofitting a home with a VSHP that is oversized for the cooling load, the duct size should not change when different sized units are simulated. This was achieved by using the same fan model for all of the variable speed heat pumps and scaling the power with ratio of the current airflow to the maximum airflow of the 5-ton unit to the 2.3 power, which has been found to be typical for variable speed motors.

The duct leakage model used by default in BEopt was modified in order to make the duct leakage rate scale with the airflow rate. The nominal duct leakage rate was assumed to be at the maximum airflow of the baseline 13 SEER HP. The duct leakage was then scaled based

on the airflow of the unit at each timestep using equation, which was derived from ASHRAE Handbook equations assuming a duct leakage exponent of 0.6 (ASHRAE, 2013a).

$$
\text { Leakage }_{\text {Current }}=\text { Leakage }_{\text {Nominal }}\left(\frac{A F R_{\text {Current }}}{A F R_{\text {Nominal }}}\right)^{0.2}
$$

where,

AFR $=$ airflow rate

The house sizes were maintained when the ducts were brought inside the conditioned space, reducing the cooling load below 2.5-tons.

The equivalent moisture penetration depth (EMPD) moisture model was used in EnergyPlus. The model was improved by adding an additional moisture buffer layer as described in a 
report by Woods et al (2013). This model was found to provide more accurate indoor humidity levels in simulations and was therefore utilized for this study.

While the focus of this paper is the mixed-humid climate, Figure 1: simulations were also run for locations in the cold climate region north of the mixed-humid climate.

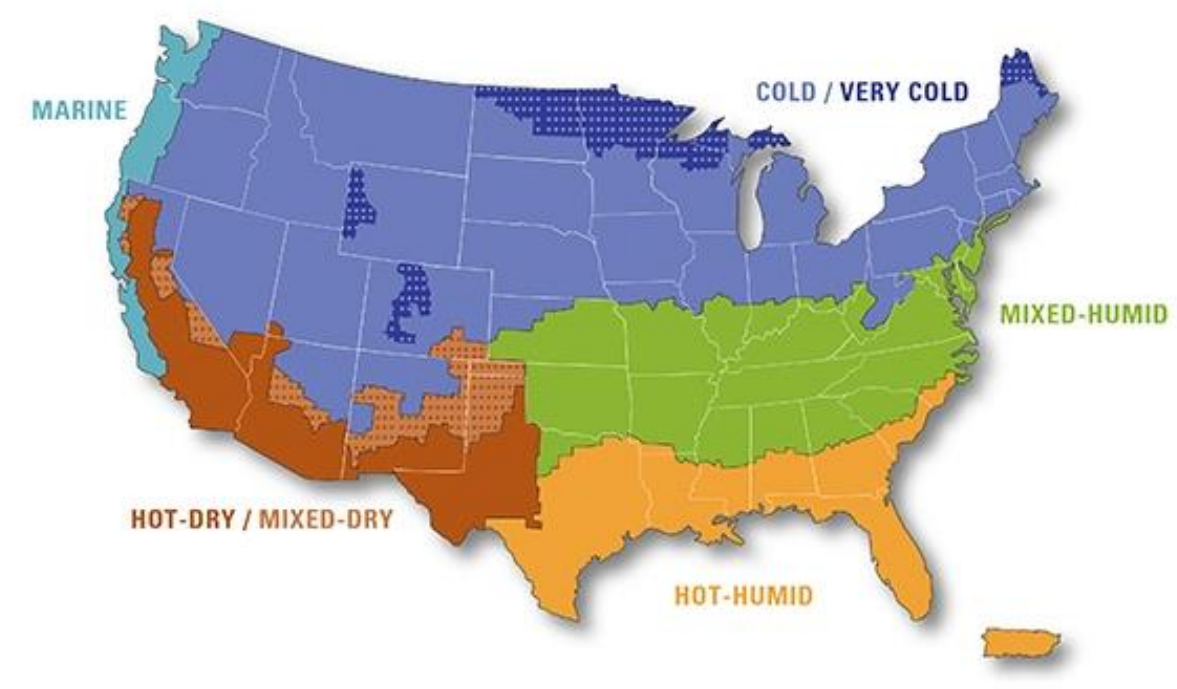

\section{Figure 1: Climate zones in the United States (Office of Energy Efficiency and Renewable Energy, n.d.)}

\subsection{ENERGYPLUS EQUIPMENT MODEL}

As with the default VSHP that is modeled in BEopt (NREL, 2012), the Multispeed DX heating and cooling coil components were used in EnergyPlus for modeling the VSHPs that were tested in the research house. With this model, the performance of the equipment is defined at four separate speeds. Instead of using all four speeds to define the steady state operation of the VSHPs as is typically done, the lowest speed level was used to represent the performance of the VSHPs while cycling. Speed-1 was defined by the minimum delivered heating or cooling in an hour, e.g., the average hourly capacity when the unit runs one minimum duration cycle in the hour. This speed is used to define the operation of the system with maximum cycling losses. While single speed heat pumps may cycle three or more times an hour, the VSHPs tested rarely cycled more than once or twice an hour. This approach was used primarily because it provided a better match to the latent cooling of the equipment during cycling. There was a significant difference in the measured SHR, of the units when cycling compared to steady-state operation at the minimum speed. The latent degradation model in EnergyPlus requires continuous off-cycle indoor fan operation, which was not how the indoor fan was setup during the field test. In order to more accurately capture this increased SHR when the unit was cycling, the Speed-1 values in BEopt were used to represent cyclic operation of the field test units. Speed-2 was defined by the minimum steady-state operating capacity of the unit. Speed-3 was an intermediate speed between minimum and maximum capacity, and Speed -4 was the maximum capacity of the unit. One 
minute interval data was used to help establish the appropriate capacity lines, how they varied with outdoor air temperature (OAT), and the efficiency for Speeds 2-4. Hourly data was used for Speed-1 in order to properly capture the losses associated with cycling.

The test house experienced very different heating and cooling loads on its two levels with the upstairs having a significantly larger cooling load and the downstairs having a larger heating load. Because of this, the operating range of the two VSHPs was quite different with neither unit providing a complete picture of the operating characteristics in both heating and cooling. Based on the manufacturer's specifications and visual inspection, the outdoor units share the same compressor, coil, and minimum compressor speed. The indoor units also share the same coil face area, rows of tubes, and fin spacing. The most significant difference between the units is that the 3-ton unit is capable of operating at higher compressor speeds than the 2ton unit, thus providing higher capacities. Due to these similarities and based on laboratory test data from the manufacturer, the data sets for the two units were combined after normalization.

\subsubsection{Cooling Performance Curves}

The cooling performance of each speed is defined by the capacity, SHR, coefficient of performance (COP), and airflow at $95^{\circ} \mathrm{F} \mathrm{OAT,} 80^{\circ} \mathrm{F}$ return air dry bulb temperature, and $67^{\circ} \mathrm{F}$ return air wet bulb temperature as well as curves defining the change in capacity and efficiency with OAT and return air wet bulb temperature. Since the return air conditions of the research house were not at $67^{\circ} \mathrm{F}$ wet bulb temperature, the capacity and efficiency were corrected to this condition using a correlation derived from the manufacturer's expanded cooling performance data. The corresponding coefficients of this correlation were also used in the performance curves to define how the capacity and efficiency vary with return air wet bulb. Since EnergyPlus models the indoor blower separately from the coil, the fan power was subtracted from the total power and added to the measured cooling capacity. The measured capacity from the two units was then normalized by dividing the measured capacity (adjusted for return air wet bulb temperature) by the max cooling capacity at $95^{\circ} \mathrm{F}$ OAT. Figure 2 shows the average one minute and hourly normalized capacity data for the 2ton VSHP that ran in the research house in addition to the one minute data from the 3-ton VSHP that was also normalized by dividing by a 2-ton max cooling capacity. The solid lines show how the capacity for each speed level varies with OAT and the dashed lines show the bounds for the data that was included for each speed. As seen in the figure, the 2-ton unit, cooling the lower level of the house, had a very small cooling load and spent the vast majority of its runtime cycling at minimum speed. The VSHPs appeared to have a minimum cycle length in cooling that was $\sim 9.5$ minutes. This is seen by the distinct line of data along the Speed 1 capacity line and the slightly less distinct line of data at double the capacity ratio of Speed 1. 


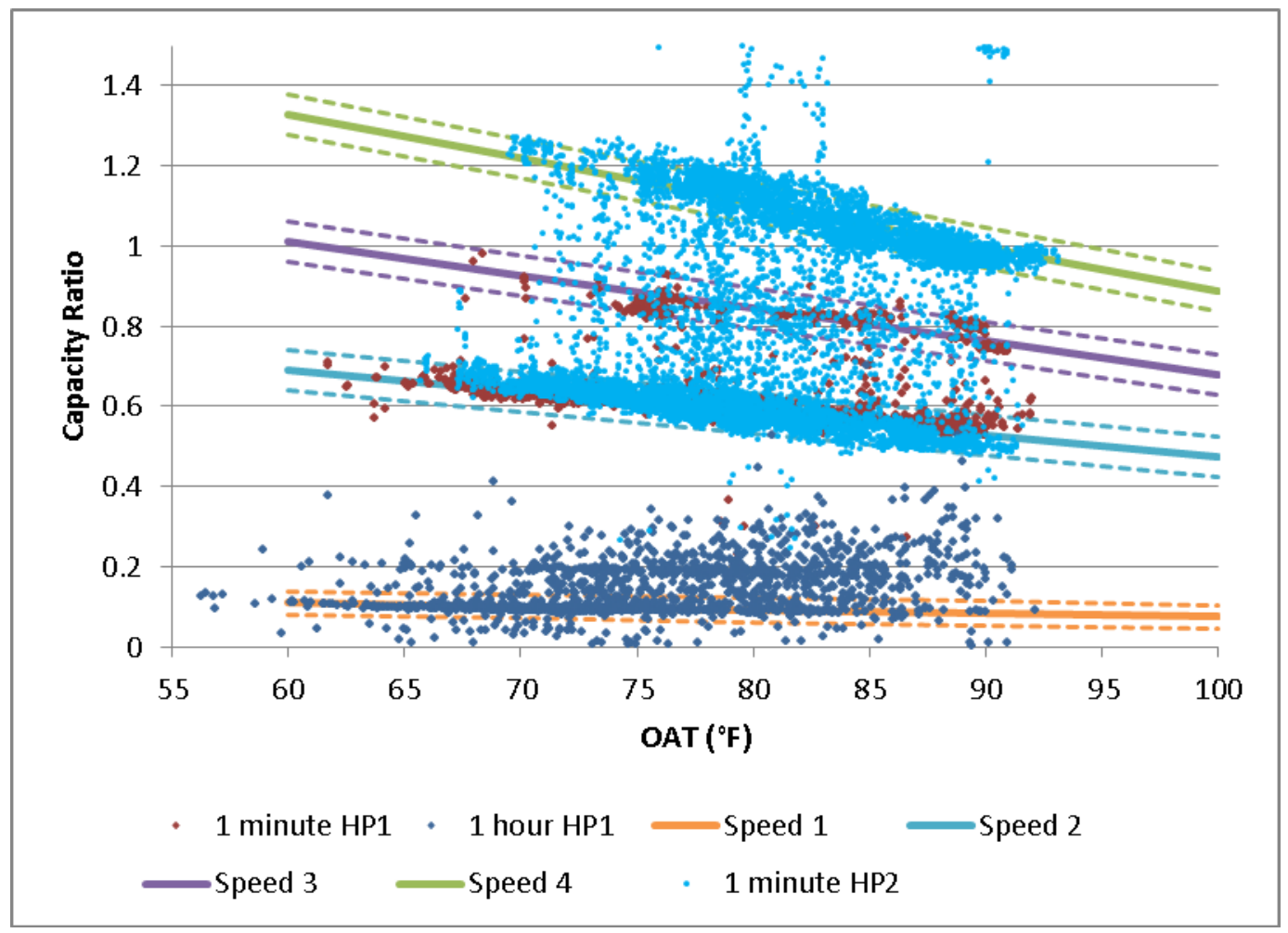

Figure 2: 2-ton VSHP normalized cooling capacity data

Figure 3 shows the normalized capacity data for the 3-ton unit that served the upstairs floor of the house. It had a much higher cooling load, but still spent the majority of the time operating at minimum speed or an intermediate speed. There was not a distinct line of data with which to characterize Speed 1 on the 3-ton unit as there was with the 2-ton unit, so the minimum cycle length of 9.5 minutes was used to calculate the appropriate Speed 1 line. This was done by multiplying the Speed 2 minimum operating capacity line by the minimum cycle length divided by 60 minutes to obtain the average capacity of the unit if it ran for one cycle at minimum capacity in an hour. 


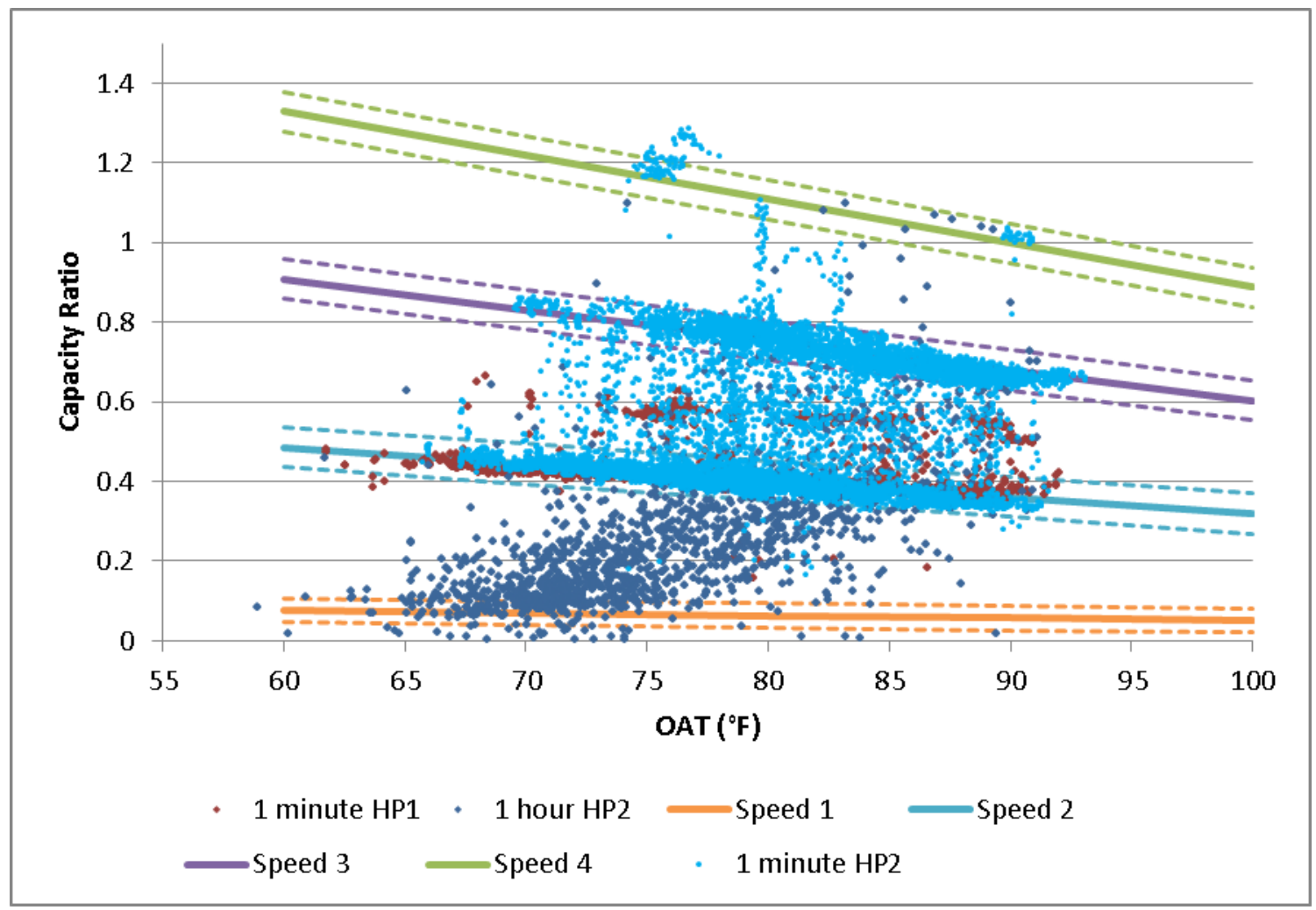

Figure 3: 3-ton VSHP normalized cooling capacity data

After the measured data was categorized by speed level, the measured energy input ratio was normalized by dividing by the energy input ratio at $95^{\circ} \mathrm{F}$ OAT and maximum capacity. These values were then averaged for each speed level for OAT bins of $5^{\circ} \mathrm{F}$. Normalized data from both units was used in order to better fill out temperature ranges and results are shown in Figure 4 for a 2-ton unit and Figure 5 for a 3-ton unit. The energy input ratio (EIR) ratio curves (the inverse of COP ratios) generally show very similar efficiency for the different speeds, with the one exception being Speed 1 that represents cyclic operation. This is in contrast to the default 22 SEER VSHP that is an option in BEopt whose comparable curves are shown in Figure 6 (all speeds represent steady-state operation). These show a clear and significant efficiency gain from operating at the minimum speed across the entire range of OATs. These curves were generated from a VSHP from a different manufacturer though and suggest that the efficiency trends of VSHPs may vary significantly between manufacturers. Additional laboratory test data from a study by EPRI (Hunt, et al., 2013) on a VSHP from the same manufacturer as the ones in this study also suggests that the cooling efficiency at different compressor speeds is similar at most OATs as seen in Figure 7. A second source of laboratory test data also showed that the minimum compressor speed for this unit was less efficient than intermediate compressor speeds at temperatures below $95^{\circ} \mathrm{F}$ and had similar efficiency to the maximum compressor speed at standard external static pressures (Winkler, 2015). 


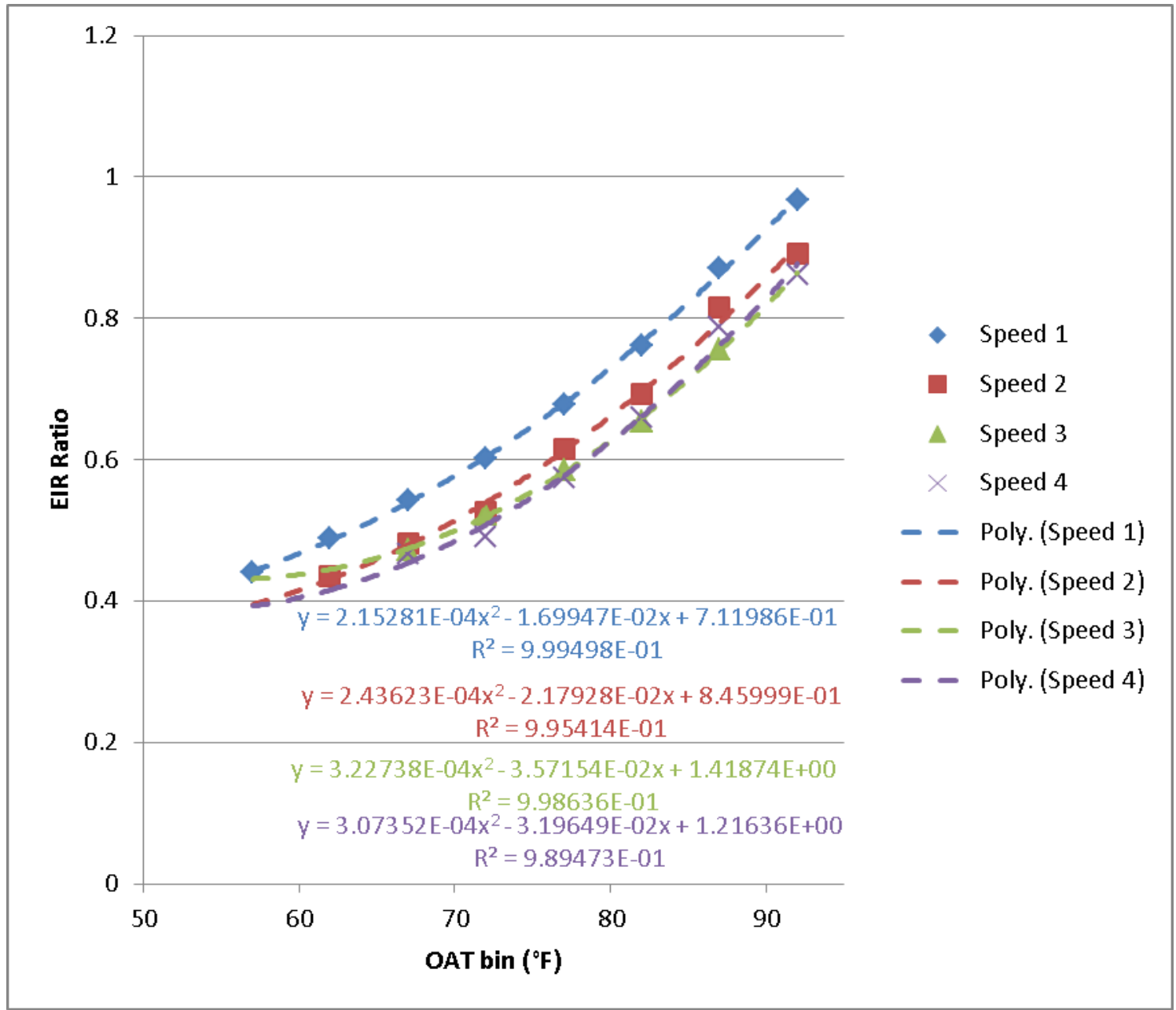

Figure 4: 2-ton normalized cooling efficiency data 


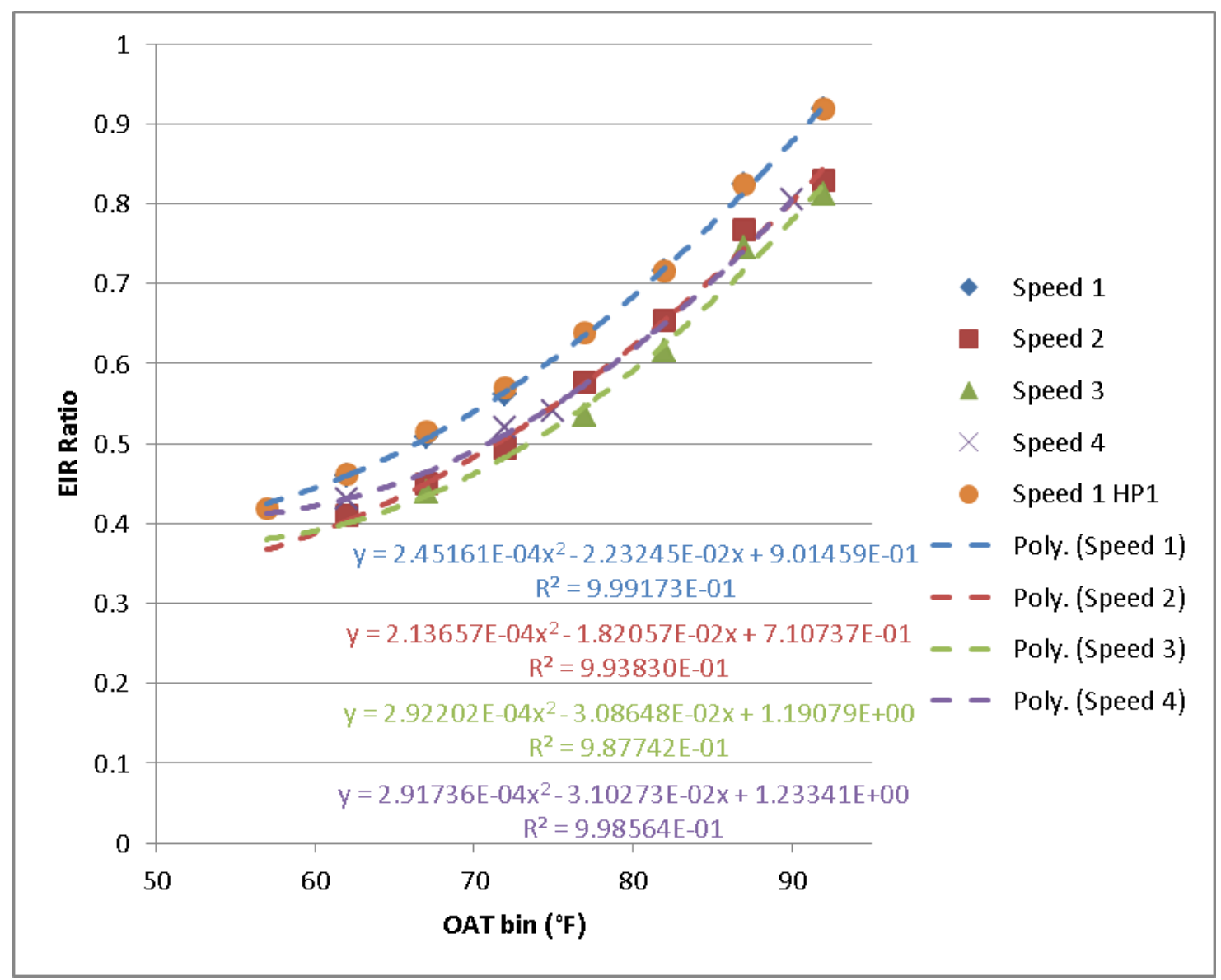

Figure 5: 3-ton normalized cooling efficiency data

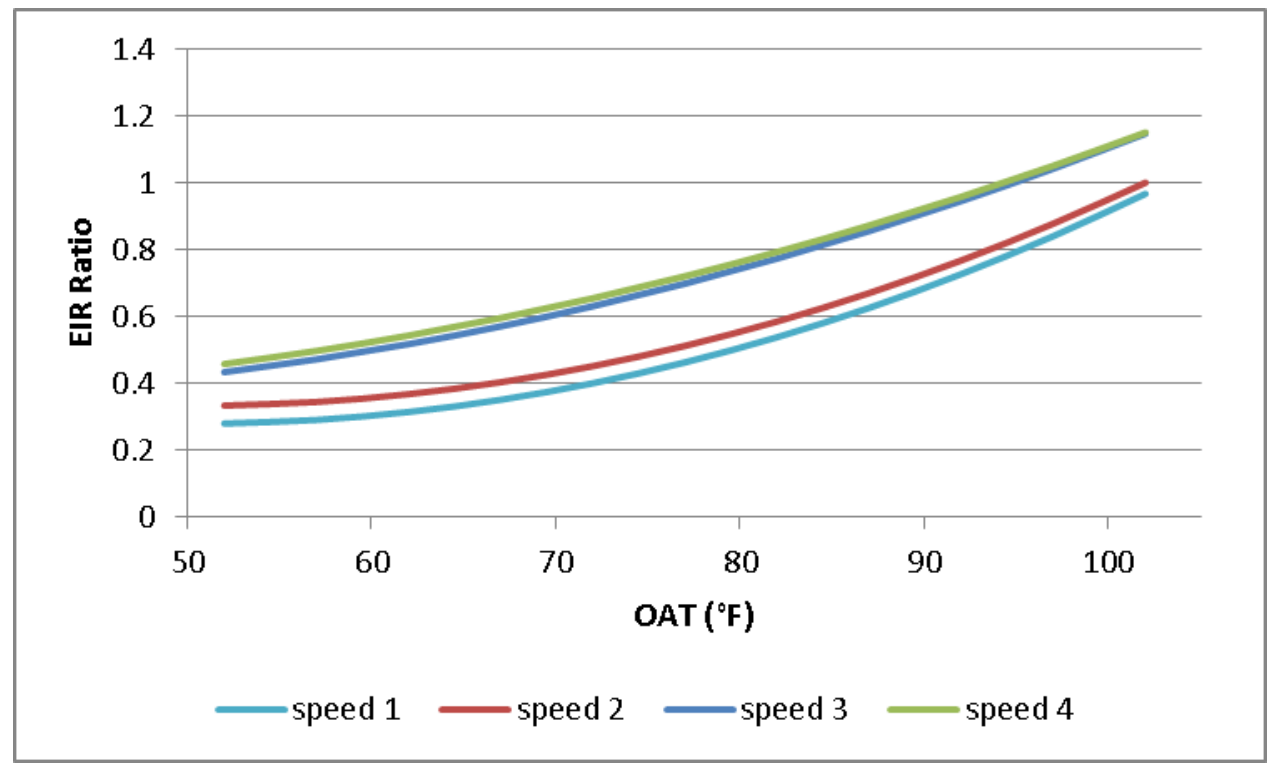

Figure 6: Normalized cooling efficiency curves for 22 SEER VSHP option in BEopt 


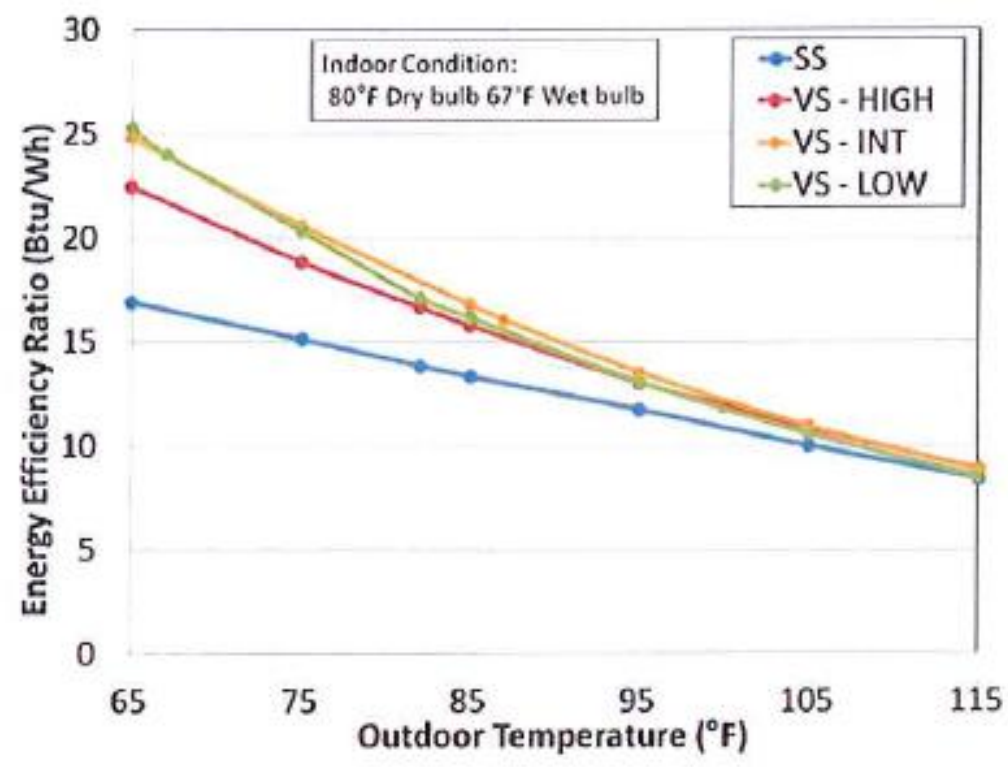

Figure 7: Laboratory cooling efficiency comparison of a VSHP to a single speed heat pump taken from (Hunt, et al, 2013)

The rated capacity each speed level was calculated by taking the capacity ratio at $95^{\circ} \mathrm{F}$ from the line fits in Figure 2 and Figure 3 and multiplying by the rated cooling capacity for the appropriate unit. The rated COP for each speed was calculated similarly from the EIR ratio curves in Figure 6.

The average $\mathrm{cfm} / \mathrm{ton}$ for each speed level based on the measured data was used to calculate the rated airflows by multiplying them by the corresponding rated capacities. The rated SHRs were also taken as an average value from the data. Adjustments were made to some of these values that will be explained in the later section on model validation.

EnergyPlus also provides inputs for capacity and efficiency variations as a function of indoor airflow ratio (airflow divided rated airflow). Since the variable speed heat pumps modulate indoor airflow to the desired level based on compressor speed, OAT, and indoor humidity regardless of external static pressure, these modifier curves were not used by setting them to constant values of one.

Details of the EnergyPlus inputs are available in Appendix B.

\subsubsection{Heating Performance Curves}

The heating performance of the VSHPs is defined by the capacity, COP, and airflow at an OAT of $47^{\circ} \mathrm{F}$ and indoor temperature of $70^{\circ} \mathrm{F}$ as well with curves defining the change in capacity and efficiency with OAT and return air temperature. As with the cooling data, corrections for return air temperature were made to the measured capacity and COP data based on correlations from the manufacturer's expanded heating data. The same correlation coefficients were also used in the EnergyPlus curves relating the change in capacity and COP 
to the return air temperature of the units. Defining the speed levels based on the heating capacity of the units was not as straight forward as with the cooling mode. The VSHPs tested increase both the maximum and minimum compressor speed at lower OATs to achieve higher heating capacities and reduce the use of supplemental resistance heat. A plot of the heating capacity divided by the rated heating capacity for the entire size range of units is shown in Figure 8. The curves shown would be best represented by at least a third order polynomial, but the multi-speed DX coil module only allows second order curves. With this limitation the maximum capacity curves, speed 4, were generated using low temperature data in order to accurately capture the maximum heating capacity of the VSHPs and the supplemental resistance heating balance point. This approach results in reduced maximum heating capacities at temperatures above $\sim 40^{\circ} \mathrm{F}$, but this inconsistency should have minimal impact on the simulation results since maximum heating capacity should not be required at temperatures above $40^{\circ} \mathrm{F}$.

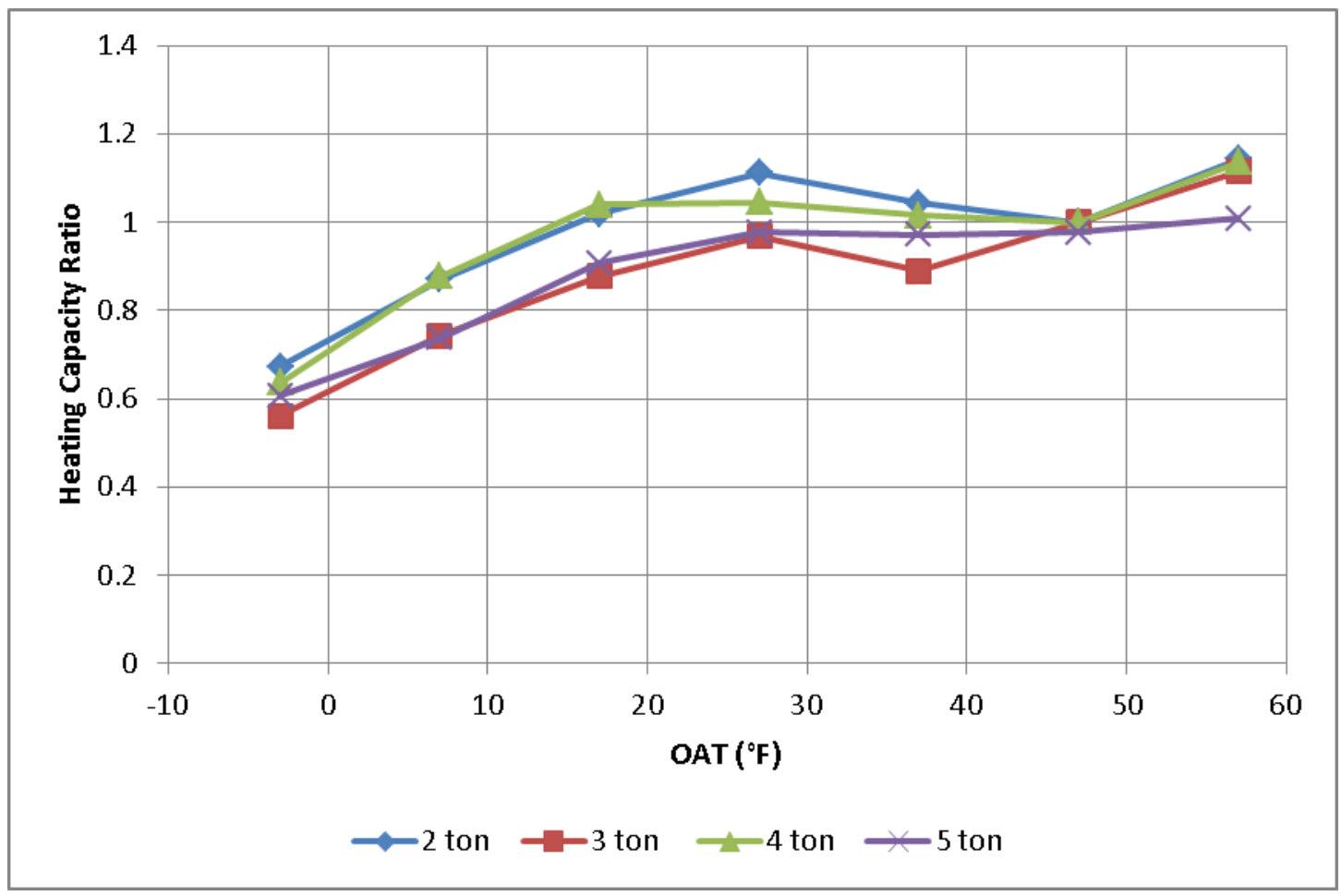

Figure 8: Heating capacity ratio vs. OAT from manufacturer's expanded product data for all size units

With the maximum capacity curve set, one minute and one hour data were used to set the other three speed levels for the two units as seen in Figure 9 and Figure 10. Since the minimum compressor speed also changes with OAT, creating a curve shaped similarly to those in Figure 8, matching the actual behavior of the system was not possible. Instead, a straight line was used to represent Speed 2 that roughly intercepted both the mild temperature capacity level and the lower temperature capacity levels. Speed 3 was also set as a straight line that crossed the average capacity ratios of the Speed 2 and 4 lines at $0^{\circ} \mathrm{F}$ and $47^{\circ} \mathrm{F}$. Speed 1, once again, was placed to represent the performance of the unit when it is cycling frequently. 


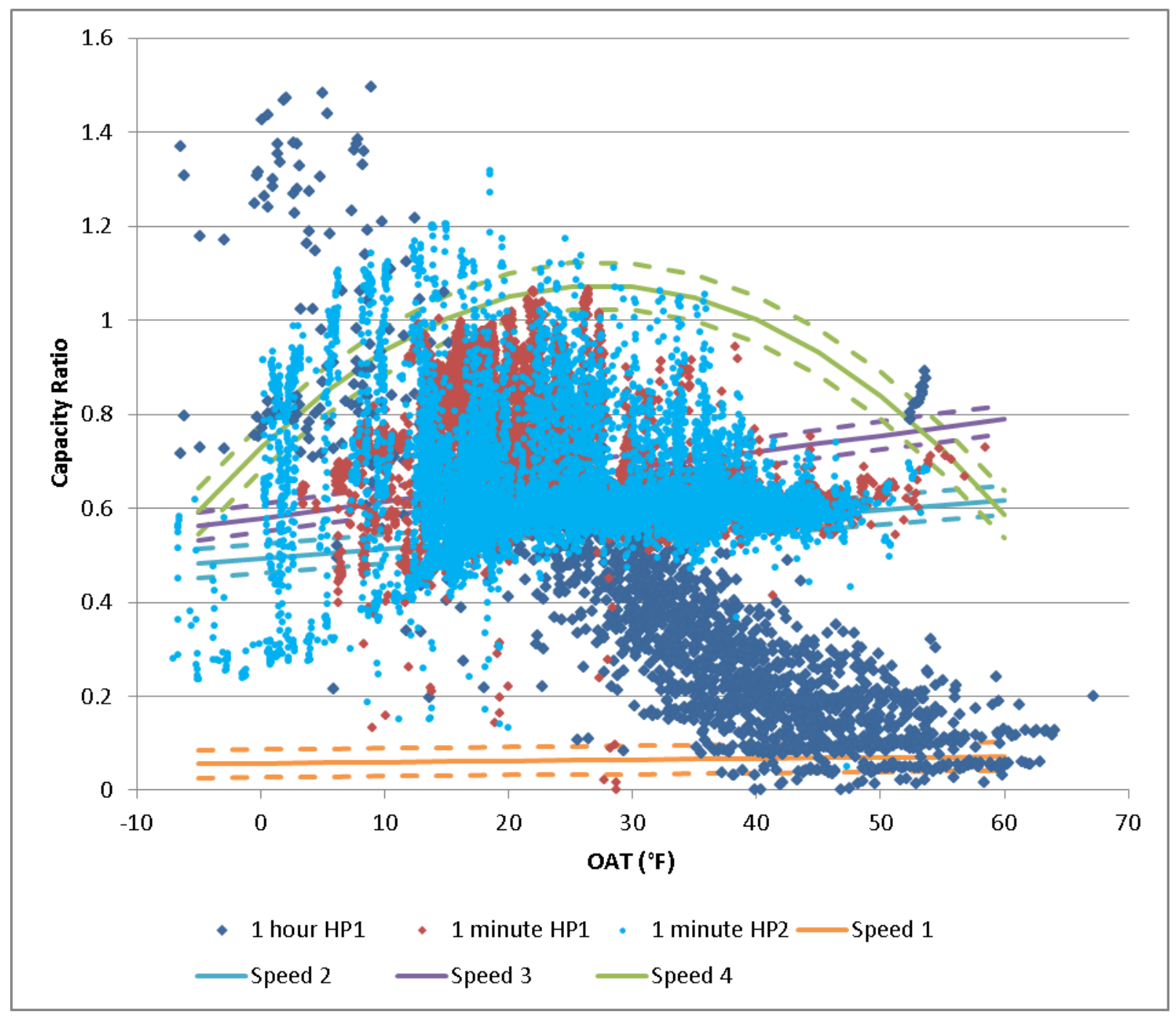

Figure 9: 2-ton VSHP normalized heating capacity data 


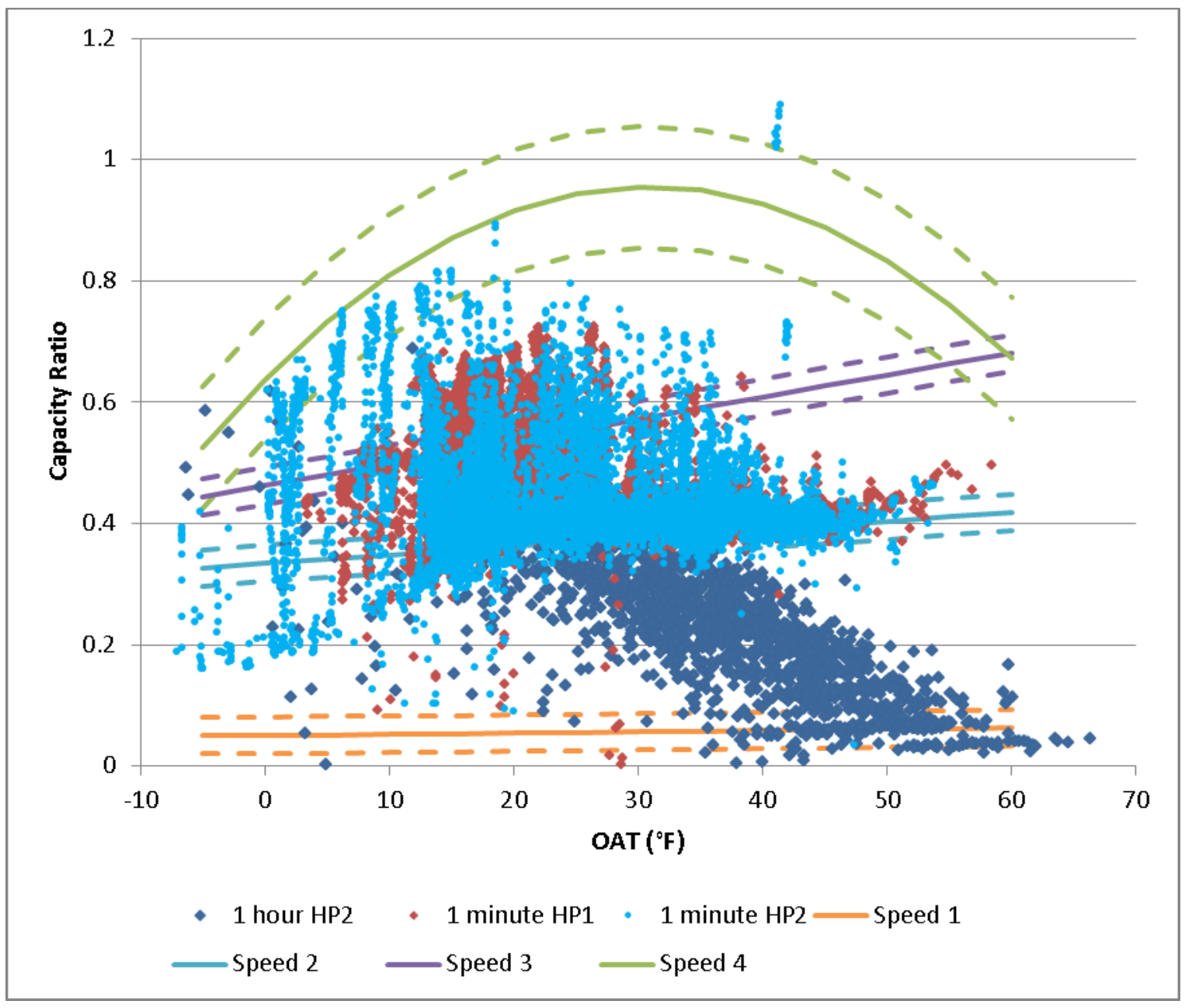

Figure 10: 3-ton VSHP normalized heating capacity data

Since the defrost cycle of heat pumps and resulting efficiency reduction only occur at low outdoor air temperatures, it is difficult to accurately capture how efficiency changes as a function of OAT with a second order polynomial. Because of this, the one minute data that had been filtered to remove defrost cycles and supplemental resistance heat use were used to generate the efficiency curves. In the heating mode, the data shows that the maximum speed, Speed 4, achieves higher efficiencies than the lower speeds at low temperatures as seen in Figure 11 and Figure 12. 


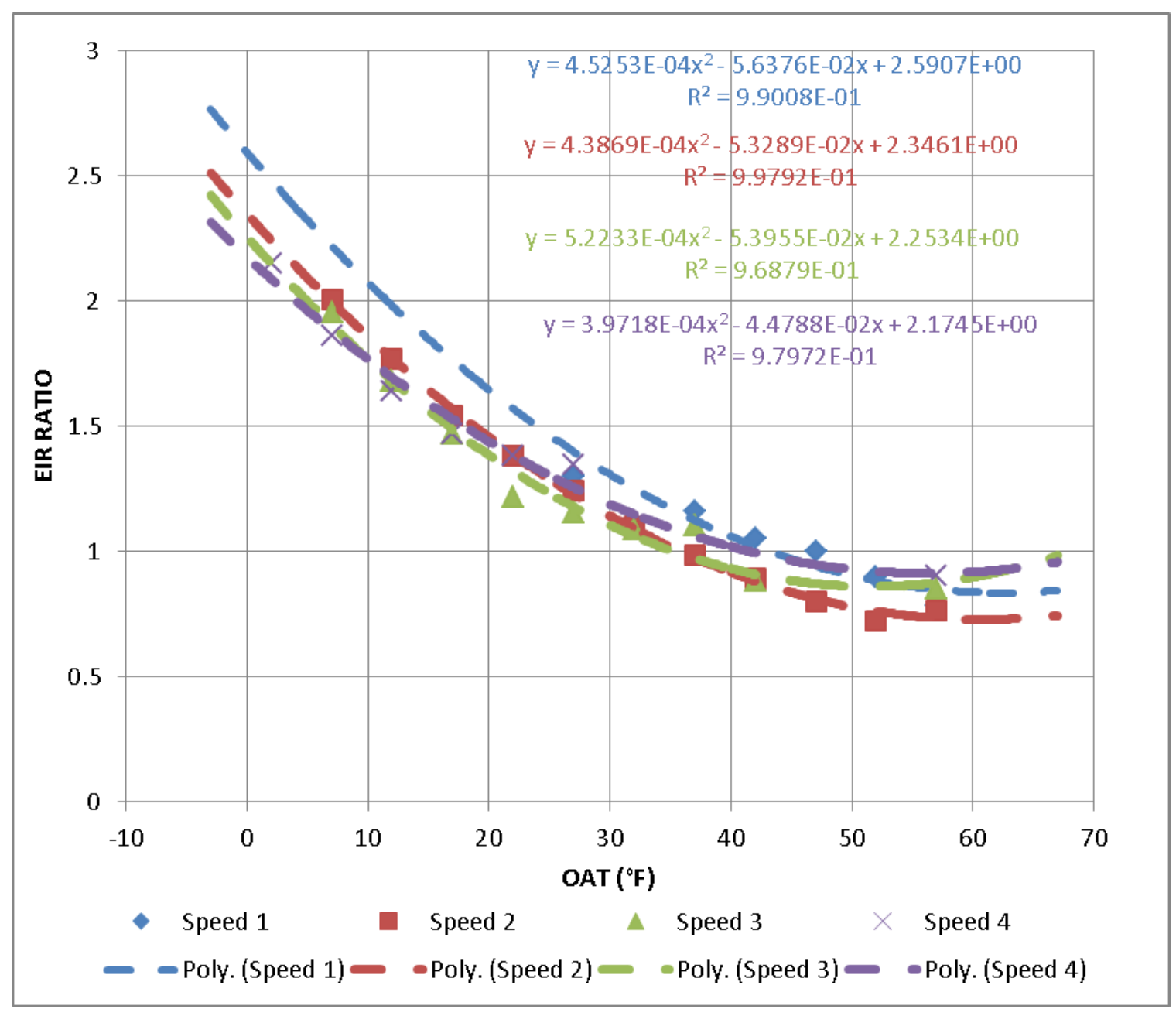

Figure 11: 2-ton VSHP normalized heating efficiency data 


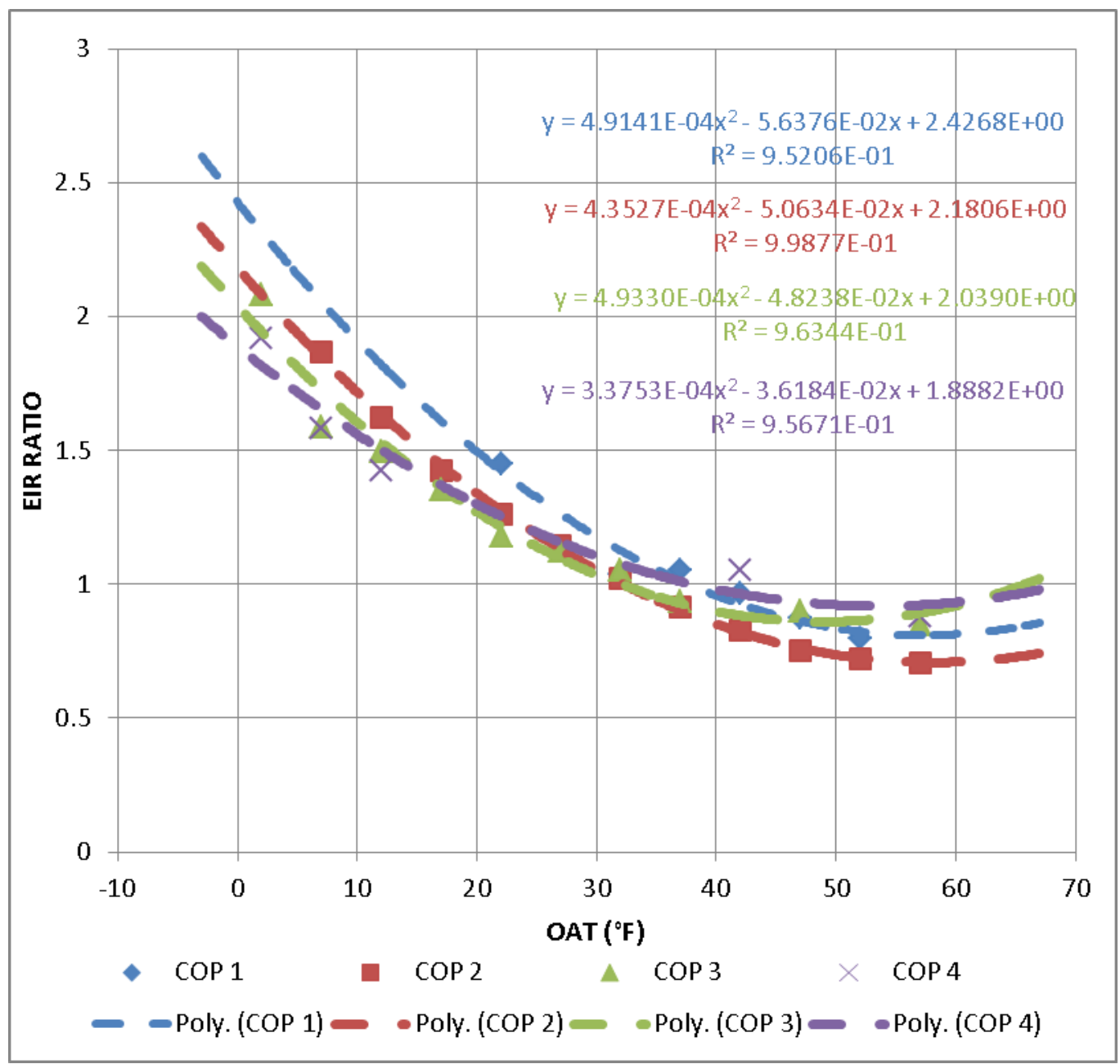

Figure 12: 3-ton VSHP normalized efficiency data

\subsubsection{Equipment Model Validation}

The 2-ton and 3-ton VSHP equipment models developed from the measured data were validated by simulating the equipment performance individually in a near adiabatic box in EnergyPlus. The hourly measured sensible and latent loads from 2014 were used as internally generated loads in the simulation. The measured return air temperatures were also used as the thermostat set points. In this way, the VSHPs are responding to the same sensible load under the same return air conditions as the measured data. While the heating season was fairly straightforward, the cooling season required matching the modeled return air humidity ratio to the measured return air humidity ratio. This ensures that the latent capacity of the VSHP in the model is being simulated under the same conditions as the measured data. This required tweaking the rated SHR for the different speed levels, particularly Speed 1 that represents the performance of the unit while cycling. The latent capacity of the equipment was measured by two different means in the research house; via air-side measurements and measurement of the condensate drained from the fan coils. Since the air-side measurements do not account for moisture on the coil or in the drain pan that may evaporate back into the air during off cycles, the latent capacity calculated from the drained condensate was used for 
comparison with the latent capacity of the model. Details on the model validation are found in Appendix C. 


\section{INTERPRETATION OF RESULTS}

The results of the simulations were evaluated based on annual heating and cooling energy use, peak power use, and comfort during the cooling season. The comfort during the cooling season is evaluated by comparing the hours outside of the ASHRAE 55 (ASHRAE, 2013b) comfort zone. The VSHPs are deemed to have acceptable comfort if the number of hours outside of the comfort zone is less than or equal to that of the baseline single speed heat pump that has been sized to the cooling load.

It is important to note that many VSHPs have different modes of operation. Since controlling humidity was one of the primary goals of the VSHP field test, the units were operated in a "comfort" mode while cooling. In this mode, the indoor airflow is reduced, resulting in higher latent capacity, and the unit can reduce the airflow further if there is additional need for dehumidification. The unit is rated in "efficiency" mode with generally higher airflows and lower latent capacity. In the heating mode, the unit was operated in "efficiency" mode.

The VSHP curves in BEopt were generated from laboratory test data with the unit operating at indoor airflow rates that would be used for ratings tests. Therefore any additional dehumidification capability of this unit is not captured in the performance curves used in this analysis.

Since the field test VSHP was modeled with the lowest speed representing operation when the unit was cycling, the model indicates that the unit is running almost continuously even at very low loads. This causes the duct losses to be exaggerated for this unit, which can be seen by comparing the delivered heating and cooling loads between the cases with and without duct losses.

The baseline 13 SEER HP and VSHP from BEopt have a minimum compressor operating temperature limit of $0^{\circ} \mathrm{F}$. The field test VSHP can operate in the heating mode down to $15^{\circ} \mathrm{F}$ according to the manufacturer's product data. The version of EnergyPlus used for the simulations limits the minimum compressor operating temperature to $-4^{\circ} \mathrm{F}$, so the heating energy savings on this unit are likely underestimated for the cold climate locations. 


\section{RESULTS}

Eighteen simulations were run for each location as shown in Table 1. All homes had their floor area adjusted in order to result in a 2.5-ton nominal cooling capacity unit with the baseline ducts. The baseline single capacity HP and VSHPs were then simulated in the same house with the same size ducts. The ducts were then modeled in the conditioned space and the 13 SEER HP capacity was resized for the new cooling load, while the VSHPs were modeled with the same integer ton cooling capacities. The cooling size ratio, the ratio of the nominal cooling capacity of the VSHP to the capacity of the auto-sized baseline 13 SEER $\mathrm{HP}$, is used to evaluate the merits of over-sizing VSHPs.

Table 1: Matrix of simulations run for each city

\begin{tabular}{|l|c|c|c|c|c|c|c|c|c|c|}
\hline & \multicolumn{7}{|c|}{$15 \%$ leakage, R-4 Insulation Ducts } & \multicolumn{3}{|c|}{ Ducts in Conditioned Space } \\
\hline $\begin{array}{l}\text { Nominal } \\
\text { cooling } \\
\text { tons }\end{array}$ & 2 & 2.5 & 3 & 4 & 5 & Autosized & 2 & 3 & 4 & 5 \\
\hline $\begin{array}{l}13 \text { SEER, } \\
7.7 \text { HSPF } \\
\text { HP }\end{array}$ & & & & & & & & & & \\
\hline $\begin{array}{l}22 \text { SEER } \\
\text { VSHP }\end{array}$ & & & & & & & & & & \\
\hline $\begin{array}{l}\text { Field Test } \\
\text { VSHP }\end{array}$ & & & & & & & & & & \\
\hline
\end{tabular}

\subsection{MIXED-HUMID CLIMATE}

Simulations were run in two cities in the mixed-humid climate, Little Rock, Arkansas and Charlotte, North Carolina. These cities are located along the southern edge of the mixedhumid climate and are used to determine how far south oversizing VSHPs is feasible while still maintaining comparable comfort to a single speed heat pump sized to the cooling load.

\subsubsection{Charlotte, North Carolina}

Charlotte has 3,065 heating degree days (HDD) and 1,713 cooling degree days (CDD) (ASHRAE, 2013a). Figure 13 shows the simulation results for Charlotte. The house simulated with the baseline HP had a peak cooling demand to peak heating demand ratio of 0.89. The chart in the upper left shows the hours uncomfortable while the indoor air is above $71.6^{\circ} \mathrm{F}$ (this limit was used to exclude hours when the units were heating). The VSHP from the field test has fewer uncomfortable hours than the 13 SEER HP baseline even when the nominal cooling capacity was twice that of the baseline. The 22 SEER VSHP from BEopt had more hours that were uncomfortable than the baseline. This is likely due to the fact that the performance curves do not reflect any enhanced dehumidification modes that are available on the unit. It is expected that this unit could achieve the same or better comfort as the baseline system with enhanced dehumidification activated. It should be noted that even though the 2-ton VSHPs were undersized compared to the baseline system, neither system had hours when the cooling set point was not met. 
The top right chart in Figure 13 shows the annual savings over the baseline heat pump for the two VSHP systems at different sizes. As noted in section 3 the duct losses for the field test VSHP are exaggerated due to the modeling approach. This causes larger heating and cooling loads and increases energy consumption while reducing savings. With this in mind, the general trend of savings versus equipment size is still expected to be accurate. Both VSHPs show decreased savings with units oversized for the cooling load. The main energy savings for oversizing a system relative to the cooling load is offsetting resistance heat use with additional heat pump heating capacity. Figure 14 shows the supplemental resistance heat use for each system. All systems use very little resistance heat, indicating that the savings potential for oversizing a VSHP relative to the cooling load in this house and climate combination is low. It should be noted that the 2-ton field test VSHP uses approximately the same amount of resistance heat as the 2.5-ton baseline heat pump. This is due to the fact that the field test VSHP runs at higher compressor speeds in the heating mode than the cooling mode allowing the unit to provide more heat at lower temperatures. Conversely, the 2-ton VSHP in BEopt uses more resistance heat than the 2.5-ton baseline heat pump indicating that it does not over-speed the compressor as much in the heating mode.

The bottom two plots show the peak power reduction for heating and cooling compared to the baseline system. Both VSHPs show significant heating peak power reduction as the unit capacity is increased. This is indicative of the units having higher efficiency at lower compressor speeds. The same trend is seen for the 22 SEER VSHP in the cooling mode, but not for the field test VSHP. As noted in section 2.2.1 the field test VSHP did not show the expected trend of increased efficiency at lower compressor speeds. Cooling size ratios in the 1.4 to 2.0 range appear to provide the highest peak power reduction, with the exception being the field tested VSHP in the cooling mode. 


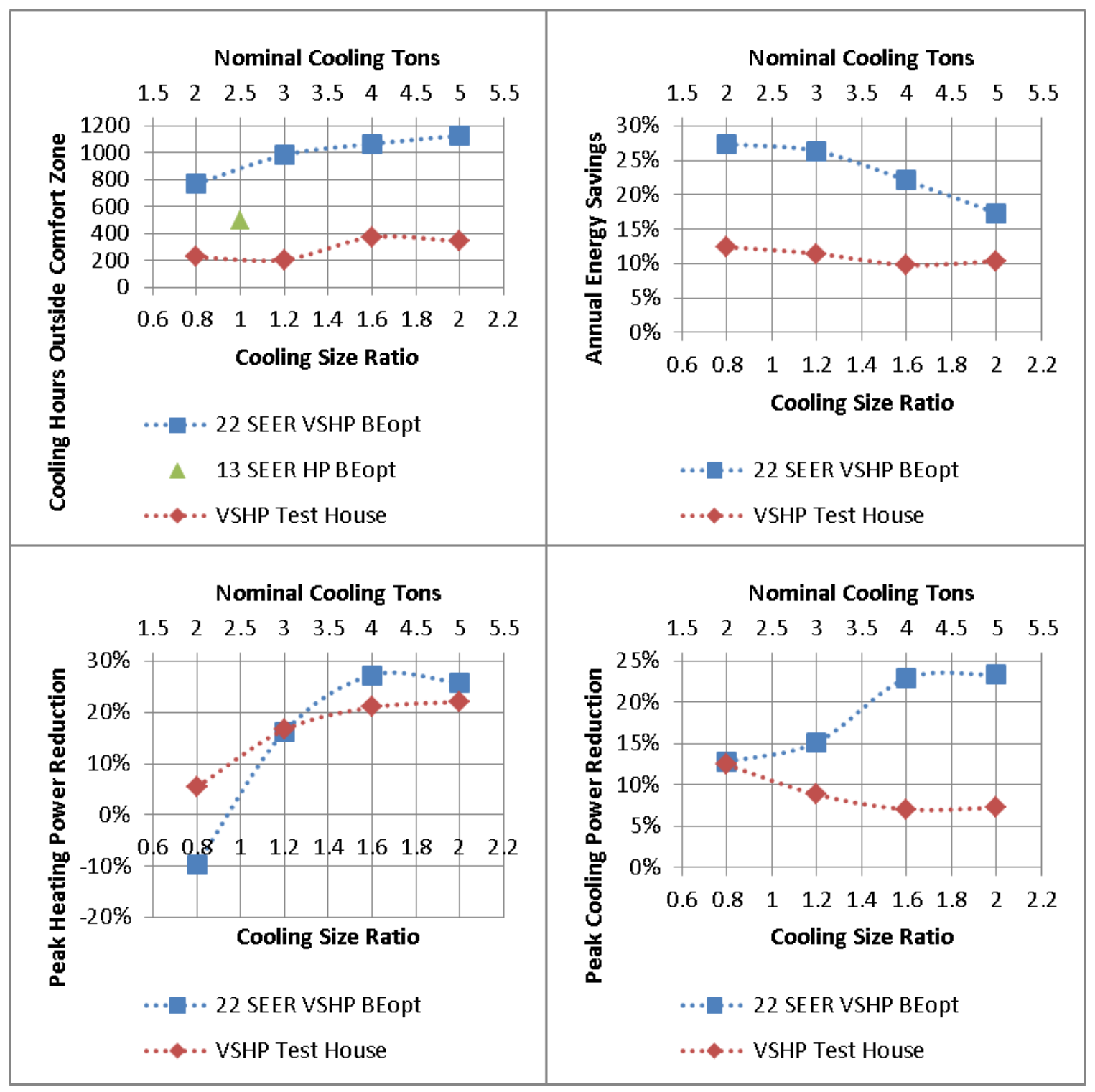

Figure 13: Comfort, energy savings, and peak power reduction plots for Charlotte, North Carolina, with $15 \%$ duct leakage and R-4 duct insulation 


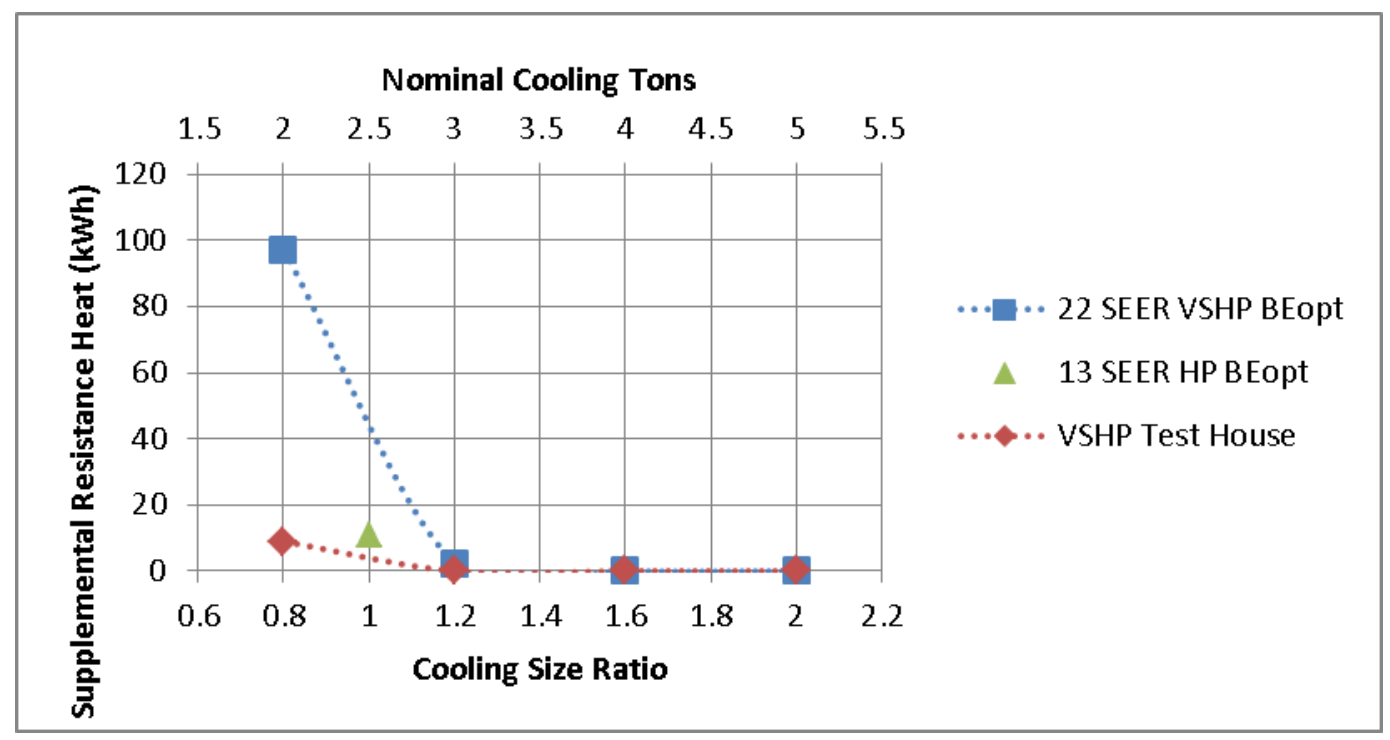

Figure 14: Supplemental resistance heat use in Charlotte, North Carolina, with 15\% duct leakage and R-4 duct insulation

Simulations were run using the same house, but with the ducts moved to the conditioned space (i.e. no duct losses). The baseline HP was resized by BEopt, but the same VSHP capacities were simulated. This produced even higher cooling size ratios than the prior simulations. The house with the baseline HP had a peak cooling demand to peak heating demand ratio of 0.94 in this configuration. Figure 15 shows comfort, energy savings, and peak power reduction plots for this setup. Examining the top left plot, this case resulted in more hours outside of the comfort range for both VSHPs. The field test VSHP was still able to maintain slightly better comfort for the 2- and 3-ton sizes that correspond to a 1.2 and 1.8 cooling size ratio respectively. Eliminating the duct conduction losses reduces the sensible cooling load, but does not reduce the latent cooling load. This requires lower SHRs from the heat pump in order to provide proper dehumidification.

The top right plot shows that the energy savings also decline as the cooling size ratio increases, similarly to the case with duct losses. The savings relative to the baseline are higher for the case without duct losses though since duct losses are larger on the VSHPs due to their increased runtime relative to single speed heat pumps.

The bottom two plots show the peak heating and cooling power for the case without duct losses. These plots show similar magnitudes of peak power reduction as the case with duct leakage, with cooling size ratios in the 1.6 to 2.0 range providing the highest peak power reduction.

As with the case including duct losses, these simulations had very minimal resistance heat usage, so the benefits of cooling size ratios greater than one are limited to peak power reductions seen on the VSHP model in BEopt. 


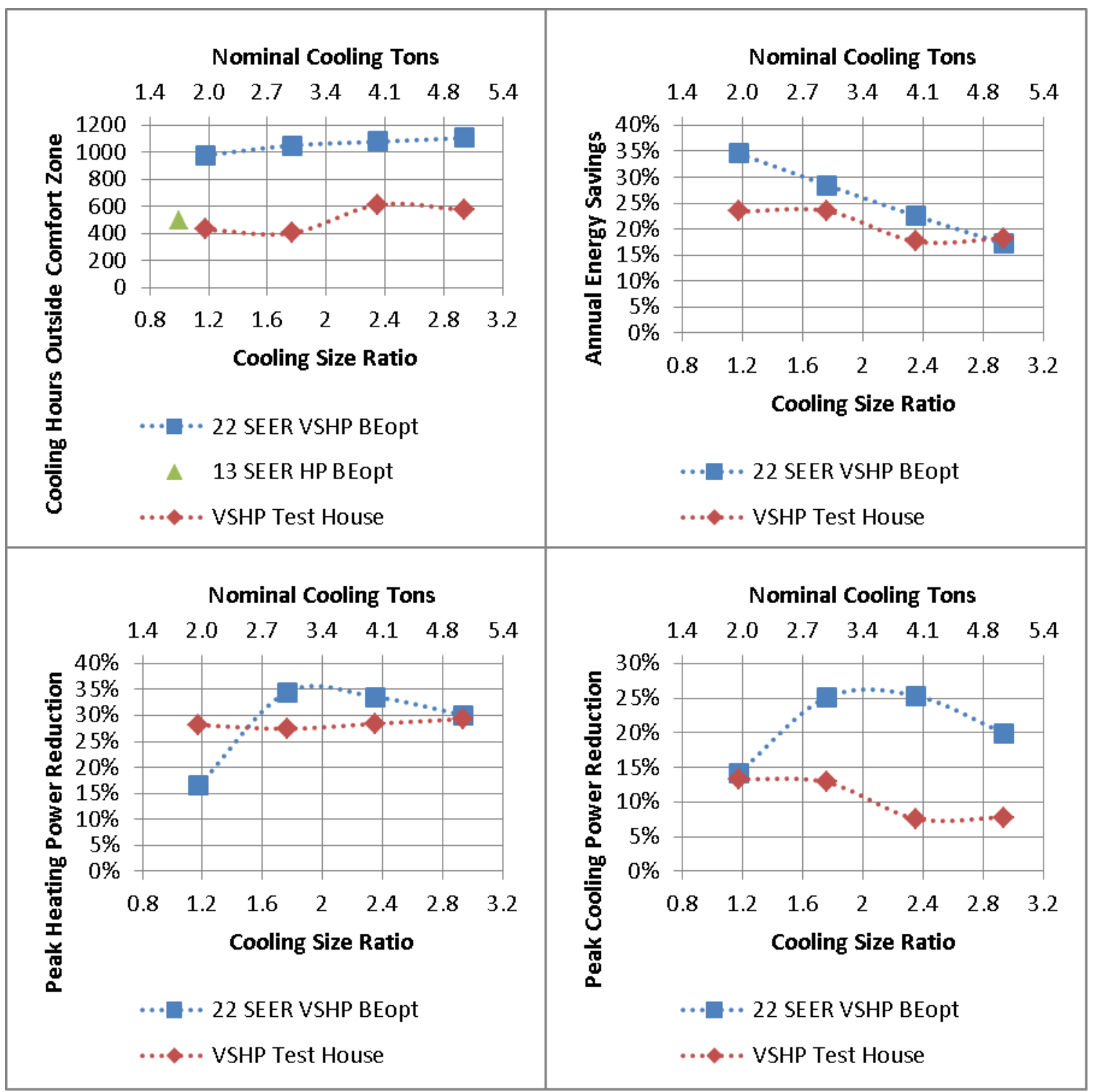

Figure 15: Comfort, energy savings, and peak power reduction plots for Charlotte, North Carolina, with ducts in the conditioned space (no duct losses)

\subsubsection{Little Rock, Arkansas}

Little Rock is located in the Southwest portion of the mixed-humid climate and has 3,158 HDD and 1,938 CDD (ASHRAE, 2013a). Simulations for this location were run in the same fashion as those presented in section 4.1.1. The house with the baseline heat pump had a peak cooling demand to peak heating demand ratio of 0.76 . Figure 16 shows the comfort, energy savings, and peak power reduction plots for Little Rock for a home with $15 \%$ duct leakage and R-4 duct insulation. The top left plot shows the hours that were uncomfortable when the air temperature in the house was above $71.6^{\circ} \mathrm{F}$ (unit not heating). The field test VSHP was able to maintain better comfort in the house for all cooling size ratios simulated (0.8 to 2.0). As noted earlier, the performance curves for the VSHP in BEopt do not take into 
account any enhanced humidity control, and this is reflected in the high number of hours outside the comfort zone. With humidity control enabled, it is expected that this unit could maintain an equivalent level of comfort as provided by the baseline 13 SEER HP.

The top right plot shows the annual energy savings of the VSHPs as compared to the baseline heat pump. As with Charlotte, there is no significant energy savings for cooling size ratios higher than one. The field test VSHP shows very little difference in energy savings across the entire range of heat pump capacities, while the VSHP in BEopt shows reduced savings at cooling size ratios greater than 1.2. The Little Rock simulations had slightly higher resistance heat use than that Charlotte cases, however it is still relatively small relative to the total annual energy use (2.6\% for the baseline 13 SEER HP), Figure 17.

The bottom two plots show the peak heating and cooling power. The peak heating power is reduced consistently as the cooling size ratio is increased. The VSHPs with cooling size ratios below one actually have increased peak heating power, and there are minimal savings at the 1.2 cooling size ratio likely due to increased duct leakage from higher airflows and resulting duct pressures. The cooling peak power is lower for the two undersized VSHPs, but this is due to the fact that these units had a few hours of unmet cooling set point that likely correspond to the peak load. This reduction in peak load is akin to demand response where the energy consumption of the unit is limited in exchange for some reduction in indoor comfort. Once above cooling size ratios of the 1, the cooling peak reduction for the VSHP in BEopt increases with increased size ratio, while the reduction for the field test VSHP remain constant due to the similar cooling efficiency of the different compressor speeds at high temperatures. 


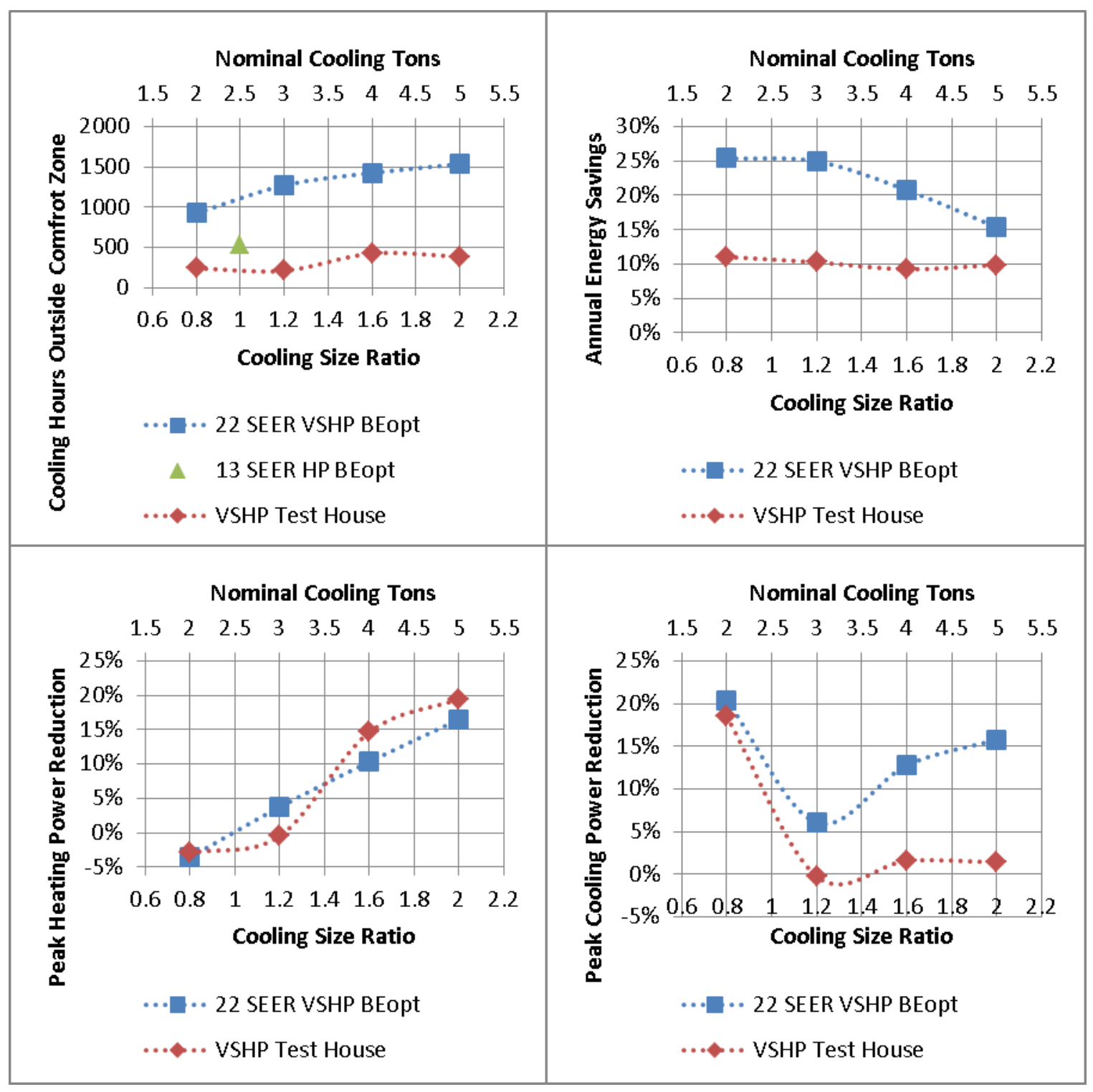

Figure 16: Comfort, energy savings, and peak power reduction plots for Little Rock, Arkansas, with 15\% duct leakage and R-4 duct insulation. 


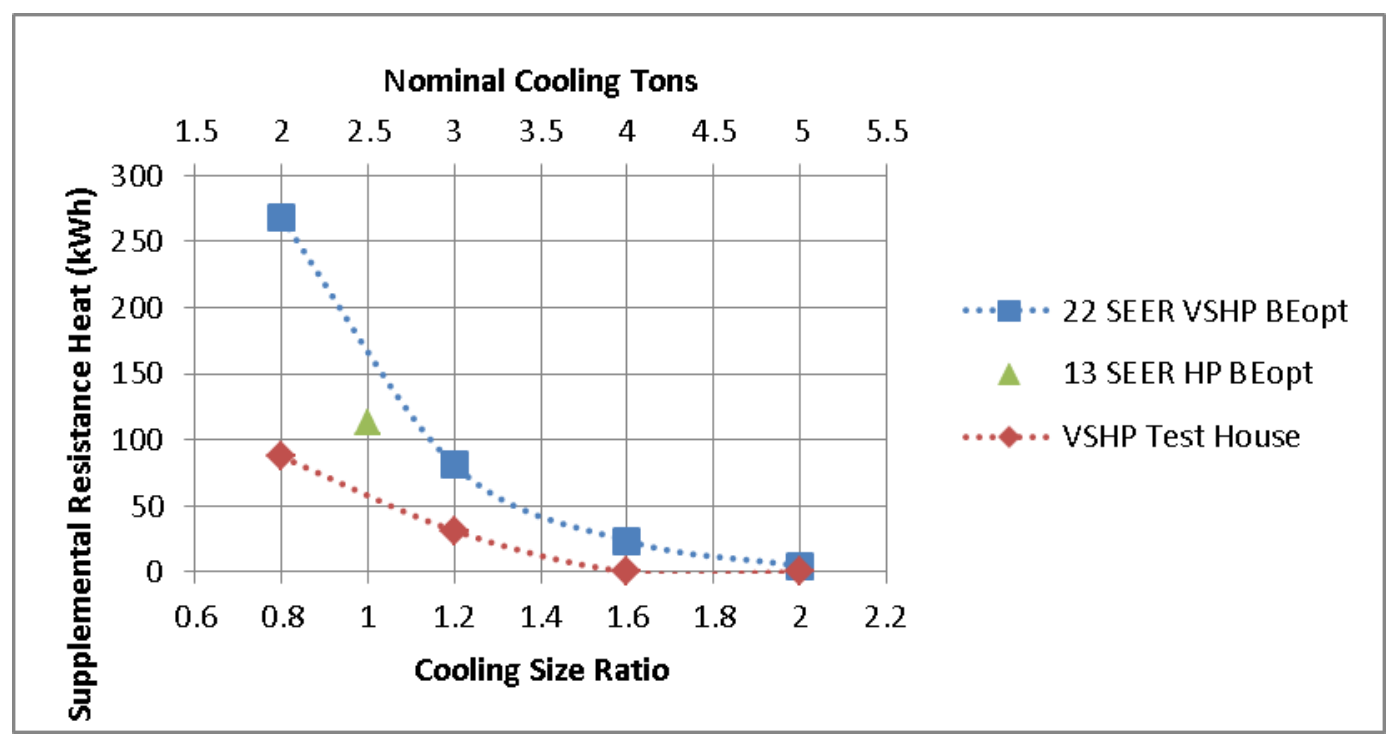

Figure 17: Supplemental resistance heat use for Little Rock, Arkansas, with $15 \%$ duct leakage and R-4 duct insulation

Additional simulations were run on the same house with the ducts installed in the conditioned space. This change alone reduced the baseline unit sized by BEopt from 2.5-tons to 1.8-tons, however the peak cooling demand to peak heating demand ratio was unchanged at 0.76 for the house with the baseline HP. Figure 18 shows plots for the comfort, energy savings, and peak power reduction for this case. Once again, moving the ducts to the conditioned space resulted in more hours outside the comfort zone for the VSHPs as seen in the top left plot. The field test VSHP was able to provide slightly better comfort at cooling size ratios up to $\sim 1.7$, but at higher cooling size ratios the number of hours outside of the comfort zone exceeded those of the baseline 13 SEER HP.

The top right plot shows the energy savings for the VSHPs decline as the cooling size ratio increases. This trend is very similar to the cases ran in Charlotte with the ducts installed in the conditioned space.

The bottom two plots show the peak heating and cooling power demand of the units. Both VSHPs show increased peak heating power reduction at higher cooling size ratios. The VSHP from BEopt shows a peak cooling power reduction at a cooling size ratio of $\sim 2.2$, while the field test VSHP shows declining peak cooling power reductions as the cooling size ratio increases. 


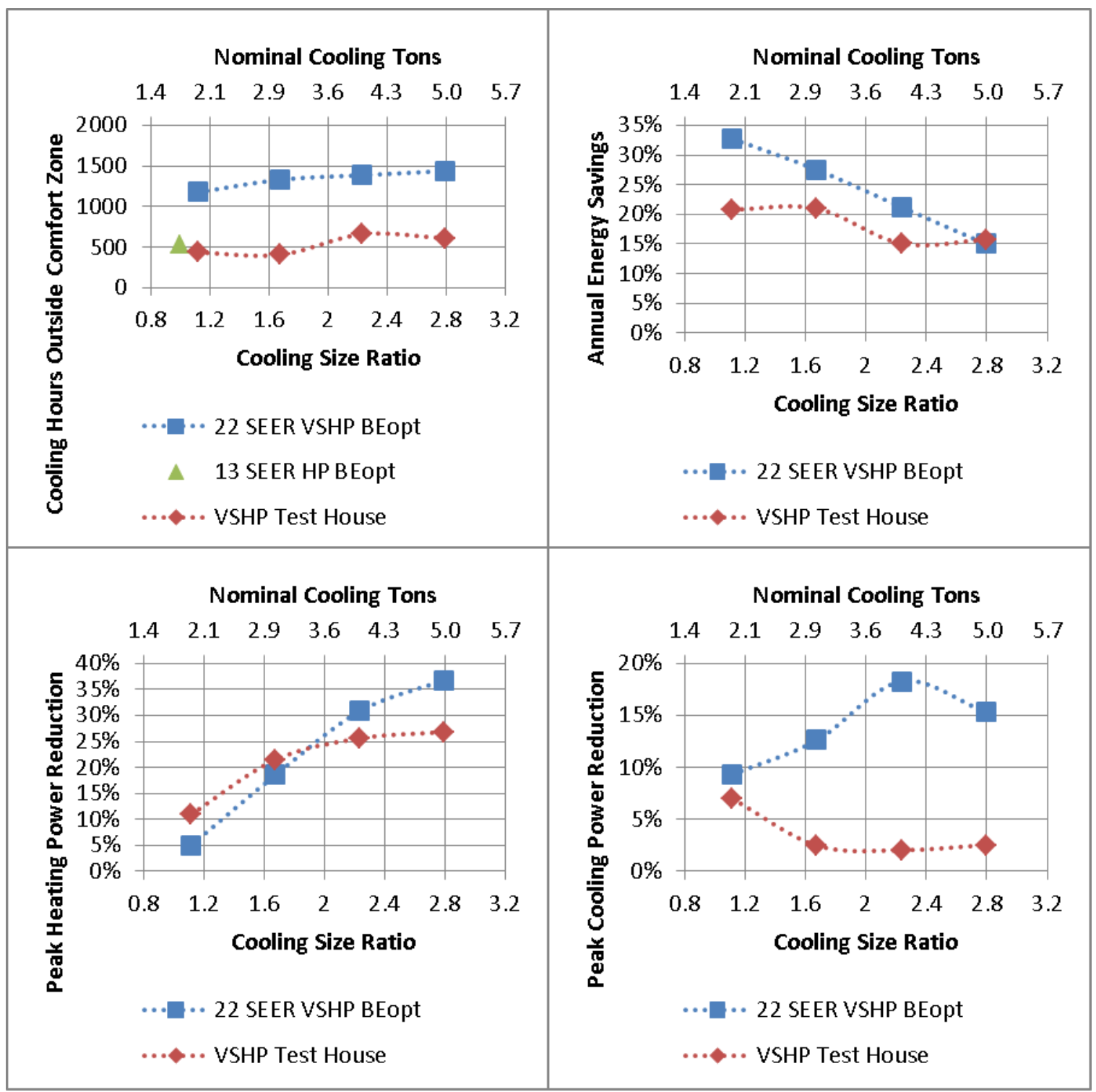

Figure 18: Comfort, energy savings, and peak power reduction plots for Little Rock, Arkansas, with ducts in the conditioned space (no duct losses)

\subsection{COLD CLIMATE}

Simulations were performed for two cities, Pittsburgh, Pennsylvania and Des Moines, Iowa, that are located in the cold climate, Figure 1. These cities still have humidity to contend with during the cooling season, but also experience substantially lower temperatures in the winter months.

\subsubsection{Des Moines, Iowa}

Des Moines is located near the southern boundary of the cold climate and has 6,172 HDD and 1,034 CDD (ASHRAE, 2013a). The peak cooling demand to peak heating demand ratio 
for the house with the baseline HP was 0.51. Figure 19 shows plots for the comfort, energy savings, and peak power reduction for the VSHPs at different cooling size ratios for cases with $15 \%$ duct leakage and R-4 duct insulation. The field test VSHPs had fewer hours outside of the comfort zone at all cooling size ratios simulated. The VSHP in BEopt had more hours outside of the comfort zone, but the performance curves do not reflect any enhanced dehumidification capabilities of the unit.

The top right plot shows the energy savings of the VSHPs compared to the baseline 13 SEER HP. Unlike the mixed-humid climates, both VSHPs show energy savings from increased cooling size ratios. The VSHP in BEopt shows the highest savings in the 1.2 to 1.6 cooling size ratio range, while the field test VSHP shows increasing savings up to the largest cooling size ratio simulated, 2.0.

The bottom two plots show the heating and cooling peak power reduction of the VSHPs. As noted in section 3, the minimum compressor operating temperature for the baseline HP and $\mathrm{VSHP}$ in BEopt is $0^{\circ} \mathrm{F}$. The field test VSHP can operate down to $-15^{\circ} \mathrm{F}$ per the manufacturer's product data, but was limited to $-4^{\circ} \mathrm{F}$ by EnergyPlus. Because Des Moines experiences temperature below $-4^{\circ} \mathrm{F}$, the peak heating power for all systems tested is for $100 \%$ resistance heat usage. Because the heating airflows are higher on the higher capacity units, the duct losses are also larger due to the increase in duct static pressure. This results in higher heating loads and higher heating energy use as shown in the bottom left plot of Figure 19: Comfort, energy savings and peak power reduction plots for Des Moines, Iowa, with $15 \%$ duct leakage and R-4 duct insulation. To get a better feel for the peak power reduction, the peak heating power when the heat pumps were running were compared. For the first comparison, the peak heating power during hours when the baseline heat pump ran the entire hour was pulled along with the associated hour of the year. The heating power for the VSHPs was then pulled for this same hour of the year. The outdoor air temperature for this hour falls very close to the $0^{\circ} \mathrm{F}$ minimum compressor operating temperature for the two units with models from BEopt. This comparison is shown on the left side of Figure 20. Since the field test heat pump can operate at lower temperatures outdoor temperatures, the peak heating power for the field test VSHP, when the heat pump ran the entire hour, was pulled along with the associated hour of the year. The outdoor temperature for this hour was close to the $-4^{\circ} \mathrm{F}$ minimum compressor operating temperature imposed by EnergyPlus. The peak heating power for the other units was pulled at the same hour of the year for comparison and is shown in the right side of Figure 20.

The heating peak power reduction is mostly due to the reduction of resistance heat use, shown in Figure 21. The field test VSHP uses less resistance heat than the VSHP in BEopt for the same capacity unit due to the additional heating capacity available from running the compressor at higher speeds and the lower outdoor temperature at which the compressor is able to run. The 5-ton field test VSHP shows no additional reduction in resistance heat use compared to the 4 -ton unit due to the $-4^{\circ} \mathrm{F}$ limit on compressor operation imposed by EnergyPlus. Without this limit, the 5-ton unit would use even less resistance heat. 


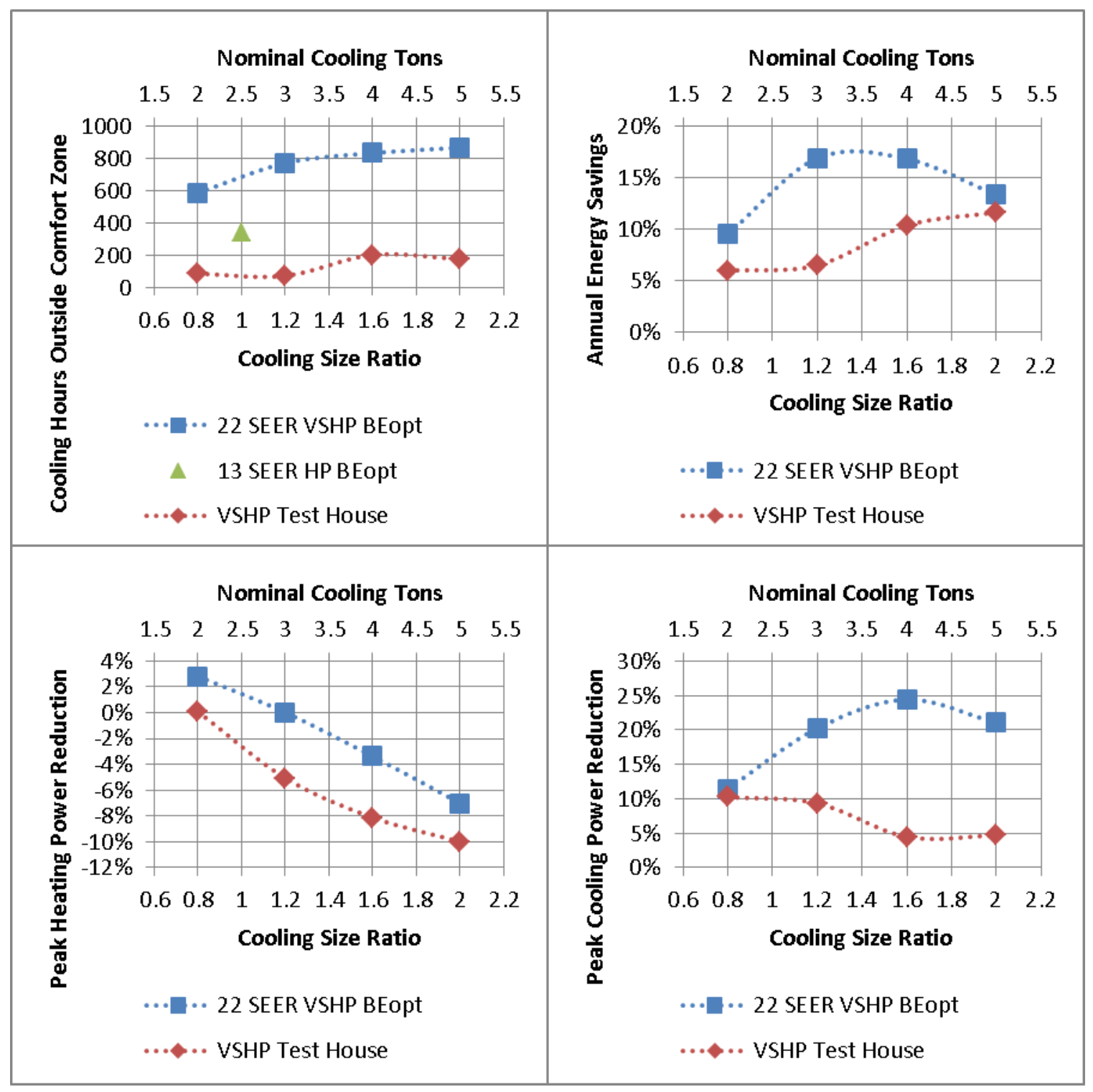

Figure 19: Comfort, energy savings and peak power reduction plots for Des Moines, Iowa, with $15 \%$ duct leakage and R-4 duct insulation 


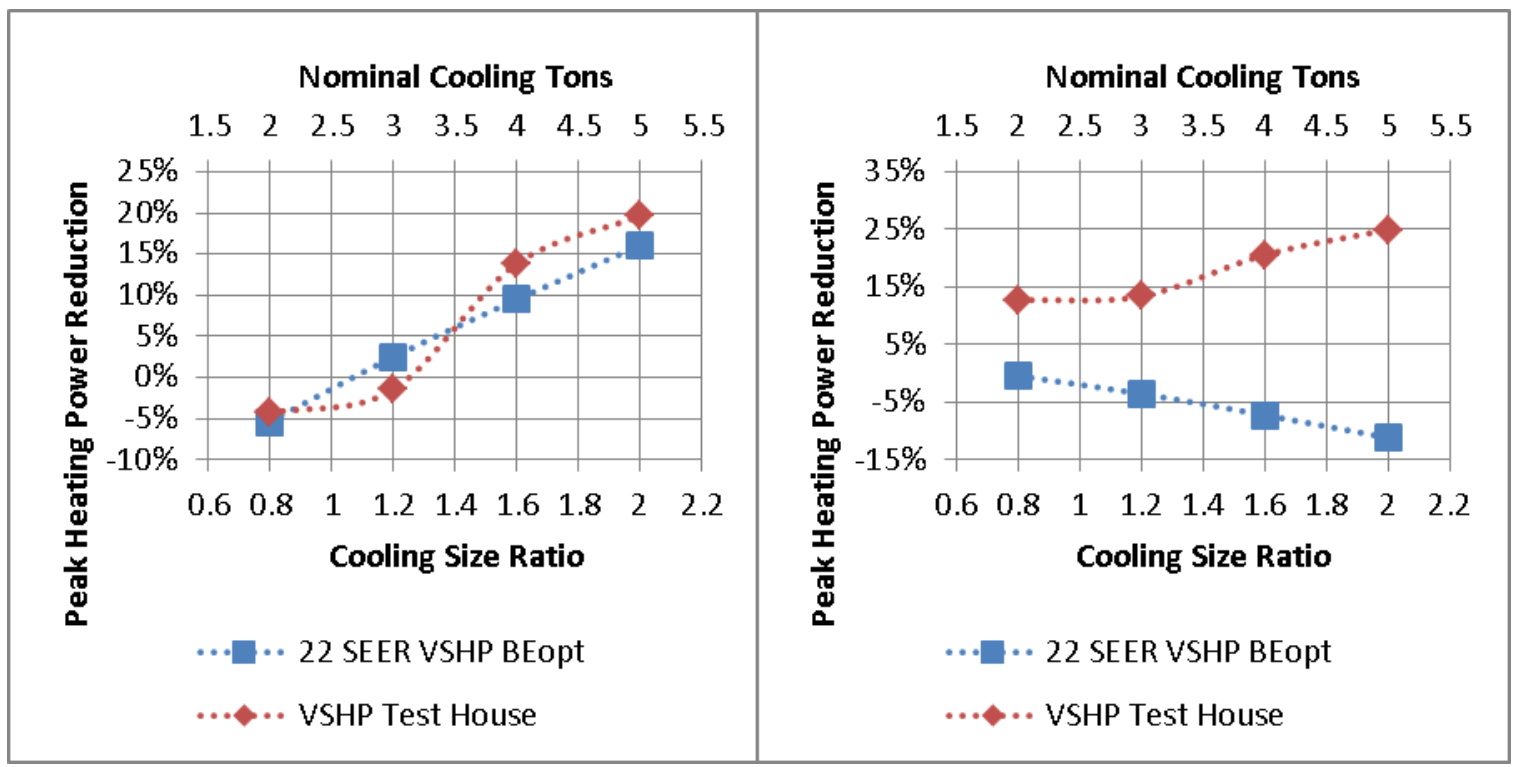

Figure 20: Peak heating power reduction at $3^{\circ} \mathrm{F}$ (left) and $-2^{\circ} \mathrm{F}$ (right) outdoor air temperature for Des Moines, Iowa, with 15\% duct leakage and R-4 duct insulation

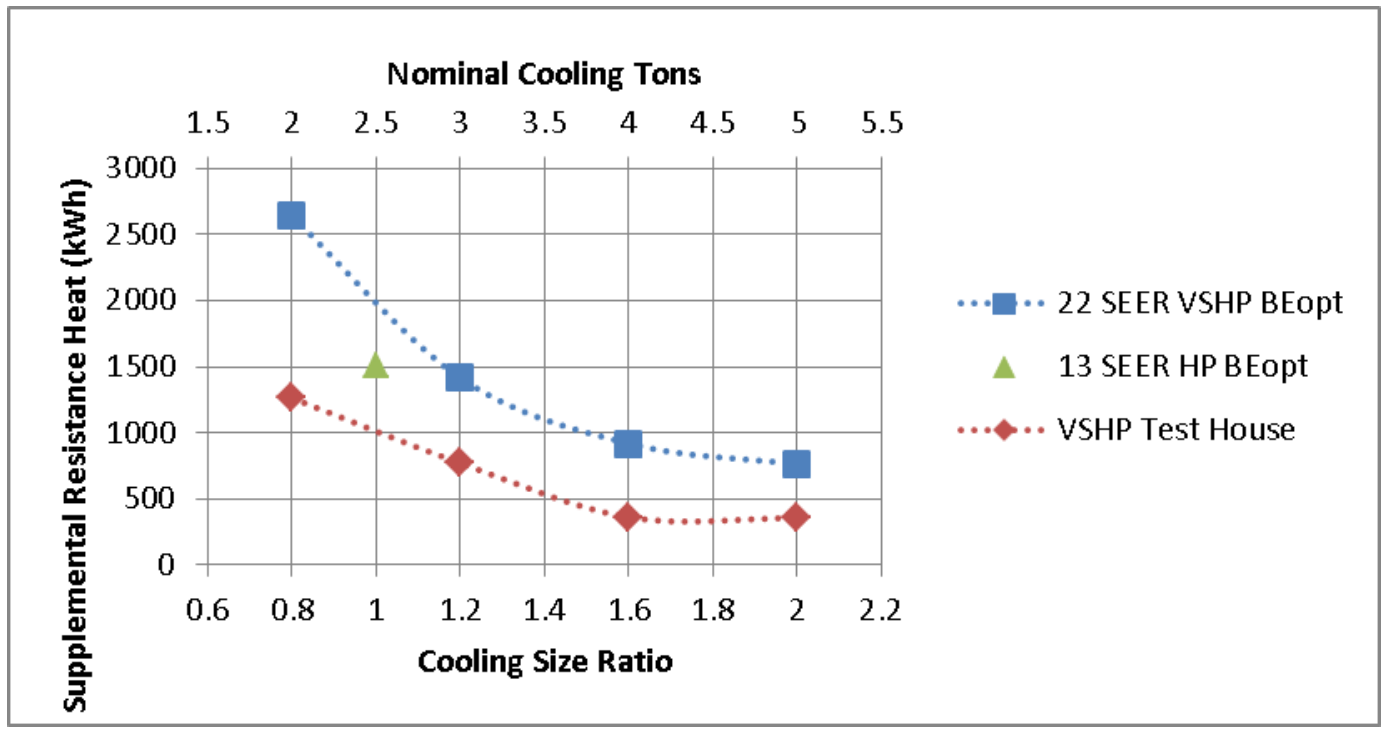

Figure 21: Supplemental resistance heat use for Des Moines, IA with $15 \%$ duct leakage and R-4 duct insulation

Simulations were run for the same house, but with the ducts moved to the conditioned space. This reduced the heating and cooling load and the baseline 13 SEER HP was auto-sized for this case at 1.8-tons instead of 2.5-tons with duct losses. This increased the peak cooling demand to peak heating demand ratio to 0.57 from 0.51 . Figure 22 shows plots of the comfort, energy savings, and peak power reduction for the VSHPs with the ducts in the conditioned space. The top left plot shows the comfort for the VSHPS and baseline unit. As with the other locations, the number of hours outside of the comfort range increase when the ducts are brought into the conditioned space. The upper right plot shows the energy savings 
increase with the ducts in the conditioned space and both VSHPs show maximum savings at a cooling size ratio of $\sim 1.7$. The bottom plots show the peak heating and cooling power reduction of the VSHPs. Due to the limit on compressor operation at low temperatures, all of the units have the same peak power in heating representing $100 \%$ resistance heat use. In order to get a better idea of the peak power reduction when the HPs were running, two other hours were evaluated, one warm enough that all HPs were running the entire hour, and the other with only the field test HPs operating the entire hour at the lowest operating temperature allowed by EnergyPlus, Figure 23. The plot on the left, at $3^{\circ} \mathrm{F}$ and all heat pumps running, the VSHPs have increasing peak power reduction as cooling size ratio increases. The field test HP shows no additional reduction between the 4- and 5-ton unit sizes because no additional resistance heat use can be offset, as seen in Figure 24. The plot on the right in Figure 23, at $-2^{\circ} \mathrm{F}$ and only the field test VSHP running, shows that both the baseline and VSHP from BEopt are running 100\% resistance heat, while the field test VSHP has increasing peak power reductions, up to $35 \%$, with increasing cooling size ratio.

The bottom right plot of Figure 22 shows the cooling peak power reduction for the VSHPs. The field test VSHP does not see any peak power reduction when oversizing above the lowest cooling size ratio evaluated of $\sim 1.1$, while the VSHP in BEopt has the highest peak power reduction at a cooling size ratio of $\sim 1.7$. 


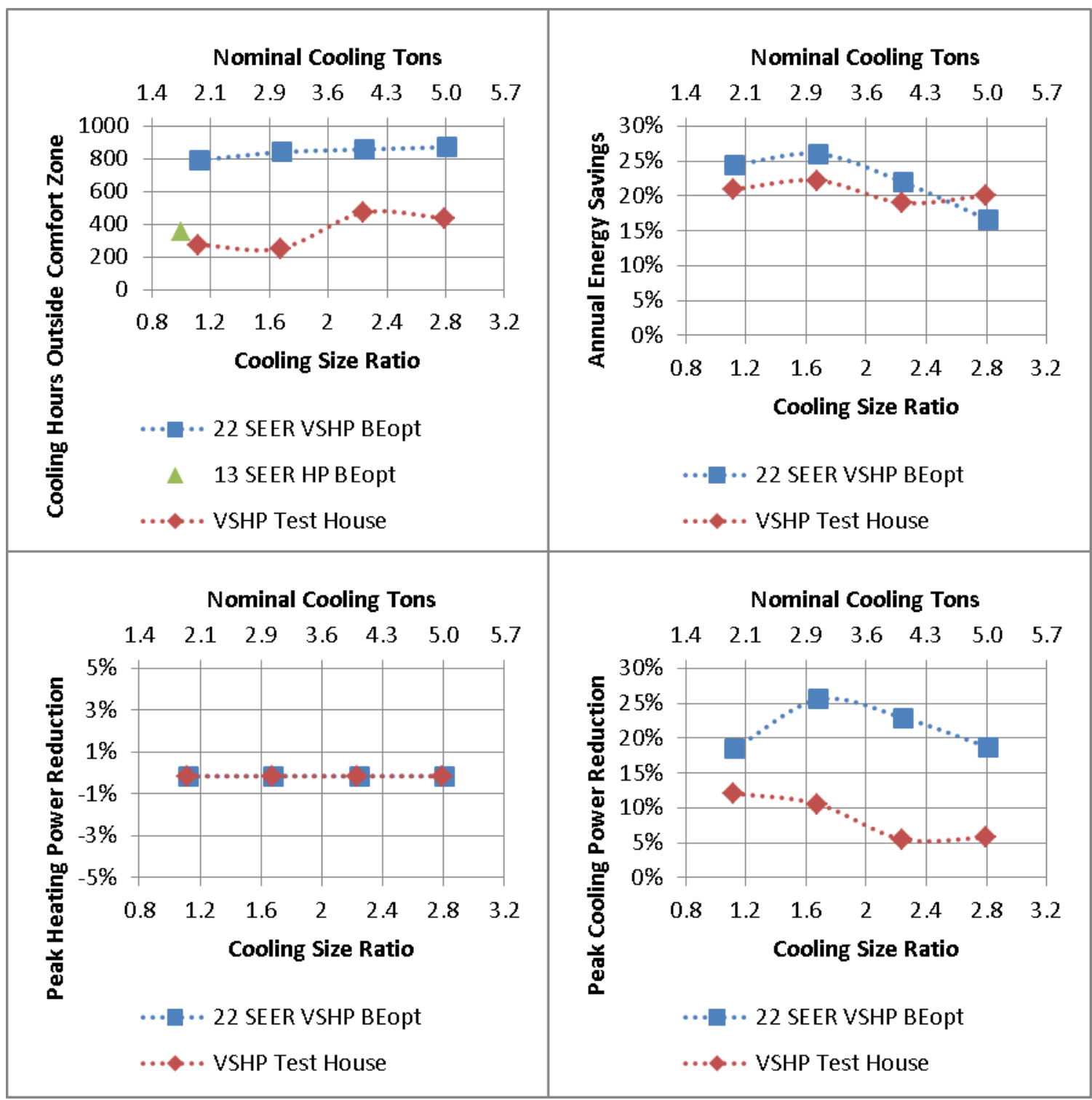

Figure 22: Comfort, energy savings, and peak power reduction plots for Des Moines, Iowa, with ducts in the conditioned space (no duct losses) 


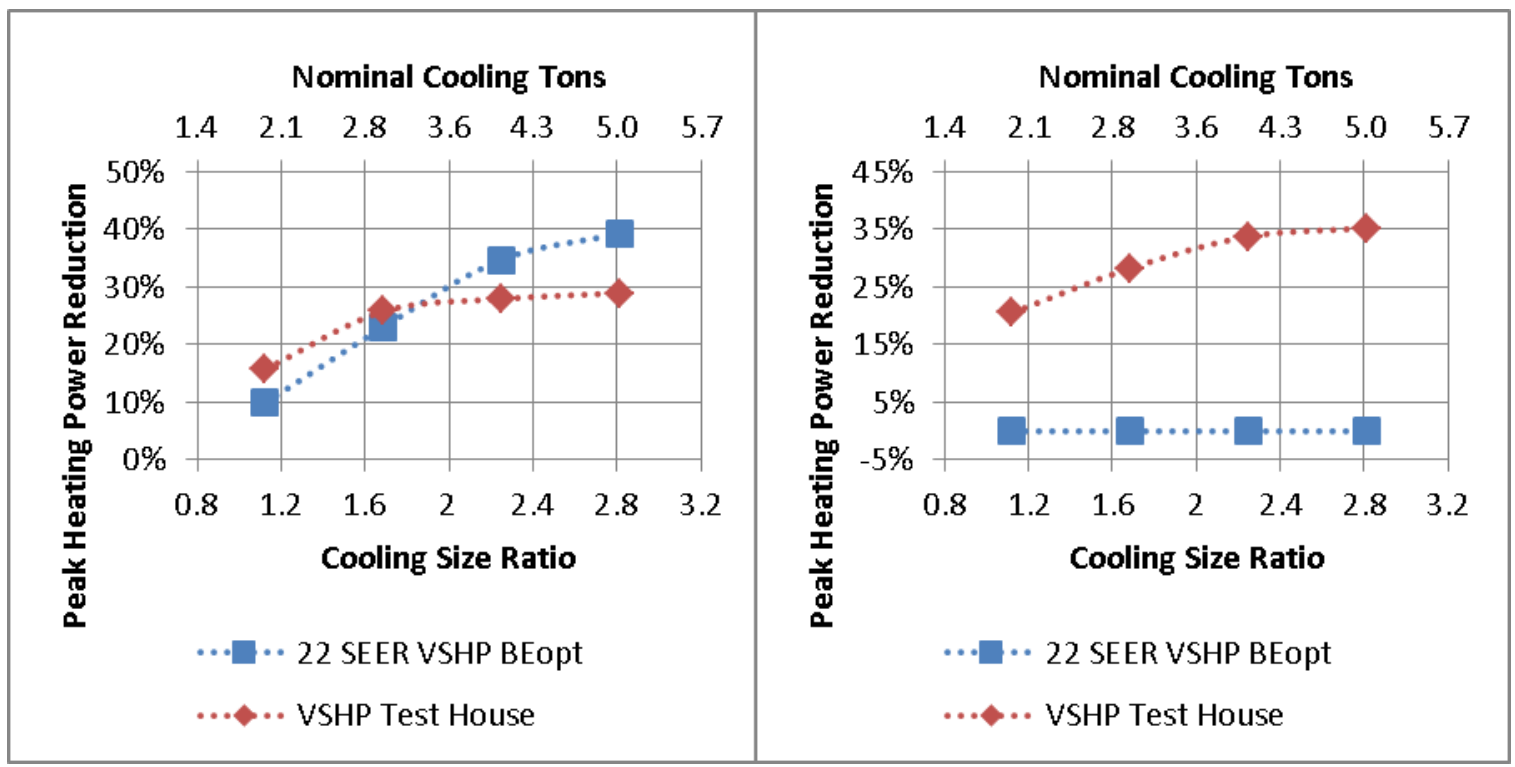

Figure 23: Peak heating power reduction at $3^{\circ} \mathrm{F}$ (left) and $-2^{\circ} \mathrm{F}$ (right) outdoor air temperature for Des Moines, Iowa, with ducts in the conditioned space (no duct losses)

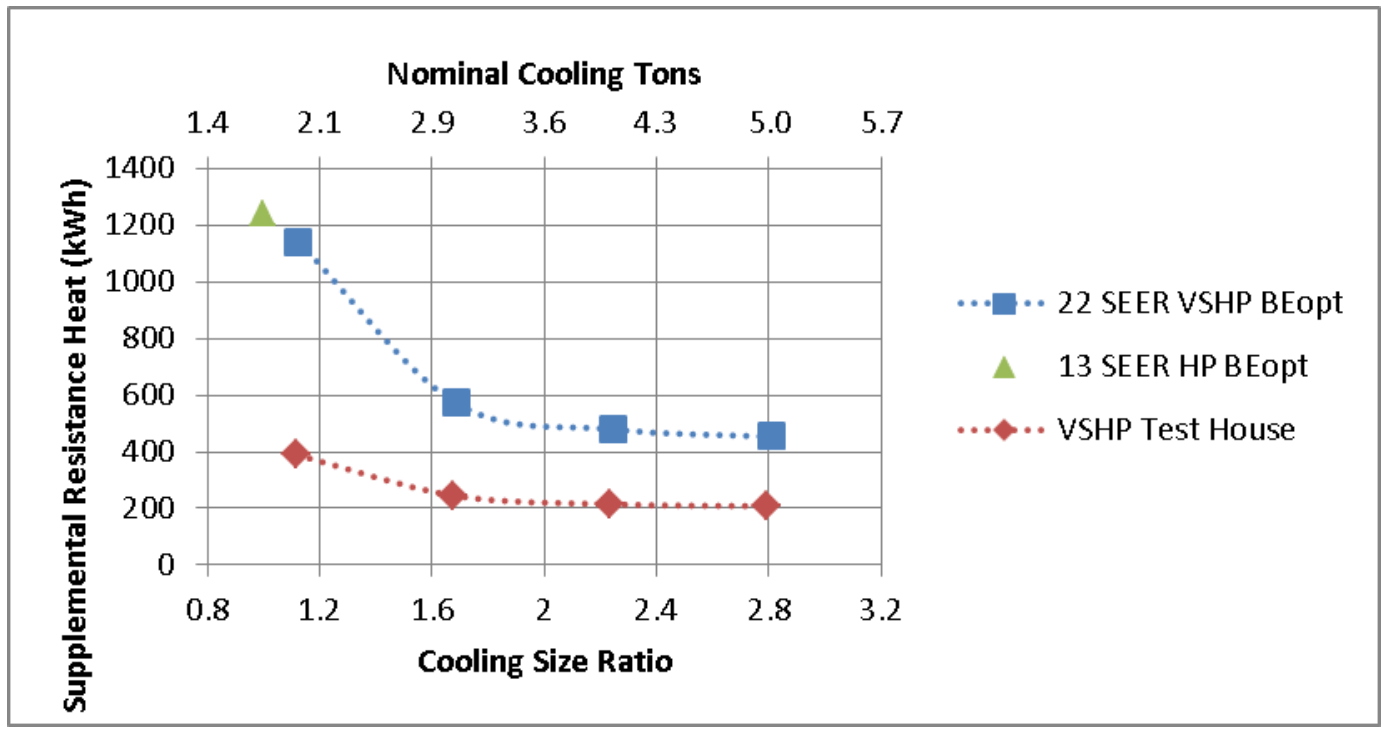

Figure 24: Supplemental resistance heat use for Des Moines, Iowa, with ducts in the conditioned space (no duct losses)

\subsubsection{Pittsburgh, Pennsylvania}

Pittsburgh is also located in the cold climate, but near the eastern edge. It has ,5583 HDD and 782 CDD (ASHRAE, 2013a). The peak cooling demand to peak heating demand ratio for the baseline HP in this house was 0.47 . Figure 25 shows plots for comfort, energy savings, and peak power reduction for the case of ducts with $15 \%$ leakage and R-4 duct insulation. The top left plot shows the hours outside of the comfort range, and, as with the other cases, the field test VSHP has fewer hours outside of the comfort range. The top right 
plot shows the energy savings of the two VSHPs compared to the baseline 13 SEER HP. Both VSHPs show significant savings with cooling size ratios in the 1.6-2.0 range. The bottom plots show the peak heating and cooling power reduction of the VSHPs. The minimum outdoor temperature in the simulation falls below the minimum compressor operating temperature of the VSHP in BEopt, resulting in no peak heating power reduction. The peak power of this unit increases with cooling size ratio due to increased duct leakage at higher airflow rates. The field test VSHP shows increasing peak power reduction all the way up to the maximum cooling size ratio simulated of 2.0 and eliminates all supplemental resistance heat use, Figure 26. The bottom right plot shows the peak cooling power reduction. As with the other cases, the field test VSHP does not show any cooling peak power reduction with increased cooling size ratios, while the VSHP in BEopt shows a peak reduction of $\sim 24 \%$ at a cooling size ratio of 1.6 .

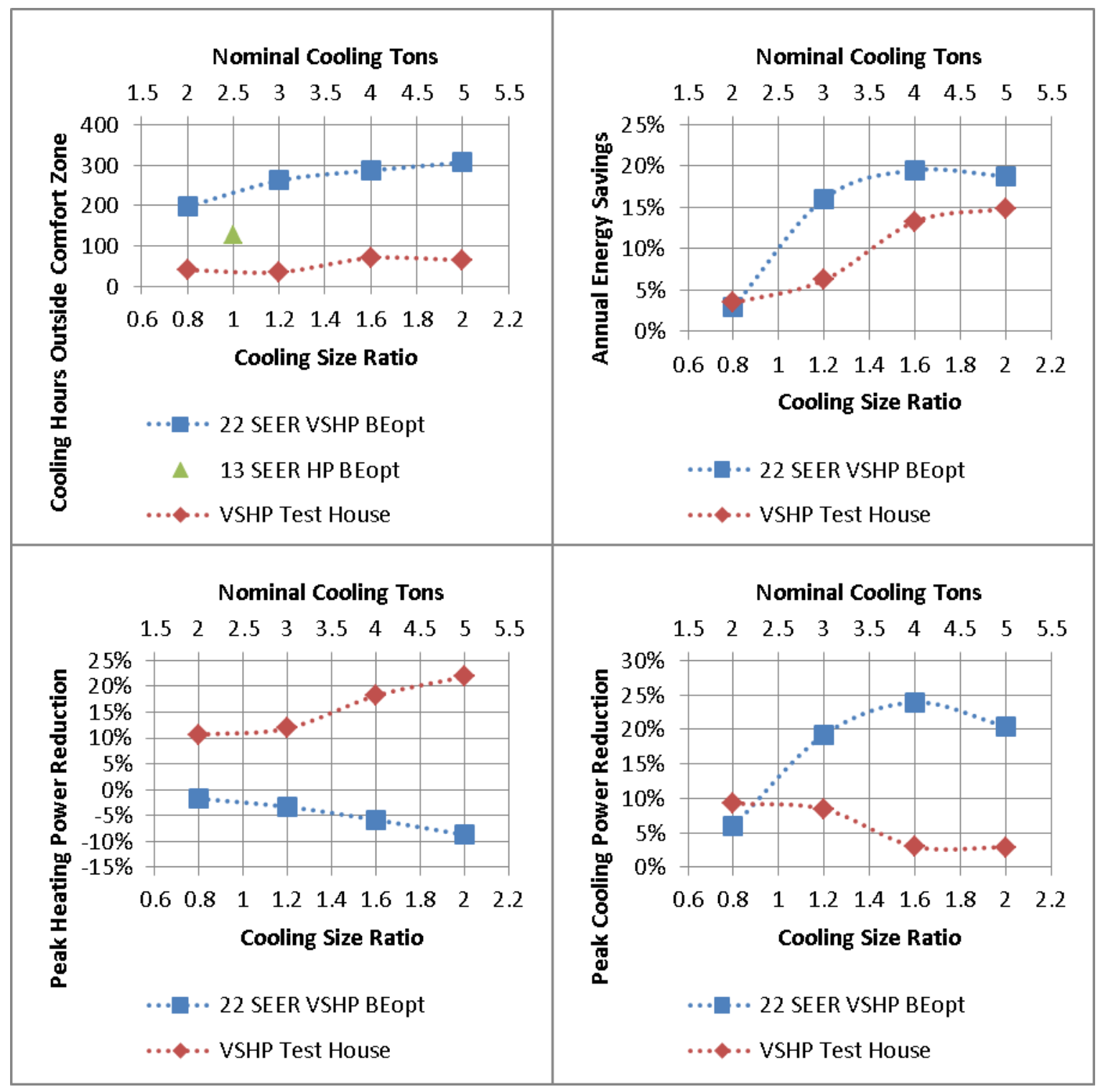

Figure 25: Comfort, energy savings, and peak power reduction for Pittsburgh, Pennsylvania, with $15 \%$ duct leakage and R-4 duct insulation 


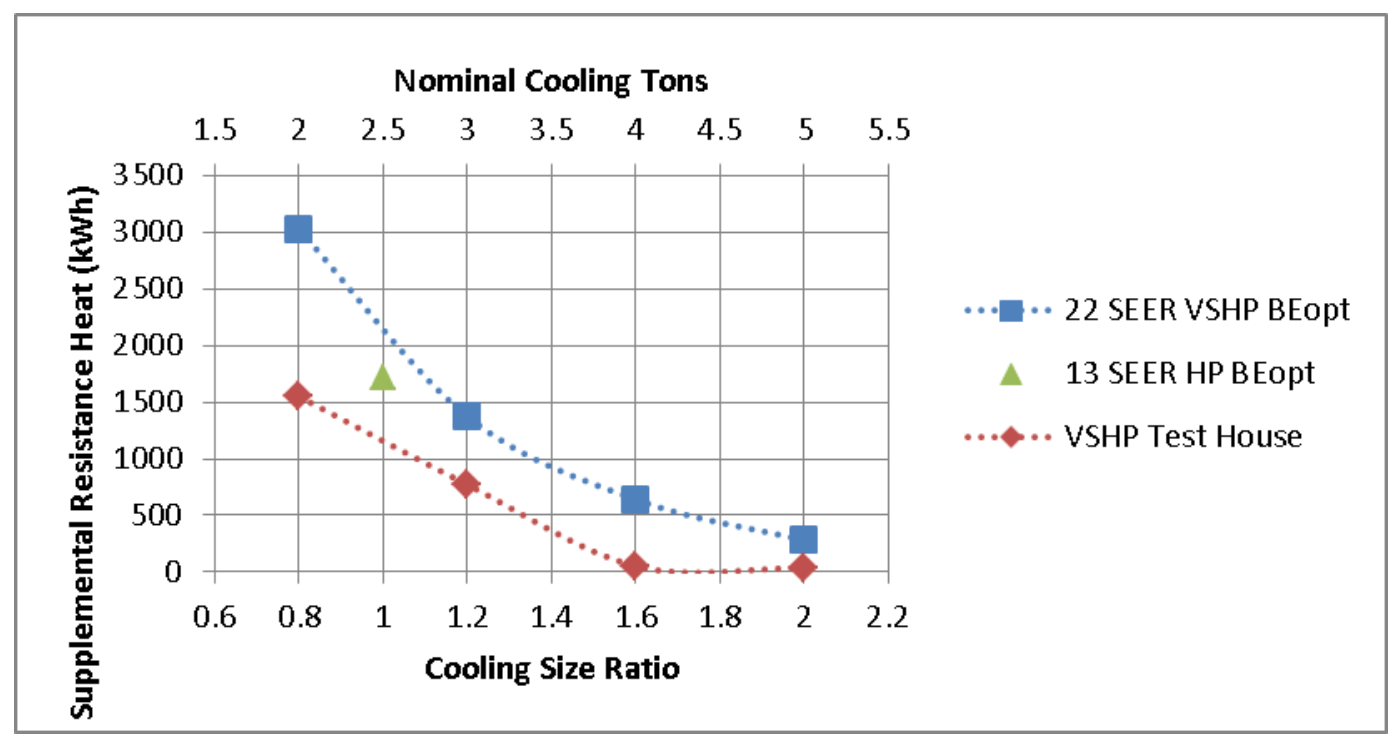

Figure 26: Supplemental resistance heat use for Pittsburgh, Pennsylvania, with 15\% duct leakage and R-4 duct insulation

Simulations were also run for the same house but with the ducts located in the conditioned space. This reduced the baseline unit size from 2.5-tons to 1.74-tons. The peak cooling demand to peak heating demand ratio was unchanged at 0.47 . The sizes of the VSHPs were not changed, resulting in higher cooling size ratios when compared to the case with duct losses. Figure 27 shows plots for the comfort, energy savings, and peak power reduction for the VSHPs when compared to the baseline 13 SEER HP. The top left plot shows the hours outside of the comfort zone and shows that only the field test VSHP, at cooling size ratios up to $\sim 1.7$, provides equivalent or better comfort than the baseline HP. The top right plot shows the annual energy savings of the VSHPs. With the ducts brought into the conditioned space and resulting decreased heating load, the field test VSHP shows that there is very little influence of cooling size ratio on the energy savings, Figure 28. This is due to the fact that there is very little resistance heat use, similar to the Little Rock cases with duct losses. The VSHP in BEopt shows increased energy savings up to a 1.7 cooling size ratio, due to the lower heating capacity of the unit relative to the rated cooling capacity. The bottom right plot of Figure 27 shows the cooling peak power reduction of the VSHPs. Once again, the field test unit does not show any cooling peak power reduction benefits by increasing the cooling size ratio, while the VSHP in BEopt shows the highest reduction at a cooling size ratio of 1.7 . 


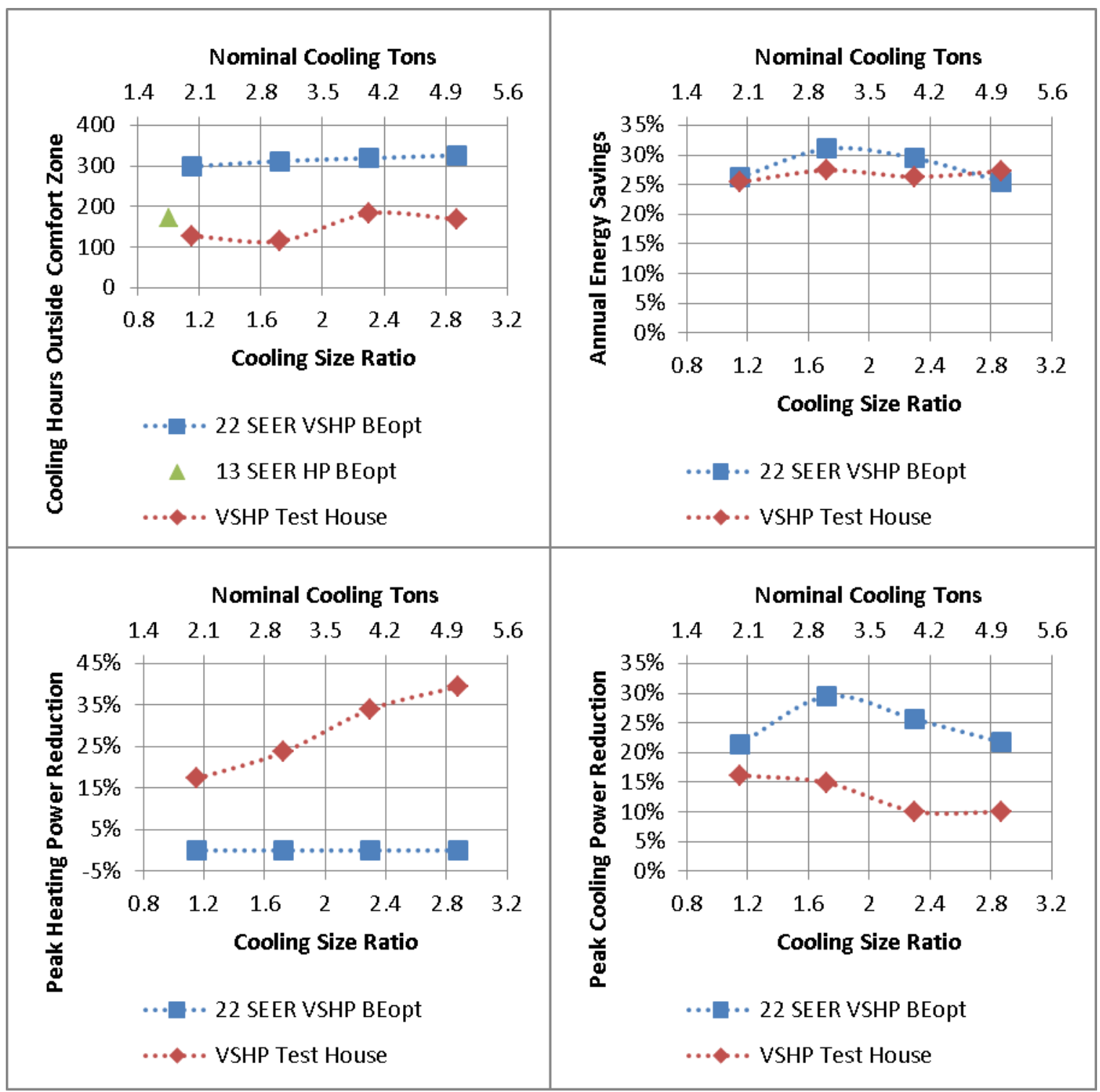

Figure 27: Comfort, energy savings, and peak power reduction for Pittsburgh, Pennsylvania, with ducts in the conditioned space (no duct losses) 


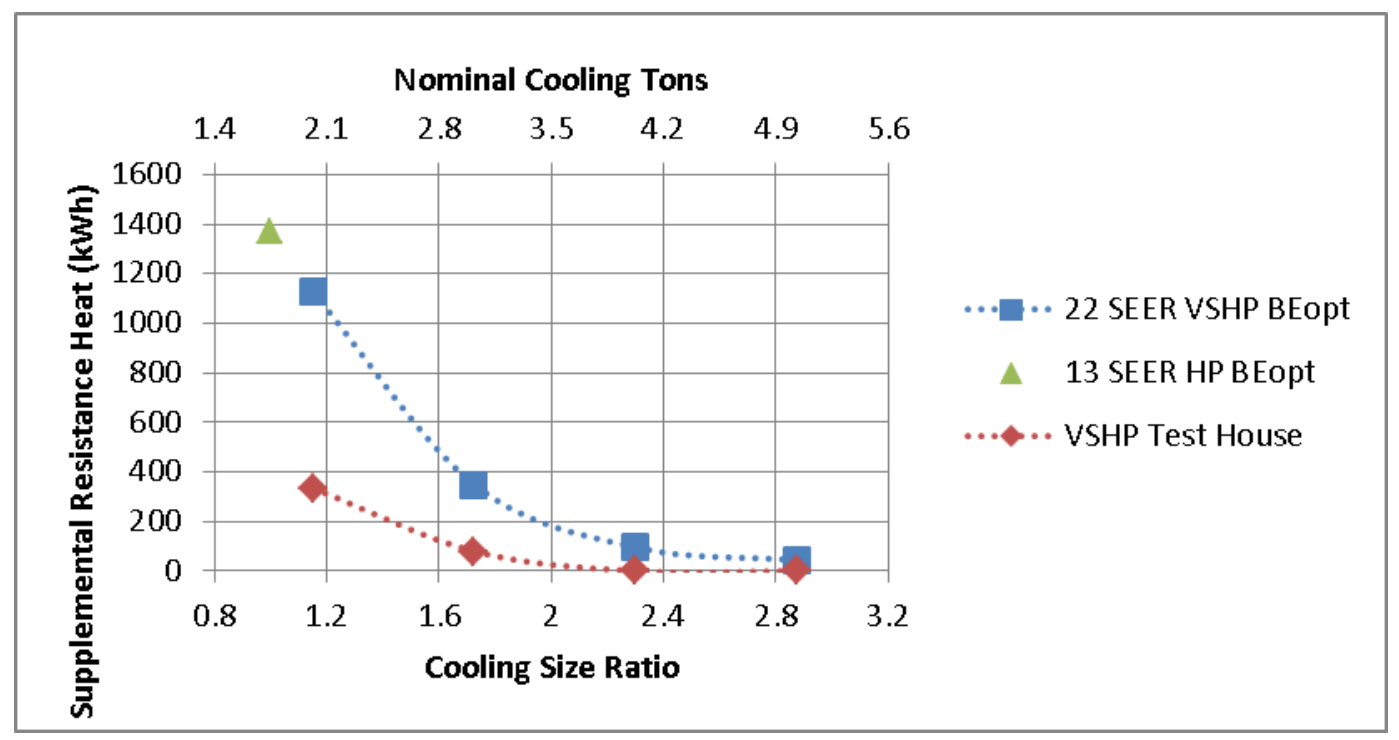

Figure 28: Supplemental resistance heat use for Pittsburgh, Pennsylvania, with ducts in the conditioned space (no duct losses) 


\section{CONCLUSIONS}

The field test VSHP model showed the ability to maintain comfort as good as or better than the baseline single speed HP at cooling size ratios up to 1.7 to 2.0 depending on the climate and duct losses. This unit was modeled in an operational mode that provides humidity control by reducing the indoor blower speed to increase the latent capacity of the unit. The VSHP in BEopt was not modeled in an equivalent operational mode, so it was unable to meet the same comfort levels. It is expected that this unit could provide similar comfort to the field test VSHP if it were operated in a mode that provides humidity control.

The simulations in locations at the southern edge of the mixed-humid climate did not show any annual energy savings by increasing the cooling size ratio. The simulations at the southern edge of the cold climate showed annual energy savings increase three to 10 percentage points by increasing the cooling size ratio from 1 to 1.6-2.0. These locations had peak cooling demand to peak heating demand ratios of $\sim 0.5$, while the homes in the mixedhumid climate had ratios of 0.76 to 0.94 . This ratio may be able to be used as a first pass indicator of whether increasing the capacity of a VSHP will provide energy savings in a specific home.

There are significant heating peak power reductions possible by increasing the capacity of a VSHP in order to meet as much of the heating load as possible with the use of resistance heat. The mixed-humid climate locations showed up to $35 \%$ reduction in peak heating power for increasing the cooling size ratio of the installed VSHP. This peak power reduction, however, also came with overall increased energy use in this climate. In the cold climate, the heating peak power reduction was often dictated by the lowest temperature that the heat pump was able to run. The baseline HP and VSHP in BEopt were limited to $0^{\circ} \mathrm{F}$, while the field test VSHP was limited to $-4^{\circ} \mathrm{F}$ by EnergyPlus (the manufacturer's data indicates a minimum operating temperature of $-15^{\circ} \mathrm{F}$ ). When the VSHP is at OATs at which it is capable of operating, increasing its size reduced the peak heating power demand by up to $26 \%$ over a VSHP sized for the cooling load.

The peak cooling power of the VSHPs differed significantly. The field test VSHP did not have the expected trend of increased efficiency at reduced capacity as expected. This could be in part due to the control running at lower airflows at low capacity in order to control the humidity. Additional investigation, likely in the form of laboratory tests would be required to definitively determine how the enhanced humidity control mode impacts efficiency compared to standard operation. The VSHP in BEopt did show peak cooling power reduction as unit capacity was increased. This is expected since the unit would be operating at a lower compressor speed and higher efficiency during the peak cooling demand. Up to a $17 \%$ reduction in peak cooling power was seen by increasing the cooling size ratio of the VSHP in BEopt from 1.0 to 1.7.

The duct losses did not have a major impact on the optimal cooling size ratio with respect to annual energy savings in any of the cases. However, it did make a significant impact on the energy savings when compared to the baseline single speed heat pump. The longer runtimes of the VSHPs increased the duct losses when compared to a single speed heat pump that 
cycles more often. This makes it important to ensure that ducts are evaluated and improved if needed in order to ensure maximum savings when upgrading to a VSHP.

The way in which a manufacturer achieves the different rated capacity in any model family also has an impact on what size unit is going to provide the highest energy savings. The field test VSHPs were rated at 2- and 3-tons of cooling. The actual outdoor units used the same model compressor though and had the same size coil. The additional capacity of the 3-ton unit is achieved by running the compressor at higher speeds. Both units also had the same minimum operating compressor speed, and therefore similar minimum capacities and performance at low loads. In a situation like this, it is likely always better from an operating efficiency perspective to choose the 3-ton unit even if your load only requires the 2-ton unit. This is illustrated in the energy savings plots in the mixed-humid climate. There is little need for the added capacity of the 3-ton unit in these homes, but the 3-ton unit provides the nearly identical levels of comfort and energy savings. The 3-ton unit will run at the same minimum speed, but will have additional capacity to cope with off-design conditions and thereby provide additional comfort in the cooling season or additional savings by avoiding resistance heat use in the winter. In addition, the unit will be able to use the extra capacity to respond to changes in the thermostat temperature set point more quickly.

Some VSHPs run at higher compressor speeds in the heating mode than the cooling mode, providing additional heating capacity at low temperatures and reducing the benefits of oversizing relative to the cooling load. The field test VSHPs have a rated low temperature $\left(17^{\circ} \mathrm{F}\right)$ heating capacity to rated cooling capacity ratio of 0.87 to 1.05 per the manufacturer's data compared to the VSHP in BEopt that has a ratio of 0.64 . This is a significant difference and will impact how much the cooling capacity must be oversized in order to meet the heating capacity.

The similarities and differences between different capacity units in a model family will vary depending on the manufacturer. These unit specific details are critical to choosing the VSHP capacity that will yield the highest energy savings without compromising comfort. In addition, the house construction, climate, and occupant behavior will influence the balance of the heating and cooling load on the house as well as the sensible and latent cooling demand. All of these factors need to be considered when trying to select the proper unit for the highest energy savings. Based on the simulations performed in this study, it is likely that VSHPs with an enhanced dehumidification mode can be sized up to two times the cooling load of the house without any reduction in comfort when compared to a single speed heat pump assuming a typical home and occupant behavior in the mixed-humid and cold climates. 


\section{REFERENCES}

ASHRAE, 2013a. ASHRAE Handbook - Fundamentals. Atlanta: American Society of Heating, Refrigeration, and Air-Conditioning Engineers.

ASHRAE, 2013b. Thermal Environmental Conditions for Human Occupancy. Atlanta: American Society of Heating, Refrigeration and Air-Conditioning Engineers.

Hendron, R., 2008. Building America Research Benchmark Definition, Golden, Colorado: National Renewable Energy Laboratory.

Hunt, W., Domitrovic, R. \& Amarnath, A., 2013. Cooling Efficiency Comparison between Residential Variable Capacity and Single Speed Heat Pump. ASHRAE Transactions, 119(2), p. 1.

Munk, J. D., Odukomaiya, A. O., Gehl, A. C. \& Jackson, R. K., 2014. Field Study of Performance, Comfort, and Sizing of Two Variable-Speed Heat Pumps Installed in a Single 2-Story Residence. Seattle, WA, ASHRAE.

NREL, 2012. BEoptE+ v1.3, Golden: National Renewable Energy Laboratory.

Office of Energy Efficiency and Renewable Energy, n.d. Building America Climate-Specific Guidance. [Online]

Available at: http://energy.gov/eere/buildings/building-america-climate-specificguidance [Accessed 13 March 2015].

U.S. EIA, 2009. 2009 Residential Energy Consumption Survey. [Online] Available at: http://www.eia.gov/consumption/residential/data/2009/

Winkler, J., 2015. Senior Engineer [Interview] (27 January 2015).

Woods, J., Winkler, J. \& Christensen, D., 2013. Evaluation of Effective Moisture Penetration Depth Model for Estimating Moisture Buffering in Buildings, Golden: National Renewable Energy Laboratory. 


\section{APPENDIX A}

Table 2: BEopt inputs for each city's baseline case

\begin{tabular}{|c|c|c|c|c|c|}
\hline & & $\begin{array}{l}\text { Little Rock } \\
\text { Baseline }\end{array}$ & $\begin{array}{l}\text { Charlotte } \\
\text { Baseline }\end{array}$ & $\begin{array}{l}\text { Des Moines } \\
\text { Baseline }\end{array}$ & $\begin{array}{l}\text { Pittsburgh } \\
\text { Baseline }\end{array}$ \\
\hline \multicolumn{6}{|c|}{ GEOMETRY SCREEN } \\
\hline \multicolumn{2}{|c|}{ Total Finished Floor Area } & 1080 & 1248 & 1248 & 1904 \\
\hline Beds & & 3 & 3 & 3 & 3 \\
\hline Baths & & 2 & 2 & 2 & 2 \\
\hline $\begin{array}{l}\text { Left Walls } \\
\text { Attached }\end{array}$ & & FALSE & FALSE & FALSE & FALSE \\
\hline $\begin{array}{l}\text { Right Walls } \\
\text { Attached }\end{array}$ & & FALSE & FALSE & FALSE & FALSE \\
\hline $\begin{array}{l}\text { Back Walls } \\
\text { Attached }\end{array}$ & & FALSE & FALSE & FALSE & FALSE \\
\hline \multicolumn{6}{|c|}{ OPTIONS SCREEN } \\
\hline \multirow[t]{2}{*}{ Building } & Orientation & North & North & North & North \\
\hline & Neighbors & None & None & None & None \\
\hline \multirow[t]{10}{*}{ Operation } & Heating Set Point & $71^{\circ} \mathrm{F}$ & $71^{\circ} \mathrm{F}$ & $71^{\circ} \mathrm{F}$ & $71^{\circ} \mathrm{F}$ \\
\hline & Cooling Set Point & $76^{\circ} \mathrm{F}$ & $76^{\circ} \mathrm{F}$ & $76^{\circ} \mathrm{F}$ & $76^{\circ} \mathrm{F}$ \\
\hline & $\begin{array}{l}\text { Humidity } \\
\text { Buffering }\end{array}$ & EMPD, Medium & EMPD, Medium & EMPD, Medium & EMPD, Medium \\
\hline & $\begin{array}{l}\text { Misc Electric } \\
\text { Loads }\end{array}$ & Benchmark & Benchmark & Benchmark & Benchmark \\
\hline & Misc Gas Loads & None & None & None & None \\
\hline & $\begin{array}{l}\text { Misc Hot Water } \\
\text { Loads }\end{array}$ & Benchmark & Benchmark & Benchmark & Benchmark \\
\hline & $\begin{array}{l}\text { Natural } \\
\text { Ventilation }\end{array}$ & None & None & None & None \\
\hline & Walls & $\begin{array}{l}\text { Wood Stud, R13 } \\
\text { Batt-Gr 1, 2x4, } \\
\text { 16"o.c. }\end{array}$ & $\begin{array}{l}\text { Wood Stud, R13 } \\
\text { Batt-Gr 1, 2x4, } \\
\text { 16"o.c. }\end{array}$ & $\begin{array}{l}\text { Wood Stud, R13 } \\
\text { Batt-Gr 1, 2x4, } \\
16 \text { "o.c. + 1" } \\
\text { Foam }\end{array}$ & $\begin{array}{l}\text { Wood Stud, R13 } \\
\text { Batt-Gr } 1,2 \times 4, \\
16 \text { "o.c. + 1" } \\
\text { Foam }\end{array}$ \\
\hline & Exterior Finish & $\begin{array}{l}\text { Benchmark, } 0.6 \\
\text { absorptivity, } 0.9 \\
\text { emmissivity }\end{array}$ & $\begin{array}{l}\text { Benchmark, } 0.6 \\
\text { absorptivity, } 0.9 \\
\text { emmissivity }\end{array}$ & $\begin{array}{l}\text { Benchmark, } 0.6 \\
\text { absorptivity, } 0.9 \\
\text { emmissivity }\end{array}$ & $\begin{array}{l}\text { Benchmark, } 0.6 \\
\text { absorptivity, } 0.9 \\
\text { emmissivity }\end{array}$ \\
\hline & Interzonal Walls & $\begin{array}{l}\text { Wood Stud, R13 } \\
\text { Batt-Gr 1, 2x4, } \\
16 \text { "o.c. }\end{array}$ & $\begin{array}{l}\text { Wood Stud, R13 } \\
\text { Batt-Gr 1, 2x4, } \\
16 \text { "o.c. }\end{array}$ & $\begin{array}{l}\text { Wood Stud, R19 } \\
\text { Batt-Gr 1, 2x4, } \\
\text { 24"o.c. }\end{array}$ & $\begin{array}{l}\text { Wood Stud, R19 } \\
\text { Batt-Gr 1, 2x4, } \\
\text { 24"o.c. }\end{array}$ \\
\hline \multirow[t]{3}{*}{ Ceilings/Roofs } & Unfinished Attic & $\begin{array}{l}\text { Ceiling R30 } \\
\text { Fiberglass } \\
\text { Blown-In, } \\
\text { Vented }\end{array}$ & $\begin{array}{l}\text { Ceiling R30 } \\
\text { Fiberglass } \\
\text { Blown-In, } \\
\text { Vented } \\
\end{array}$ & $\begin{array}{l}\text { Ceiling R38 } \\
\text { Fiberglass } \\
\text { Blown-In, } \\
\text { Vented } \\
\end{array}$ & $\begin{array}{l}\text { Ceiling R38 } \\
\text { Fiberglass } \\
\text { Blown-In, } \\
\text { Vented } \\
\end{array}$ \\
\hline & Roofing Material & $\begin{array}{l}\text { Asphalt } \\
\text { Shingles, White } \\
\text { or cool colors }\end{array}$ & $\begin{array}{l}\text { Asphalt } \\
\text { Shingles, White } \\
\text { or cool colors }\end{array}$ & $\begin{array}{l}\text { Asphalt } \\
\text { Shingles, White } \\
\text { or cool colors }\end{array}$ & $\begin{array}{l}\text { Asphalt } \\
\text { Shingles, White } \\
\text { or cool colors }\end{array}$ \\
\hline & Radiant Barrier & None & None & None & None \\
\hline \multirow[t]{2}{*}{ Foundation } & Slab & Uninsulated & Uninsulated & 2ft R10 Exterior & 2ft R10 Exterior \\
\hline & Exposed Floor & $20 \%$ & $20 \%$ & $20 \%$ & $20 \%$ \\
\hline Thermal Mass & Floor Mass & Wood Surface & Wood Surface & Wood Surface & Wood Surface \\
\hline
\end{tabular}




\begin{tabular}{|c|c|c|c|c|c|}
\hline & Ext Wall Mass & 1/2" Drywall & 1/2" Drywall & 1/2" Drywall & 1/2" Drywall \\
\hline & $\begin{array}{l}\text { Partition Wall } \\
\text { Mass }\end{array}$ & 1/2" Drywall & 1/2" Drywall & 1/2" Drywall & 1/2" Drywall \\
\hline & Ceiling Mass & $\begin{array}{l}\text { 1/2" Ceiling } \\
\text { Drywall }\end{array}$ & $\begin{array}{l}\text { 1/2" Ceiling } \\
\text { Drywall }\end{array}$ & $\begin{array}{l}\text { 1/2" Ceiling } \\
\text { Drywall }\end{array}$ & $\begin{array}{l}\text { 1/2" Ceiling } \\
\text { Drywall }\end{array}$ \\
\hline \multirow[t]{5}{*}{$\begin{array}{l}\text { Windows } \\
\text { \&Shading }\end{array}$} & Window Areas & $\begin{array}{l}15.0 \% \text { F } 25 \text { B25 } \\
\text { L25 R25 }\end{array}$ & $\begin{array}{l}15.0 \% \text { F25 B25 } \\
\text { L25 R25 }\end{array}$ & $\begin{array}{l}15.0 \% \text { F } 25 \text { B25 } \\
\text { L25 R25 }\end{array}$ & $\begin{array}{l}15.0 \% \text { F25 B25 } \\
\text { L25 R25 }\end{array}$ \\
\hline & Window Type & $\begin{array}{l}\text { SHGC } 0.3, \text { U- } \\
\text { Value } 0.4\end{array}$ & $\begin{array}{l}\text { SHGC } 0.3, \mathrm{U}- \\
\text { Value } 0.4\end{array}$ & $\begin{array}{l}\text { SHGC } 0.34, \mathrm{U}- \\
\text { Value } 0.34\end{array}$ & $\begin{array}{l}\text { SHGC } 0.34, \text { U- } \\
\text { Value } 0.34\end{array}$ \\
\hline & Interior Shading & $\begin{array}{l}\text { Benchmark } 0.7 \\
\text { year round }\end{array}$ & $\begin{array}{l}\text { Benchmark } 0.7 \\
\text { year round }\end{array}$ & $\begin{array}{l}\text { Benchmark } 0.7 \\
\text { year round }\end{array}$ & $\begin{array}{l}\text { Benchmark } 0.7 \\
\text { year round }\end{array}$ \\
\hline & Eaves & $2 \mathrm{ft}$ & $2 \mathrm{ft}$ & $2 \mathrm{ft}$ & $2 \mathrm{ft}$ \\
\hline & Overhangs & None & None & None & None \\
\hline \multirow[t]{2}{*}{ Airflow } & Infiltration & $\begin{array}{l}\text { Tight, SLA } \\
0.00036,7.4 \\
\text { ACH 50Pa } \\
\end{array}$ & $\begin{array}{l}\text { Tight, SLA } \\
0.00036,7.4 \\
\text { ACH 50Pa } \\
\end{array}$ & $\begin{array}{l}\text { Tight, SLA } \\
0.00036,7.4 \\
\text { ACH } 50 \mathrm{~Pa} \\
\end{array}$ & $\begin{array}{l}\text { Tight, SLA } \\
0.00036,7.4 \\
\text { ACH 50Pa } \\
\end{array}$ \\
\hline & $\begin{array}{l}\text { Mechanical } \\
\text { Ventilation }\end{array}$ & $\begin{array}{l}\text { Exhaust, } 100 \% \\
\text { of A- } 62.2\end{array}$ & $\begin{array}{l}\text { Exhaust, } 100 \% \\
\text { of A- } 62.2\end{array}$ & $\begin{array}{l}\text { Exhaust, } 100 \% \\
\text { of A- } 62.2\end{array}$ & $\begin{array}{l}\text { Exhaust, } 100 \% \\
\text { of A- } 62.2\end{array}$ \\
\hline \multirow[t]{5}{*}{ Major Appliances } & Refrigerator & $\begin{array}{l}\text { Benchmark, } 434 \\
\mathrm{kWh} / \mathrm{yr}\end{array}$ & $\begin{array}{l}\text { Benchmark, } 434 \\
\mathrm{kWh} / \mathrm{yr}\end{array}$ & $\begin{array}{l}\text { Benchmark, } 434 \\
\mathrm{kWh} / \mathrm{yr}\end{array}$ & $\begin{array}{l}\text { Benchmark, } 434 \\
\mathrm{kWh} / \mathrm{yr}\end{array}$ \\
\hline & Cooking Range & $\begin{array}{l}\text { Electric } \\
\text { Conventional, } \\
500 \mathrm{kWh} / \mathrm{yr} \\
\end{array}$ & $\begin{array}{l}\text { Electric } \\
\text { Conventional, } \\
500 \mathrm{kWh} / \mathrm{yr} \\
\end{array}$ & $\begin{array}{l}\text { Electric } \\
\text { Conventional, } \\
500 \mathrm{kWh} / \mathrm{yr} \\
\end{array}$ & $\begin{array}{l}\text { Electric } \\
\text { Conventional, } \\
500 \mathrm{kWh} / \mathrm{yr} \\
\end{array}$ \\
\hline & Dishwasher & $\begin{array}{l}\text { Standard, } 318 \\
\mathrm{kWh} / \mathrm{yr}\end{array}$ & $\begin{array}{l}\text { Standard, } 318 \\
\mathrm{kWh} / \mathrm{yr}\end{array}$ & $\begin{array}{l}\text { Standard, } 318 \\
\mathrm{kWh} / \mathrm{yr}\end{array}$ & $\begin{array}{l}\text { Standard, } 318 \\
\mathrm{kWh} / \mathrm{yr}\end{array}$ \\
\hline & Clothes Washer & $\begin{array}{l}\text { Standard, } 1.41 \\
\text { Modified EF }\end{array}$ & $\begin{array}{l}\text { Standard, } 1.41 \\
\text { Modified EF }\end{array}$ & $\begin{array}{l}\text { Standard, } 1.41 \\
\text { Modified EF }\end{array}$ & $\begin{array}{l}\text { Standard, } 1.41 \\
\text { Modified EF }\end{array}$ \\
\hline & Clothes Dryer & Electric, 3.1 EF & Electric, $3.1 \mathrm{EF}$ & Electric, $3.1 \mathrm{EF}$ & Electric, 3.1 EF \\
\hline \multirow[t]{4}{*}{$\begin{array}{l}\text { Space } \\
\text { Conditioning }\end{array}$} & Heat Pump & $\begin{array}{l}\text { SEER 13, HSPF } \\
7.7\end{array}$ & $\begin{array}{l}\text { SEER 13, HSPF } \\
7.7\end{array}$ & $\begin{array}{l}\text { SEER 13, HSPF } \\
7.7\end{array}$ & $\begin{array}{l}\text { SEER 13, HSPF } \\
7.7\end{array}$ \\
\hline & Ducts & $\begin{array}{l}\text { Typical, R4 } \\
\text { Insulation, } 0.15 \\
\text { leakage fraction }\end{array}$ & $\begin{array}{l}\text { Typical, R4 } \\
\text { Insulation, } 0.15 \\
\text { leakage fraction }\end{array}$ & $\begin{array}{l}\text { Typical, R4 } \\
\text { Insulation, } 0.15 \\
\text { leakage fraction }\end{array}$ & $\begin{array}{l}\text { Typical, R4 } \\
\text { Insulation, } 0.15 \\
\text { leakage fraction }\end{array}$ \\
\hline & Ceiling Fans & Benchmark & Benchmark & Benchmark & Benchmark \\
\hline & Dehumidifier & None & None & None & None \\
\hline \multirow[t]{3}{*}{ Water Heating } & Water Heater & $\begin{array}{l}\text { Electric } \\
\text { Standard, } 0.92 \\
\text { EF }\end{array}$ & $\begin{array}{l}\text { Electric } \\
\text { Standard, } 0.92 \\
\text { EF }\end{array}$ & $\begin{array}{l}\text { Electric } \\
\text { Standard, } 0.92 \\
\text { EF }\end{array}$ & $\begin{array}{l}\text { Electric } \\
\text { Standard, } 0.92 \\
\text { EF }\end{array}$ \\
\hline & Distribution & $\begin{array}{l}\text { Uninsulated, } \\
\text { TrunkBranch, } \\
\text { Copper }\end{array}$ & $\begin{array}{l}\text { Uninsulated, } \\
\text { TrunkBranch, } \\
\text { Copper }\end{array}$ & $\begin{array}{l}\text { Uninsulated, } \\
\text { TrunkBranch, } \\
\text { Copper }\end{array}$ & $\begin{array}{l}\text { Uninsulated, } \\
\text { TrunkBranch, } \\
\text { Copper }\end{array}$ \\
\hline & Solar DHW & None & None & None & None \\
\hline
\end{tabular}




\section{APPENDIX B}

Table 3: EnergyPlus cooling and heating rated values for the field test VSHP for the model matching the measured data from the test house and the corrected models used for simulations

\begin{tabular}{|c|c|c|c|c|c|c|c|}
\hline & & $\begin{array}{l}\text { 2-ton } \\
\text { House } \\
\text { Match }\end{array}$ & $\begin{array}{l}\text { 3-ton } \\
\text { House } \\
\text { Match }\end{array}$ & $\begin{array}{l}\text { 2-ton } \\
\text { Model }\end{array}$ & $\begin{array}{l}\text { 3-ton } \\
\text { Model }\end{array}$ & $\begin{array}{l}\text { 4-ton } \\
\text { Model }\end{array}$ & $\begin{array}{l}\text { 5-ton } \\
\text { Model }\end{array}$ \\
\hline \multirow{4}{*}{$\begin{array}{l}\text { Cooling } \\
\text { Speed } 1\end{array}$} & Capacity (W) & 533 & 536 & 548 & 548 & 1076 & 1076 \\
\hline & SHR & 0.85 & 0.85 & 0.85 & 0.85 & 0.85 & 0.85 \\
\hline & COP & 2.700 & 2.550 & 2.749 & 2.749 & 2.559 & 2.559 \\
\hline & Airflow $\left(\mathrm{m}^{3} / \mathrm{s}\right)$ & 0.0325 & 0.0325 & 0.0325 & 0.0325 & 0.0638 & 0.0638 \\
\hline \multirow{4}{*}{$\begin{array}{l}\text { Cooling } \\
\text { Speed } 2\end{array}$} & Capacity (W) & 3366 & 3388 & 3463 & 3463 & 6796 & 6796 \\
\hline & SHR & 0.74 & 0.74 & 0.74 & 0.74 & 0.74 & 0.74 \\
\hline & $\mathrm{COP}$ & 3.600 & 3.400 & 3.665 & 3.665 & 3.580 & 3.580 \\
\hline & Airflow $\left(\mathrm{m}^{3} / \mathrm{s}\right)$ & 0.1578 & 0.1587 & 0.1623 & 0.1623 & 0.3185 & 0.3185 \\
\hline \multirow{4}{*}{$\begin{array}{l}\text { Cooling } \\
\text { Speed } 3\end{array}$} & Capacity (W) & 4854 & 6388 & 5097 & 6377 & 10004 & 11117 \\
\hline & SHR & 0.74 & 0.74 & 0.74 & 0.74 & 0.74 & 0.74 \\
\hline & $\mathrm{COP}$ & 3.738 & 3.452 & 3.805 & 3.721 & 3.717 & 3.635 \\
\hline & Airflow $\left(\mathrm{m}^{3} / \mathrm{s}\right)$ & 0.232 & 0.294 & 0.243 & 0.293 & 0.478 & 0.511 \\
\hline \multirow{4}{*}{$\begin{array}{l}\text { Cooling } \\
\text { Speed } 4\end{array}$} & Capacity (W) & 6342 & 9389 & 6731 & 9290 & 13212 & 15438 \\
\hline & SHR & 0.75 & 0.812 & 0.75 & 0.75 & 0.75 & 0.75 \\
\hline & $\mathrm{COP}$ & 3.679 & 3.366 & 3.890 & 3.488 & 3.622 & 3.407 \\
\hline & Airflow $\left(\mathrm{m}^{3} / \mathrm{s}\right)$ & 0.303 & 0.552 & 0.359 & 0.496 & 0.705 & 0.823 \\
\hline \multirow{3}{*}{$\begin{array}{l}\text { Heating } \\
\text { Speed } 1\end{array}$} & Capacity (W) & 378 & 554 & 466 & 466 & 985 & 985 \\
\hline & COP & 4.274 & 3.710 & 4.197 & 4.197 & 4.114 & 4.114 \\
\hline & Airflow $\left(\mathrm{m}^{3} / \mathrm{s}\right)$ & 0.037 & 0.074 & 0.045 & 0.045 & 0.048 & 0.048 \\
\hline \multirow{3}{*}{$\begin{array}{l}\text { Heating } \\
\text { Speed } 2\end{array}$} & Capacity (W) & 4182 & 4154 & 4168 & 4168 & 8811 & 8811 \\
\hline & $\mathrm{COP}$ & 4.959 & 4.198 & 4.808 & 4.808 & 4.712 & 4.712 \\
\hline & Airflow $\left(\mathrm{m}^{3} / \mathrm{s}\right)$ & 0.405 & 0.405 & 0.405 & 0.405 & 0.425 & 0.425 \\
\hline \multirow{3}{*}{$\begin{array}{l}\text { Heating } \\
\text { Speed } 3\end{array}$} & Capacity (W) & 4920 & 6086 & 4913 & 6093 & 10385 & 11330 \\
\hline & $\mathrm{COP}$ & 4.614 & 3.714 & 4.474 & 4.255 & 4.385 & 4.170 \\
\hline & Airflow $\left(\mathrm{m}^{3} / \mathrm{s}\right)$ & 0.410 & 0.432 & 0.415 & 0.521 & 0.590 & 0.625 \\
\hline \multirow{3}{*}{$\begin{array}{l}\text { Heating } \\
\text { Speed } 4\end{array}$} & Capacity (W) & 5657 & 8017 & 5657 & 8017 & 11958 & 13849 \\
\hline & $\mathrm{COP}$ & 4.246 & 3.429 & 4.020 & 3.780 & 3.940 & 3.860 \\
\hline & Airflow $\left(\mathrm{m}^{3} / \mathrm{s}\right)$ & 0.469 & 0.627 & 0.425 & 0.637 & 0.755 & 0.826 \\
\hline
\end{tabular}


Table 4: EnergyPlus biquadratic constants for cooling capacity and cooling energy input ratio

\begin{tabular}{|c|c|c|c|c|c|}
\hline & & 2-ton & 3-ton & 4-ton & 5-ton \\
\hline \multirow{6}{*}{$\begin{array}{c}\text { Cooling Speed } 1 \\
\text { Capacity }\end{array}$} & $\mathrm{C} 1$ & $1.7358 \mathrm{E}+00$ & $1.8233 \mathrm{E}+00$ & $1.7358 \mathrm{E}+00$ & $1.8233 \mathrm{E}+00$ \\
\hline & $\mathrm{C} 2$ & $-4.2615 \mathrm{E}-02$ & $-4.2615 \mathrm{E}-02$ & $-4.2615 \mathrm{E}-02$ & $-4.2615 \mathrm{E}-02$ \\
\hline & $\mathrm{C} 3$ & $2.0600 \mathrm{E}-03$ & $2.0600 \mathrm{E}-03$ & $2.0600 \mathrm{E}-03$ & $2.0600 \mathrm{E}-03$ \\
\hline & $\mathrm{C} 4$ & $-1.9600 \mathrm{E}-02$ & $-2.2100 \mathrm{E}-02$ & $-1.9600 \mathrm{E}-02$ & $-2.2100 \mathrm{E}-02$ \\
\hline & $\mathrm{C} 5$ & $0.0000 \mathrm{E}+00$ & $0.0000 \mathrm{E}+00$ & $0.0000 \mathrm{E}+00$ & $0.0000 \mathrm{E}+00$ \\
\hline & C6 & $0.0000 E+00$ & $0.0000 \mathrm{E}+00$ & $0.0000 E+00$ & $0.0000 \mathrm{E}+00$ \\
\hline \multirow{6}{*}{$\begin{array}{c}\text { Cooling Speed } 2 \\
\text { Capacity }\end{array}$} & $\mathrm{C} 1$ & $1.7358 \mathrm{E}+00$ & $1.8233 \mathrm{E}+00$ & $1.7358 \mathrm{E}+00$ & $1.8233 \mathrm{E}+00$ \\
\hline & $\mathrm{C} 2$ & $-4.2615 \mathrm{E}-02$ & $-4.2615 \mathrm{E}-02$ & $-4.2615 \mathrm{E}-02$ & $-4.2615 \mathrm{E}-02$ \\
\hline & $\mathrm{C} 3$ & $2.0600 \mathrm{E}-03$ & $2.0600 \mathrm{E}-03$ & $2.0600 \mathrm{E}-03$ & $2.0600 \mathrm{E}-03$ \\
\hline & $\mathrm{C} 4$ & $-1.9600 \mathrm{E}-02$ & $-2.2100 \mathrm{E}-02$ & $-1.9600 \mathrm{E}-02$ & $-2.2100 \mathrm{E}-02$ \\
\hline & $\mathrm{C} 5$ & $0.0000 E+00$ & $0.0000 E+00$ & $0.0000 \mathrm{E}+00$ & $0.0000 \mathrm{E}+00$ \\
\hline & C6 & $0.0000 E+00$ & $0.0000 E+00$ & $0.0000 \mathrm{E}+00$ & $0.0000 \mathrm{E}+00$ \\
\hline \multirow{6}{*}{$\begin{array}{c}\text { Cooling Speed } 3 \\
\text { Capacity }\end{array}$} & $\mathrm{C} 1$ & $1.7708 \mathrm{E}+00$ & $1.7982 \mathrm{E}+00$ & $1.7708 \mathrm{E}+00$ & $1.7982 \mathrm{E}+00$ \\
\hline & $\mathrm{C} 2$ & $-4.2615 \mathrm{E}-02$ & $-4.2615 \mathrm{E}-02$ & $-4.2615 \mathrm{E}-02$ & $-4.2615 \mathrm{E}-02$ \\
\hline & $\mathrm{C} 3$ & $2.0600 \mathrm{E}-03$ & $2.0600 \mathrm{E}-03$ & $2.0600 \mathrm{E}-03$ & $2.0600 \mathrm{E}-03$ \\
\hline & $\mathrm{C} 4$ & $-2.0600 \mathrm{E}-02$ & $-2.1384 \mathrm{E}-02$ & $-2.0600 \mathrm{E}-02$ & $-2.1384 \mathrm{E}-02$ \\
\hline & $\mathrm{C} 5$ & $0.0000 E+00$ & $0.0000 E+00$ & $0.0000 E+00$ & $0.0000 \mathrm{E}+00$ \\
\hline & C6 & $0.0000 E+00$ & $0.0000 \mathrm{E}+00$ & $0.0000 \mathrm{E}+00$ & $0.0000 \mathrm{E}+00$ \\
\hline \multirow{6}{*}{$\begin{array}{c}\text { Cooling Speed } 4 \\
\text { Capacity }\end{array}$} & $\mathrm{C} 1$ & $1.7887 \mathrm{E}+00$ & $1.7887 \mathrm{E}+00$ & $1.7887 \mathrm{E}+00$ & $1.7887 \mathrm{E}+00$ \\
\hline & $\mathrm{C} 2$ & $-4.2615 E-02$ & $-4.2615 \mathrm{E}-02$ & $-4.2615 \mathrm{E}-02$ & $-4.2615 \mathrm{E}-02$ \\
\hline & $\mathrm{C} 3$ & $2.0600 \mathrm{E}-03$ & $2.0600 \mathrm{E}-03$ & $2.0600 \mathrm{E}-03$ & $2.0600 \mathrm{E}-03$ \\
\hline & $\mathrm{C} 4$ & $-2.1112 \mathrm{E}-02$ & $-2.1112 \mathrm{E}-02$ & $-2.1112 \mathrm{E}-02$ & $-2.1112 \mathrm{E}-02$ \\
\hline & $\mathrm{C} 5$ & $0.0000 \mathrm{E}+00$ & $0.0000 \mathrm{E}+00$ & $0.0000 E+00$ & $0.0000 \mathrm{E}+00$ \\
\hline & C6 & $0.0000 E+00$ & $0.0000 E+00$ & $0.0000 \mathrm{E}+00$ & $0.0000 \mathrm{E}+00$ \\
\hline \multirow{6}{*}{$\begin{array}{c}\text { Cooling Speed } 1 \\
\text { EIR }\end{array}$} & $\mathrm{C} 1$ & $-1.3086 \mathrm{E}-01$ & $-6.3266 \mathrm{E}-02$ & $-1.3086 \mathrm{E}-01$ & $-6.3266 \mathrm{E}-02$ \\
\hline & $\mathrm{C} 2$ & $3.7426 \mathrm{E}-02$ & $3.7426 \mathrm{E}-02$ & $3.7426 \mathrm{E}-02$ & $3.7426 \mathrm{E}-02$ \\
\hline & $\mathrm{C} 3$ & $-5.9074 \mathrm{E}-04$ & $-5.9074 \mathrm{E}-04$ & $-5.9074 \mathrm{E}-04$ & $-5.9074 \mathrm{E}-04$ \\
\hline & $\mathrm{C} 4$ & $-5.5652 E-03$ & $-1.2023 \mathrm{E}-02$ & $-5.5652 E-03$ & $-1.2023 \mathrm{E}-02$ \\
\hline & $\mathrm{C} 5$ & $6.7042 \mathrm{E}-04$ & 7.9975E-04 & $6.7042 \mathrm{E}-04$ & $7.9975 \mathrm{E}-04$ \\
\hline & C6 & $0.0000 \mathrm{E}+00$ & $0.0000 \mathrm{E}+00$ & $0.0000 \mathrm{E}+00$ & $0.0000 \mathrm{E}+00$ \\
\hline \multirow{6}{*}{$\begin{array}{c}\text { Cooling Speed } 2 \\
\text { EIR }\end{array}$} & $\mathrm{C} 1$ & $-9.5812 \mathrm{E}-02$ & $-1.2289 \mathrm{E}-01$ & $-9.5812 \mathrm{E}-02$ & $-1.2289 E-01$ \\
\hline & $\mathrm{C} 2$ & $3.7426 \mathrm{E}-02$ & $3.7426 \mathrm{E}-02$ & $3.7426 \mathrm{E}-02$ & $3.7426 \mathrm{E}-02$ \\
\hline & $\mathrm{C} 3$ & $-5.9074 \mathrm{E}-04$ & $-5.9074 \mathrm{E}-04$ & $-5.9074 \mathrm{E}-04$ & $-5.9074 \mathrm{E}-04$ \\
\hline & $\mathrm{C} 4$ & $-1.1455 \mathrm{E}-02$ & $-8.9691 \mathrm{E}-03$ & $-1.1455 \mathrm{E}-02$ & $-8.9691 \mathrm{E}-03$ \\
\hline & $\mathrm{C} 5$ & $8.1009 E-04$ & 7.6117E-04 & 8.1009E-04 & 7.6117E-04 \\
\hline & C6 & $0.0000 \mathrm{E}+00$ & $0.0000 \mathrm{E}+00$ & $0.0000 \mathrm{E}+00$ & $0.0000 \mathrm{E}+00$ \\
\hline \multirow{6}{*}{$\begin{array}{c}\text { Cooling Speed } 3 \\
\text { EIR }\end{array}$} & $\mathrm{C} 1$ & $1.4170 \mathrm{E}-01$ & $5.6425 \mathrm{E}-02$ & $1.4170 \mathrm{E}-01$ & $5.6425 \mathrm{E}-02$ \\
\hline & $\mathrm{C} 2$ & $3.7426 \mathrm{E}-02$ & $3.7426 \mathrm{E}-02$ & $3.7426 \mathrm{E}-02$ & $3.7426 \mathrm{E}-02$ \\
\hline & C3 & $-5.9074 \mathrm{E}-04$ & $-5.9074 \mathrm{E}-04$ & $-5.9074 \mathrm{E}-04$ & $-5.9074 \mathrm{E}-04$ \\
\hline & $\mathrm{C} 4$ & $-2.8885 \mathrm{E}-02$ & $-2.4443 \mathrm{E}-02$ & $-2.8885 E-02$ & $-2.4443 \mathrm{E}-02$ \\
\hline & $\mathrm{C} 5$ & 1.1142E-03 & 1.0569E-03 & 1.1142E-03 & 1.0569E-03 \\
\hline & C6 & $0.0000 E+00$ & $0.0000 E+00$ & $0.0000 E+00$ & $0.0000 \mathrm{E}+00$ \\
\hline \multirow{6}{*}{$\begin{array}{c}\text { Cooling Speed } 4 \\
\text { EIR }\end{array}$} & $\mathrm{C} 1$ & $2.8635 \mathrm{E}-02$ & $8.3056 \mathrm{E}-02$ & $2.8635 \mathrm{E}-02$ & $8.3056 \mathrm{E}-02$ \\
\hline & $\mathrm{C} 2$ & $3.7426 \mathrm{E}-02$ & $3.7426 \mathrm{E}-02$ & $3.7426 \mathrm{E}-02$ & $3.7426 \mathrm{E}-02$ \\
\hline & $\mathrm{C} 3$ & $-5.9074 \mathrm{E}-04$ & $-5.9074 \mathrm{E}-04$ & $-5.9074 \mathrm{E}-04$ & $-5.9074 \mathrm{E}-04$ \\
\hline & $\mathrm{C} 4$ & $-2.3208 \mathrm{E}-02$ & $-2.4208 \mathrm{E}-02$ & $-2.3208 \mathrm{E}-02$ & $-2.4208 \mathrm{E}-02$ \\
\hline & $\mathrm{C} 5$ & 1.0443E-03 & $1.0288 \mathrm{E}-03$ & $1.0443 \mathrm{E}-03$ & $1.0288 \mathrm{E}-03$ \\
\hline & C6 & $0.0000 E+00$ & $0.0000 E+00$ & $0.0000 E+00$ & $0.0000 \mathrm{E}+00$ \\
\hline
\end{tabular}


Table 5: EnergyPlus biquadratic constants for heating capacity and heating energy input ratio

\begin{tabular}{|c|c|c|c|c|c|}
\hline & & 2-ton & 3-ton & 4-ton & 5-ton \\
\hline \multirow{6}{*}{$\begin{array}{c}\text { Heating Speed } 1 \\
\text { Capacity }\end{array}$} & $\mathrm{C} 1$ & $1.1581 \mathrm{E}+00$ & $1.0581 \mathrm{E}+00$ & $1.1581 \mathrm{E}+00$ & $1.0581 \mathrm{E}+00$ \\
\hline & $\mathrm{C} 2$ & $-5.1183 \mathrm{E}-03$ & $-5.1183 E-03$ & $-5.1183 \mathrm{E}-03$ & $-5.1183 \mathrm{E}-03$ \\
\hline & $\mathrm{C} 3$ & $0.0000 \mathrm{E}+00$ & $0.0000 \mathrm{E}+00$ & $0.0000 \mathrm{E}+00$ & $0.0000 \mathrm{E}+00$ \\
\hline & $\mathrm{C} 4$ & $6.3000 \mathrm{E}-03$ & $6.0000 \mathrm{E}-03$ & $6.3000 \mathrm{E}-03$ & $6.0000 \mathrm{E}-03$ \\
\hline & $\mathrm{C} 5$ & $-7.6813 \mathrm{E}-20$ & $1.5363 \mathrm{E}-19$ & $-7.6813 \mathrm{E}-20$ & $1.5363 \mathrm{E}-19$ \\
\hline & C6 & $0.0000 E+00$ & $0.0000 E+00$ & $0.0000 E+00$ & $0.0000 E+00$ \\
\hline \multirow{6}{*}{$\begin{array}{c}\text { Heating Speed } 2 \\
\text { Capacity }\end{array}$} & $\mathrm{C} 1$ & $1.0281 \mathrm{E}+00$ & 1.028053 & $1.0281 \mathrm{E}+00$ & 1.028053 \\
\hline & $\mathrm{C} 2$ & $-5.1183 \mathrm{E}-03$ & $-5.1183 E-03$ & $-5.1183 \mathrm{E}-03$ & $-5.1183 \mathrm{E}-03$ \\
\hline & C3 & $0.0000 \mathrm{E}+00$ & $0.0000 E+00$ & $0.0000 \mathrm{E}+00$ & $0.0000 \mathrm{E}+00$ \\
\hline & $\mathrm{C} 4$ & $6.3000 \mathrm{E}-03$ & $6.3000 \mathrm{E}-03$ & $6.3000 \mathrm{E}-03$ & $6.3000 \mathrm{E}-03$ \\
\hline & $\mathrm{C} 5$ & $2.6885 \mathrm{E}-19$ & $-1.1522 \mathrm{E}-19$ & $2.6885 \mathrm{E}-19$ & $-1.1522 \mathrm{E}-19$ \\
\hline & C6 & $0.0000 \mathrm{E}+00$ & $0.0000 E+00$ & $0.0000 \mathrm{E}+00$ & $0.0000 \mathrm{E}+00$ \\
\hline \multirow{6}{*}{$\begin{array}{c}\text { Heating Speed } 3 \\
\text { Capacity }\end{array}$} & $\mathrm{C} 1$ & $1.0266 \mathrm{E}+00$ & $1.0133 \mathrm{E}+00$ & $1.0266 \mathrm{E}+00$ & $1.0133 \mathrm{E}+00$ \\
\hline & $\mathrm{C} 2$ & $-5.1183 \mathrm{E}-03$ & $-5.1183 E-03$ & $-5.1183 \mathrm{E}-03$ & $-5.1183 \mathrm{E}-03$ \\
\hline & C3 & $0.0000 E+00$ & $0.0000 E+00$ & $0.0000 E+00$ & $0.0000 E+00$ \\
\hline & $\mathrm{C} 4$ & $8.4732 \mathrm{E}-03$ & $1.0401 \mathrm{E}-02$ & 8.4732E-03 & $1.0401 \mathrm{E}-02$ \\
\hline & $\mathrm{C} 5$ & $-1.5363 \mathrm{E}-19$ & $3.0725 \mathrm{E}-19$ & $-1.5363 \mathrm{E}-19$ & $3.0725 \mathrm{E}-19$ \\
\hline & C6 & $0.0000 \mathrm{E}+00$ & $0.0000 E+00$ & $0.0000 E+00$ & $0.0000 \mathrm{E}+00$ \\
\hline \multirow{6}{*}{$\begin{array}{c}\text { Heating Speed } 4 \\
\text { Capacity }\end{array}$} & $\mathrm{C} 1$ & $1.2937 \mathrm{E}+00$ & $1.2081 \mathrm{E}+00$ & $1.2937 \mathrm{E}+00$ & $1.2081 \mathrm{E}+00$ \\
\hline & $\mathrm{C} 2$ & $-5.1183 \mathrm{E}-03$ & $-5.1183 E-03$ & $-5.1183 \mathrm{E}-03$ & $-5.1183 \mathrm{E}-03$ \\
\hline & $\mathrm{C} 3$ & $0.0000 \mathrm{E}+00$ & $0.0000 E+00$ & $0.0000 E+00$ & $0.0000 \mathrm{E}+00$ \\
\hline & $\mathrm{C} 4$ & $-8.4874 \mathrm{E}-03$ & $-1.5371 \mathrm{E}-03$ & $-8.4874 \mathrm{E}-03$ & $-1.5371 \mathrm{E}-03$ \\
\hline & $\mathrm{C} 5$ & $-1.6550 \mathrm{E}-03$ & $-1.2444 \mathrm{E}-03$ & $-1.6550 \mathrm{E}-03$ & $-1.2444 \mathrm{E}-03$ \\
\hline & C6 & $0.0000 \mathrm{E}+00$ & $0.0000 E+00$ & $0.0000 E+00$ & $0.0000 E+00$ \\
\hline \multirow{6}{*}{$\begin{array}{c}\text { Heating Speed } 1 \\
\text { EIR }\end{array}$} & $\mathrm{C} 1$ & 7.3357E-01 & 7.0991E-01 & 7.3357E-01 & $7.0991 \mathrm{E}-01$ \\
\hline & $\mathrm{C} 2$ & $2.8200 \mathrm{E}-02$ & $2.8200 \mathrm{E}-02$ & $2.8200 \mathrm{E}-02$ & $2.8200 \mathrm{E}-02$ \\
\hline & $\mathrm{C} 3$ & $0.0000 \mathrm{E}+00$ & $0.0000 E+00$ & $0.0000 E+00$ & $0.0000 \mathrm{E}+00$ \\
\hline & $\mathrm{C} 4$ & $-5.2458 \mathrm{E}-02$ & $-5.2010 \mathrm{E}-02$ & $-5.2458 \mathrm{E}-02$ & $-5.2010 \mathrm{E}-02$ \\
\hline & $\mathrm{C} 5$ & $1.5587 \mathrm{E}-03$ & 1.8457E-03 & 1.5587E-03 & $1.8457 \mathrm{E}-03$ \\
\hline & C6 & $0.0000 \mathrm{E}+00$ & $0.0000 E+00$ & $0.0000 \mathrm{E}+00$ & $0.0000 \mathrm{E}+00$ \\
\hline \multirow{6}{*}{$\begin{array}{c}\text { Heating Speed } 2 \\
\text { EIR }\end{array}$} & $\mathrm{C} 1$ & $7.4946 \mathrm{E}-01$ & 7.2437E-01 & 7.4946E-01 & $7.2437 \mathrm{E}-01$ \\
\hline & $\mathrm{C} 2$ & $2.8200 \mathrm{E}-02$ & $2.8200 \mathrm{E}-02$ & $2.8200 \mathrm{E}-02$ & $2.8200 \mathrm{E}-02$ \\
\hline & $\mathrm{C} 3$ & $0.0000 E+00$ & $0.0000 E+00$ & $0.0000 E+00$ & $0.0000 \mathrm{E}+00$ \\
\hline & $\mathrm{C} 4$ & $-5.5988 \mathrm{E}-02$ & $-5.3781 E-02$ & $-5.5988 \mathrm{E}-02$ & $-5.3781 \mathrm{E}-02$ \\
\hline & $\mathrm{C} 5$ & $1.7535 \mathrm{E}-03$ & 1.8500E-03 & 1.7535E-03 & $1.8500 \mathrm{E}-03$ \\
\hline & C6 & $0.0000 \mathrm{E}+00$ & $0.0000 E+00$ & $0.0000 E+00$ & $0.0000 \mathrm{E}+00$ \\
\hline \multirow{6}{*}{$\begin{array}{c}\text { Heating Speed } 3 \\
\text { EIR }\end{array}$} & $\mathrm{C} 1$ & $6.2314 \mathrm{E}-01$ & 5.6602E-01 & 6.2314E-01 & $5.6602 \mathrm{E}-01$ \\
\hline & $\mathrm{C} 2$ & $2.8200 \mathrm{E}-02$ & $2.8200 \mathrm{E}-02$ & $2.8200 \mathrm{E}-02$ & $2.8200 \mathrm{E}-02$ \\
\hline & $\mathrm{C} 3$ & $0.0000 \mathrm{E}+00$ & $0.0000 E+00$ & $0.0000 E+00$ & $0.0000 \mathrm{E}+00$ \\
\hline & $\mathrm{C} 4$ & $-4.2402 \mathrm{E}-02$ & $-3.4823 \mathrm{E}-02$ & $-4.2402 E-02$ & $-3.4823 \mathrm{E}-02$ \\
\hline & C5 & 1.9422E-03 & $1.8552 \mathrm{E}-03$ & $1.9422 \mathrm{E}-03$ & $1.8552 \mathrm{E}-03$ \\
\hline & C6 & $0.0000 E+00$ & $0.0000 E+00$ & $0.0000 E+00$ & $0.0000 E+00$ \\
\hline \multirow{6}{*}{$\begin{array}{c}\text { Heating Speed } 4 \\
\text { EIR }\end{array}$} & $\mathrm{C} 1$ & $6.1712 \mathrm{E}-01$ & $5.5768 \mathrm{E}-01$ & $6.1712 \mathrm{E}-01$ & $5.5768 \mathrm{E}-01$ \\
\hline & $\mathrm{C} 2$ & $2.8200 \mathrm{E}-02$ & $2.8200 \mathrm{E}-02$ & $2.8200 \mathrm{E}-02$ & $2.8200 \mathrm{E}-02$ \\
\hline & C3 & $0.0000 \mathrm{E}+00$ & $0.0000 E+00$ & $0.0000 E+00$ & $0.0000 E+00$ \\
\hline & $\mathrm{C} 4$ & $-3.6821 \mathrm{E}-02$ & $-2.8128 \mathrm{E}-02$ & $-3.6821 \mathrm{E}-02$ & $-2.8128 \mathrm{E}-02$ \\
\hline & $\mathrm{C} 5$ & $1.3591 \mathrm{E}-03$ & 1.1719E-03 & $1.3591 \mathrm{E}-03$ & $1.1719 \mathrm{E}-03$ \\
\hline & C6 & $0.0000 \mathrm{E}+00$ & $0.0000 \mathrm{E}+00$ & $0.0000 E+00$ & $0.0000 \mathrm{E}+00$ \\
\hline
\end{tabular}


B-4 


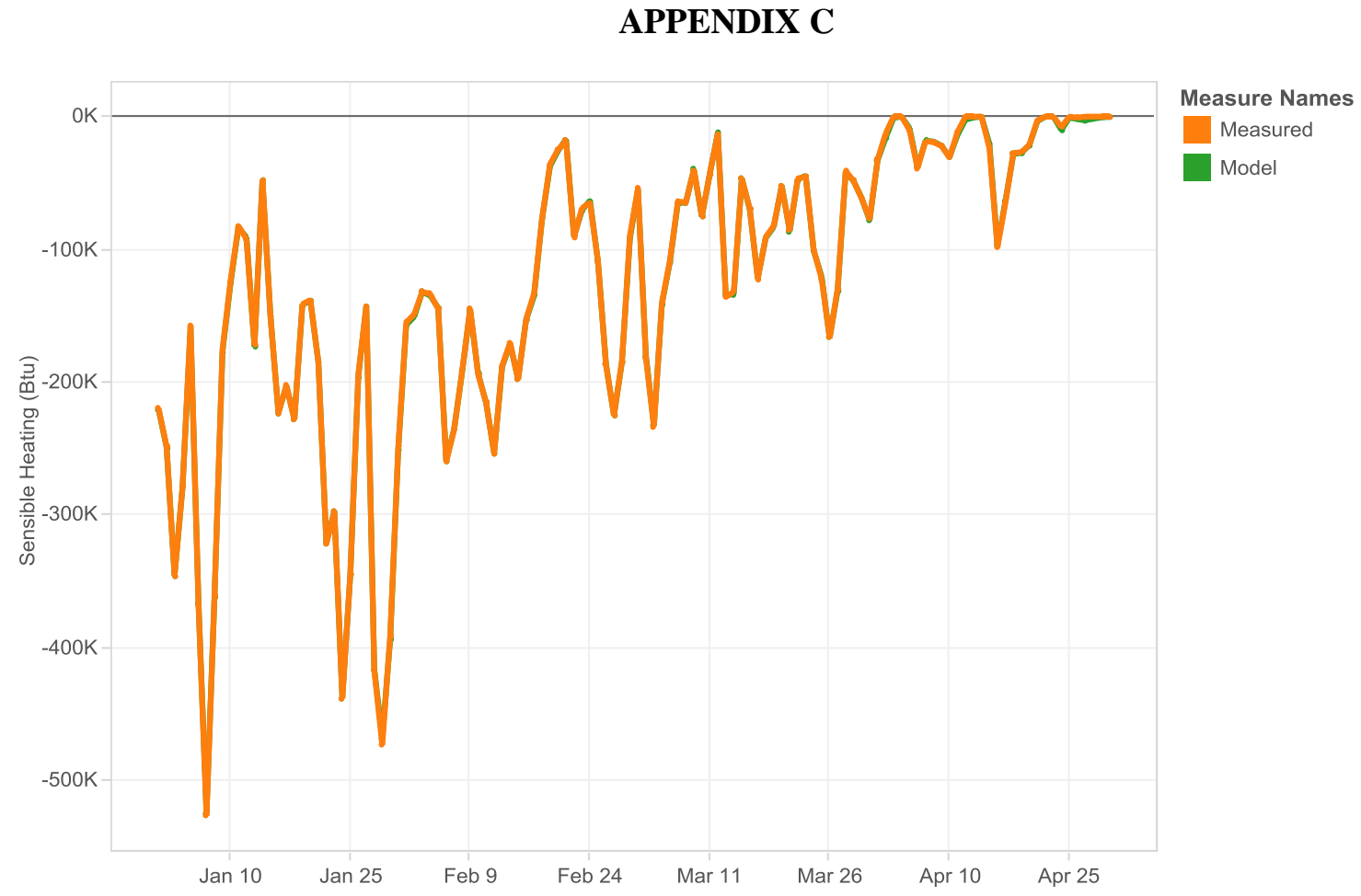

Figure 29: Comparison of sensible heating delivered between field test measurements and model verification simulation for 2-ton field test VSHP

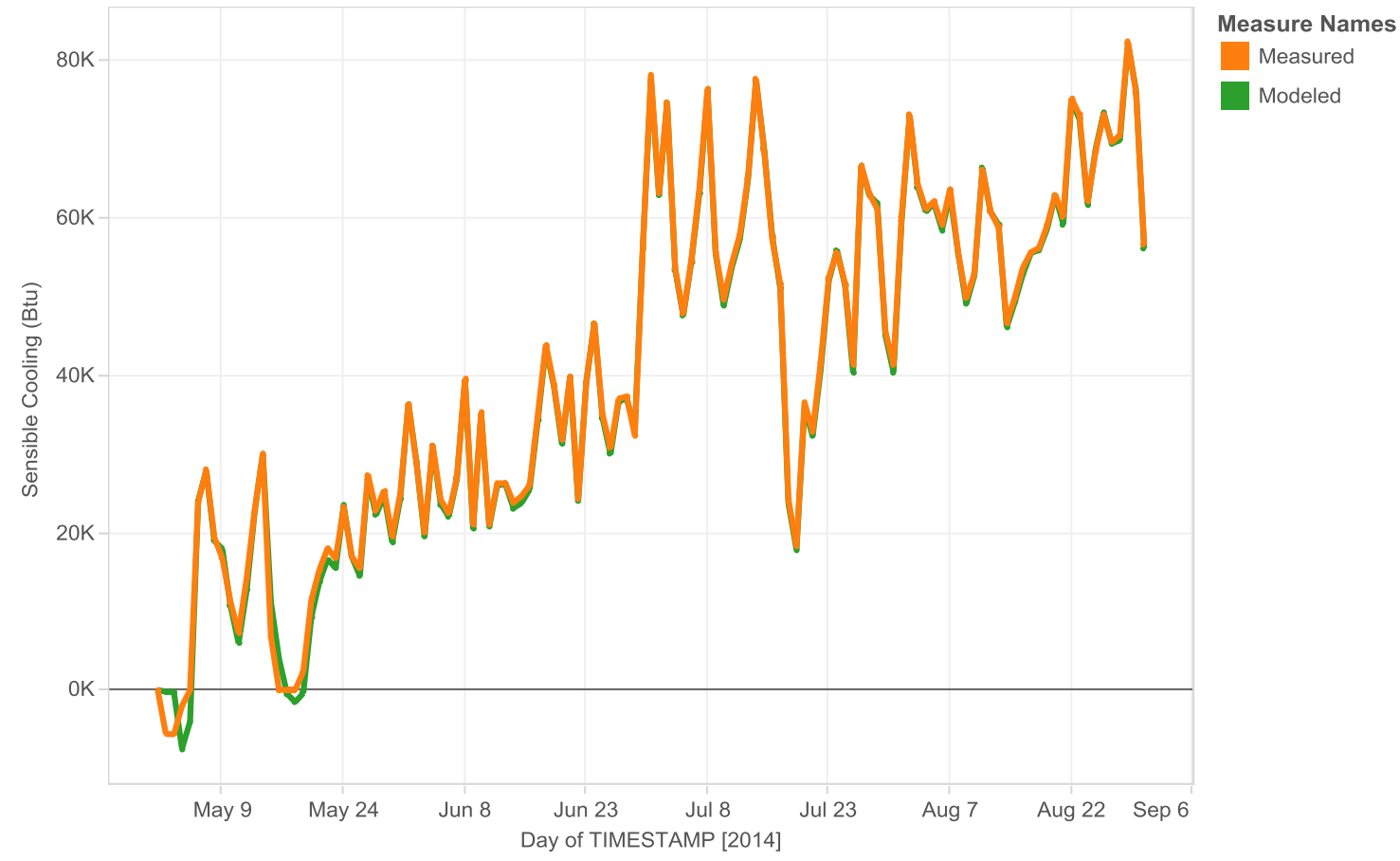

Figure 30: Comparison of sensible cooling delivered between field test measurements and model verification simulation for 2 -ton field test VSHP 


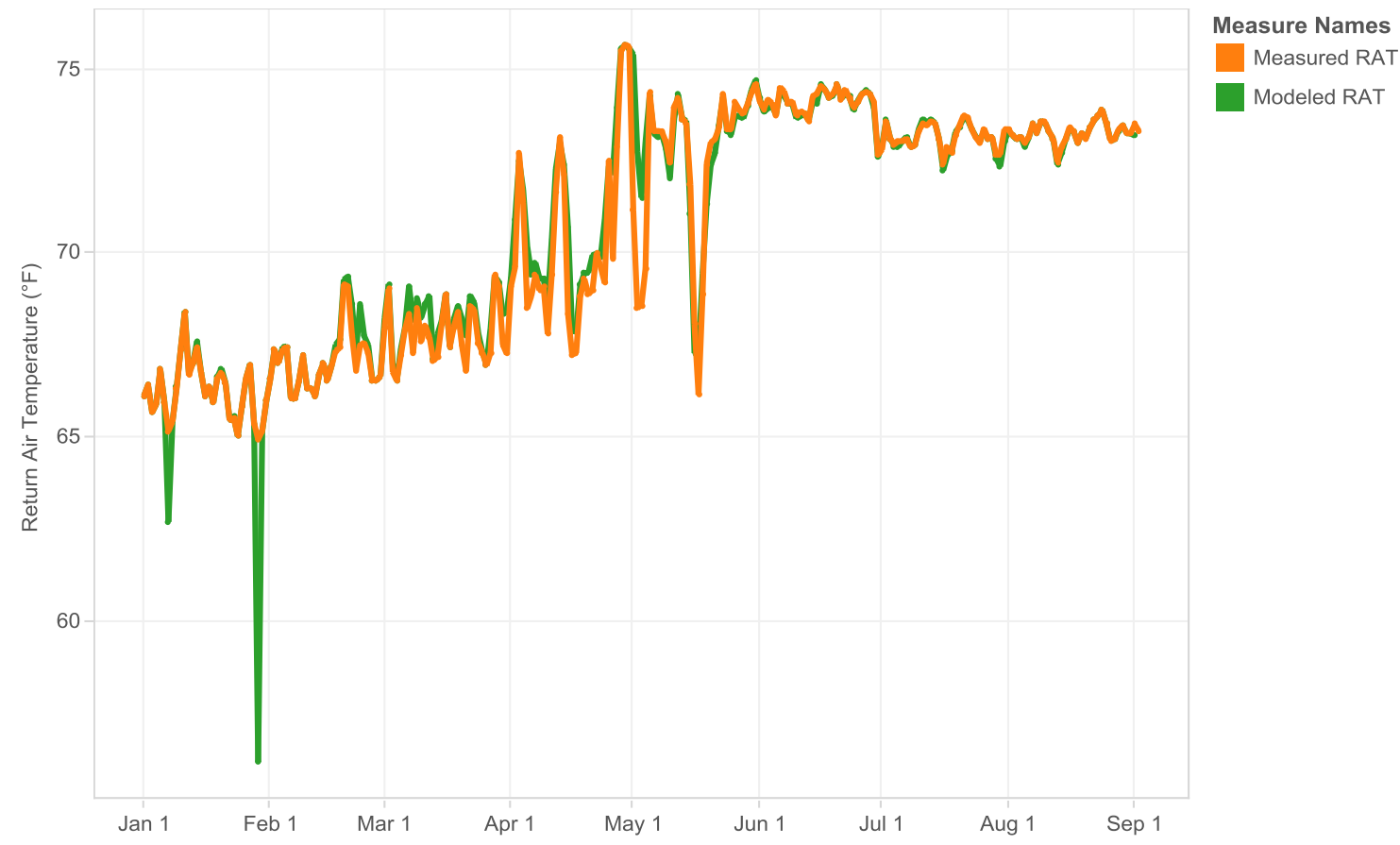

Figure 31: Comparison of return air temperature (RAT) between field test measurements and model verification simulation for 2-ton field test VSHP

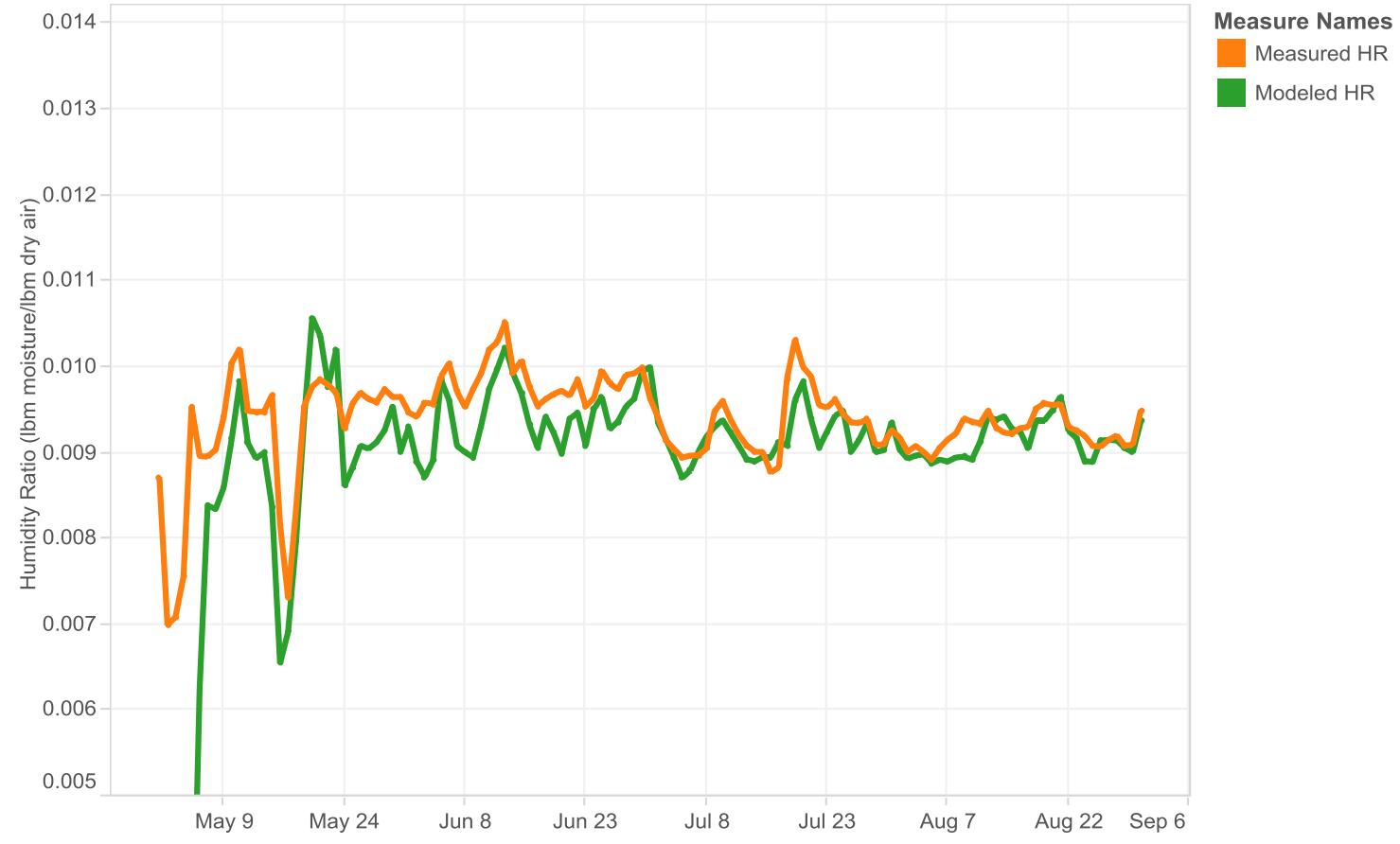

Figure 32: Comparison of return air humidity ratio between field test measurements and model verification simulation for 2-ton field test VSHP 


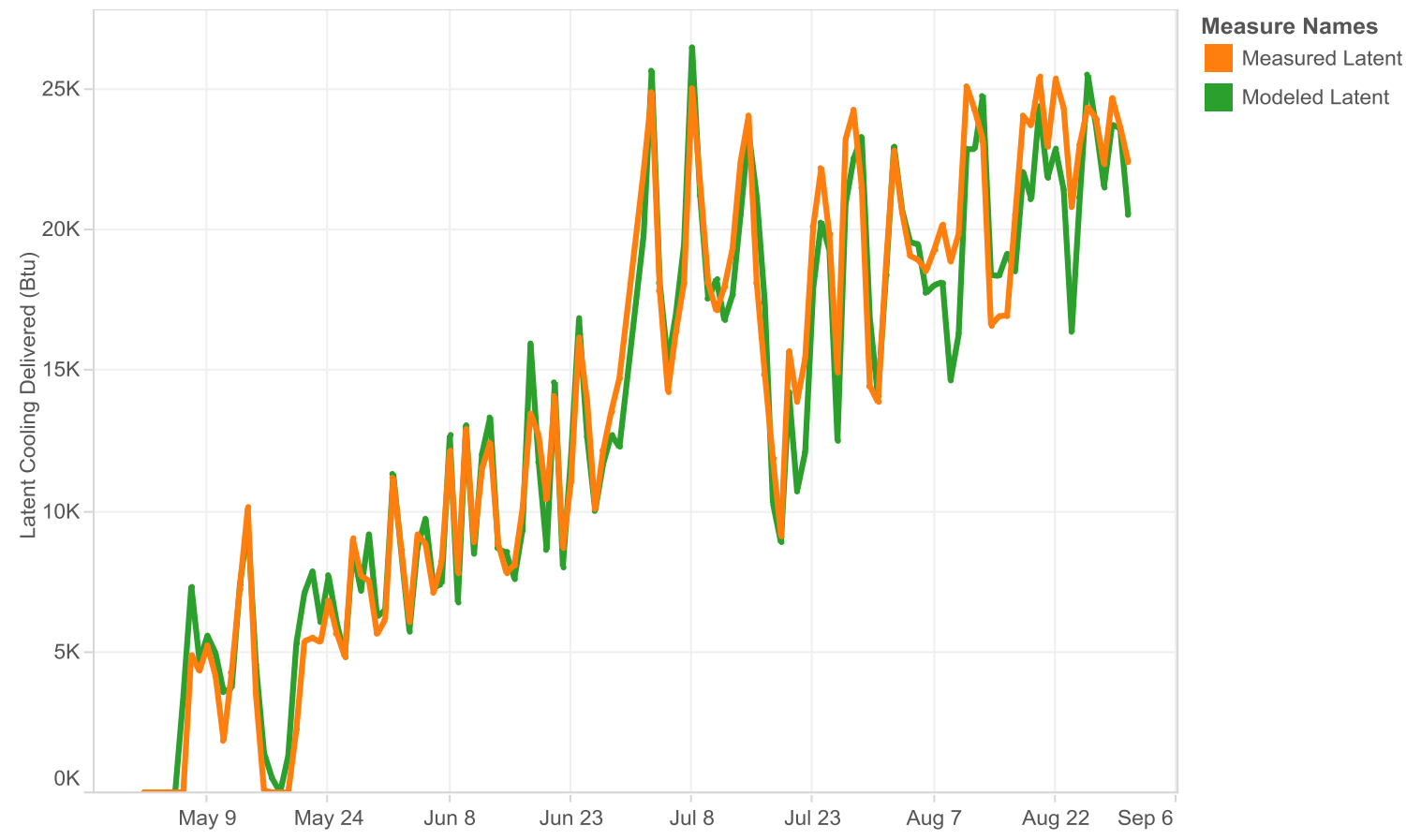

Figure 33: Comparison of latent cooling delivered between field test measurements and model verification simulation for 2 -ton field test VSHP

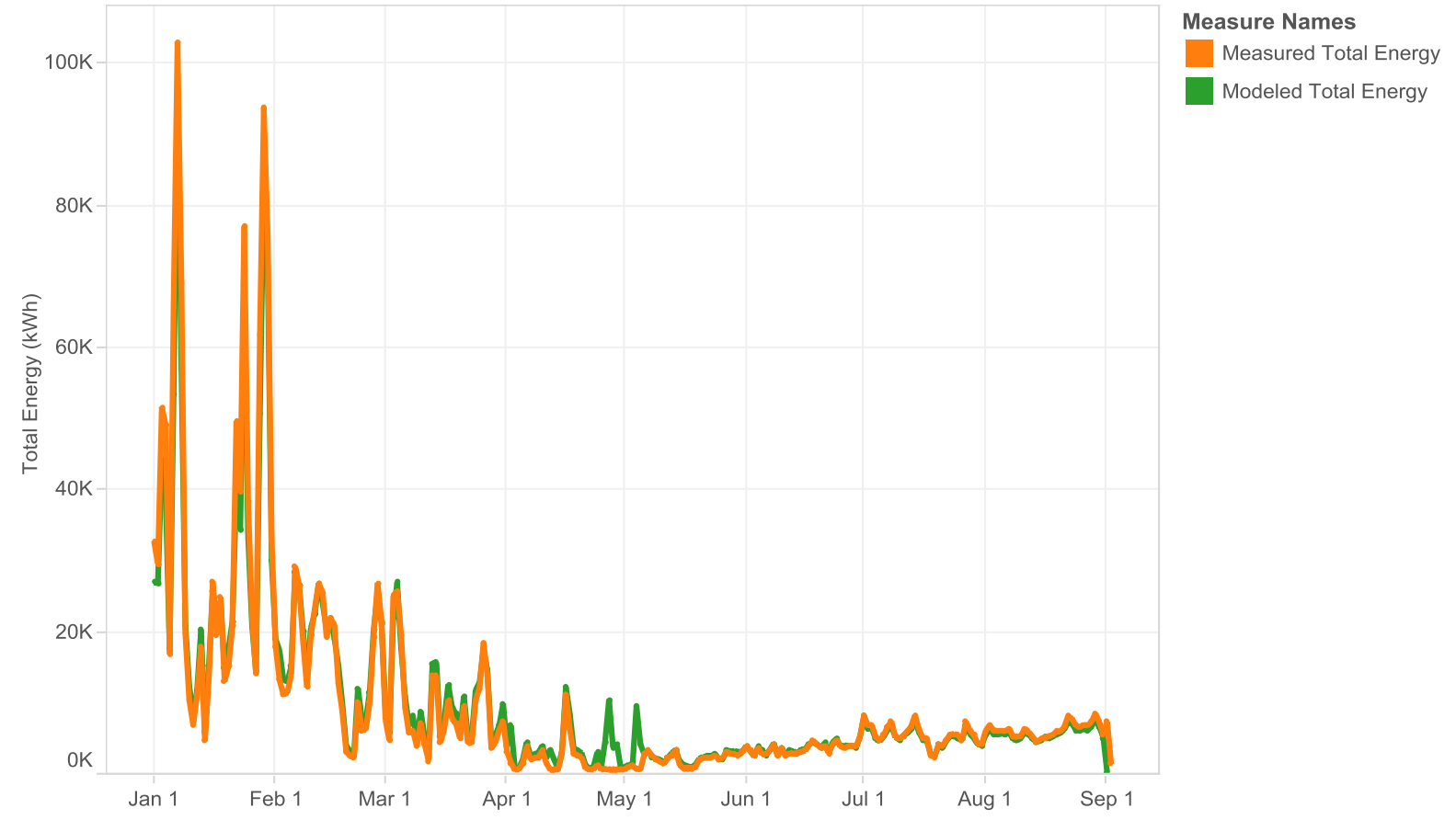

Figure 34: Comparison of heat pump system energy consumption between field test measurements and model verification simulation for 2-ton field test VSHP 


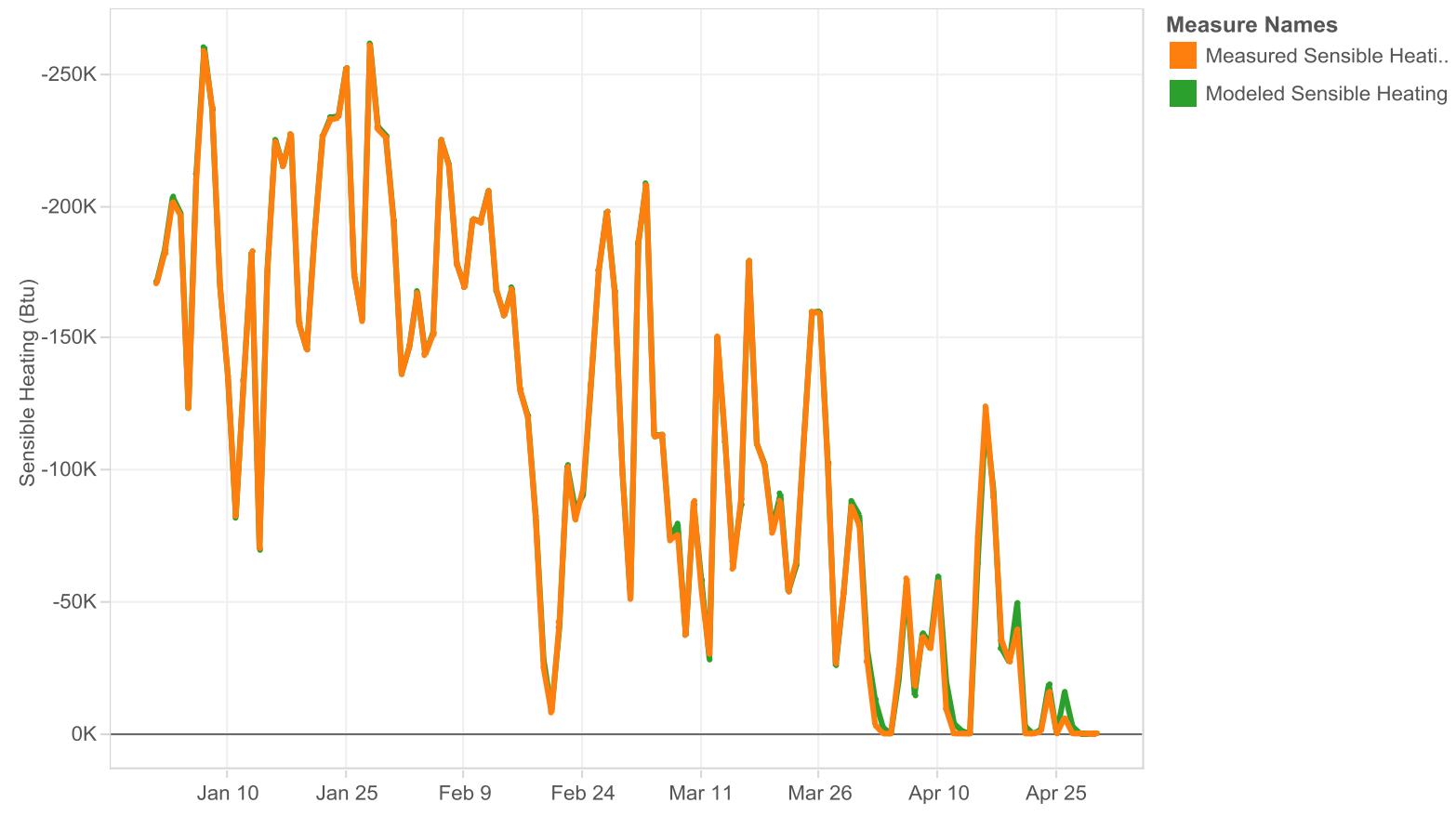

Figure 35: Comparison of sensible heating delivered between field test measurements and model verification simulation for 3-ton field test VSHP

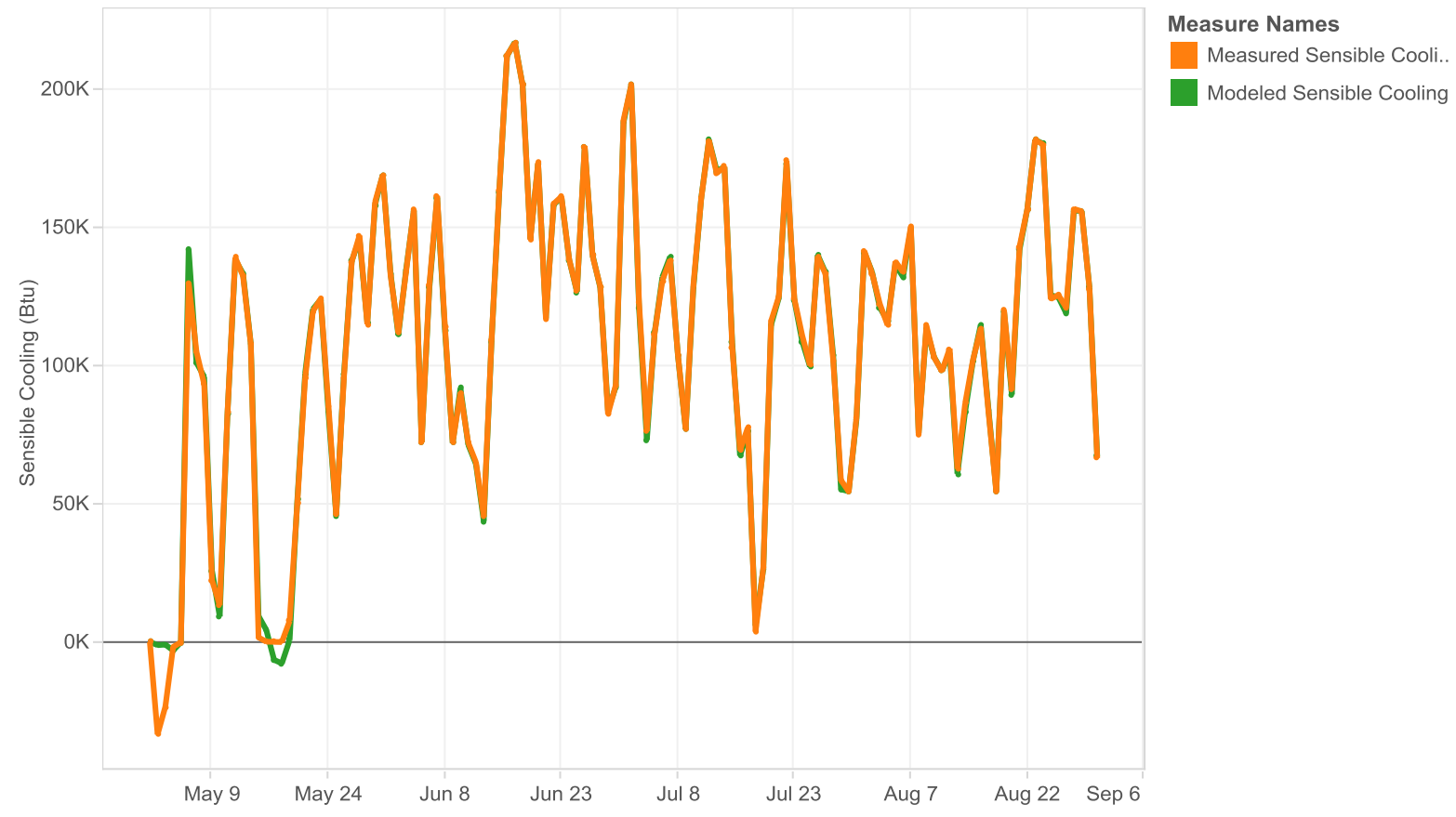

Figure 36: Comparison of sensible cooling delivered between field test measurements and model verification simulation for 3-ton field test VSHP 


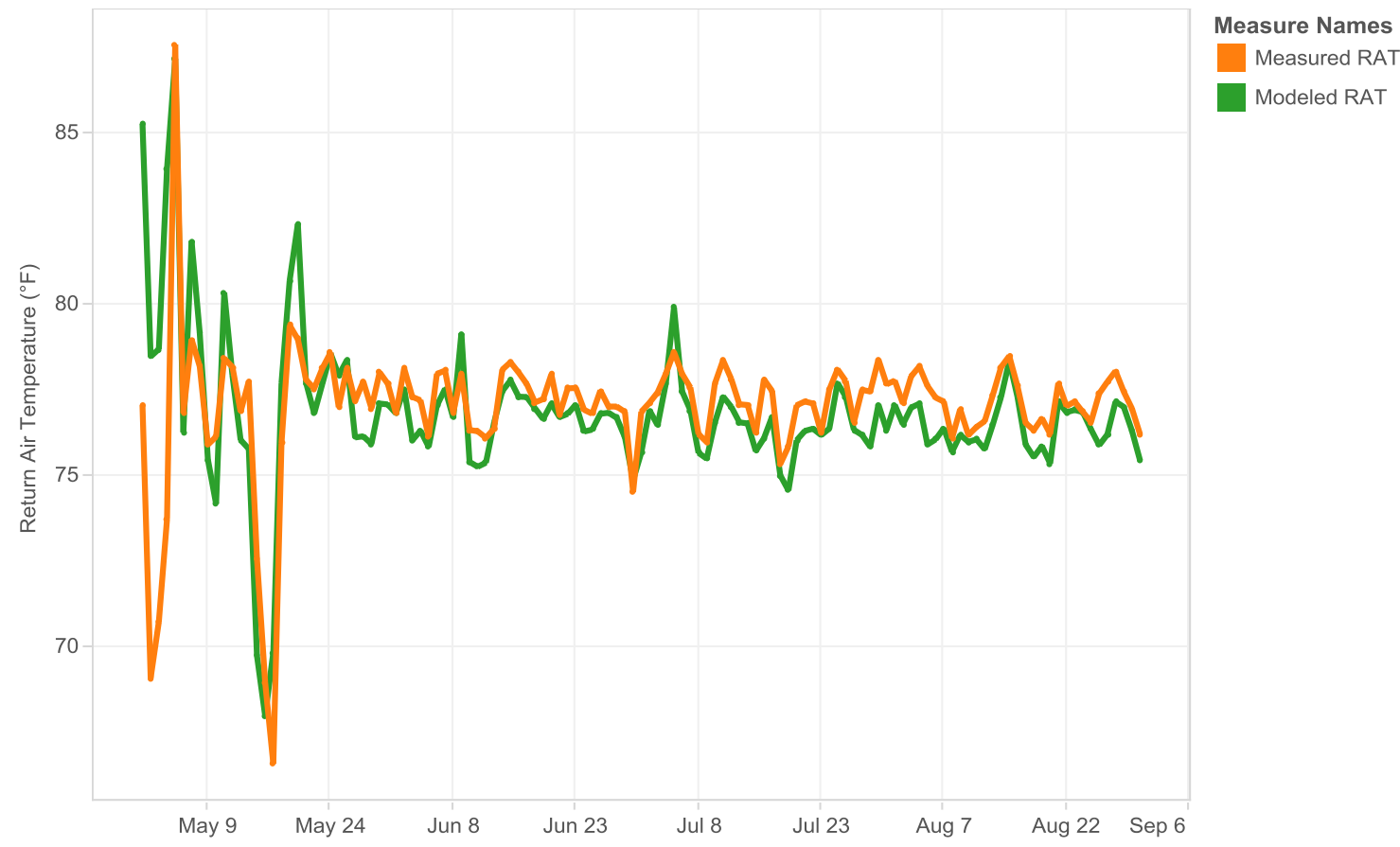

Figure 37: Comparison of return air temperature (RAT) between field test measurements and model verification simulation for 3-ton field test VSHP

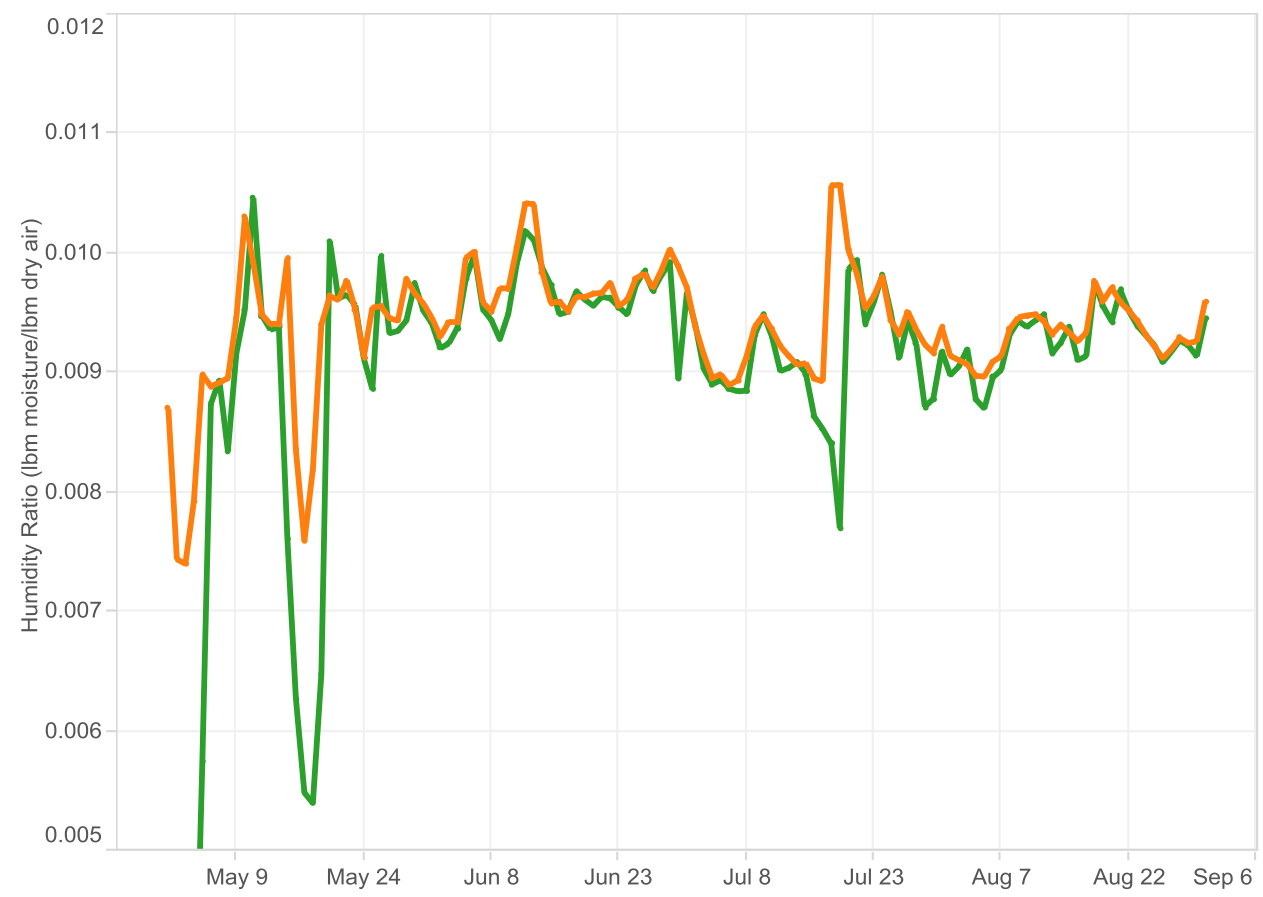

Measure Names

Figure 38: Comparison of return air humidity ratio between field test measurements and model verification simulation for 3-ton field test VSHP 


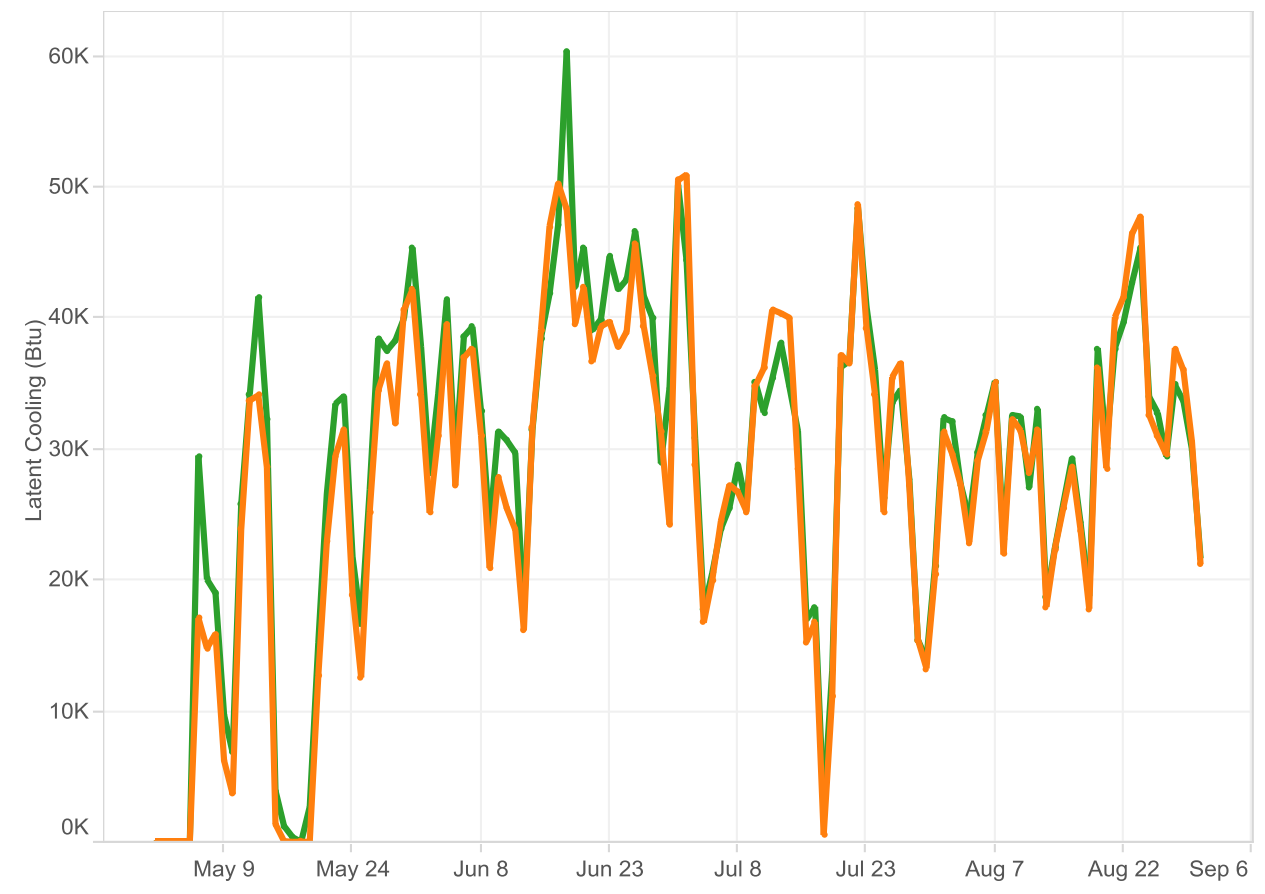

Figure 39: Comparison of latent cooling delivered between field test measurements and model verification simulation for 3-ton field test VSHP

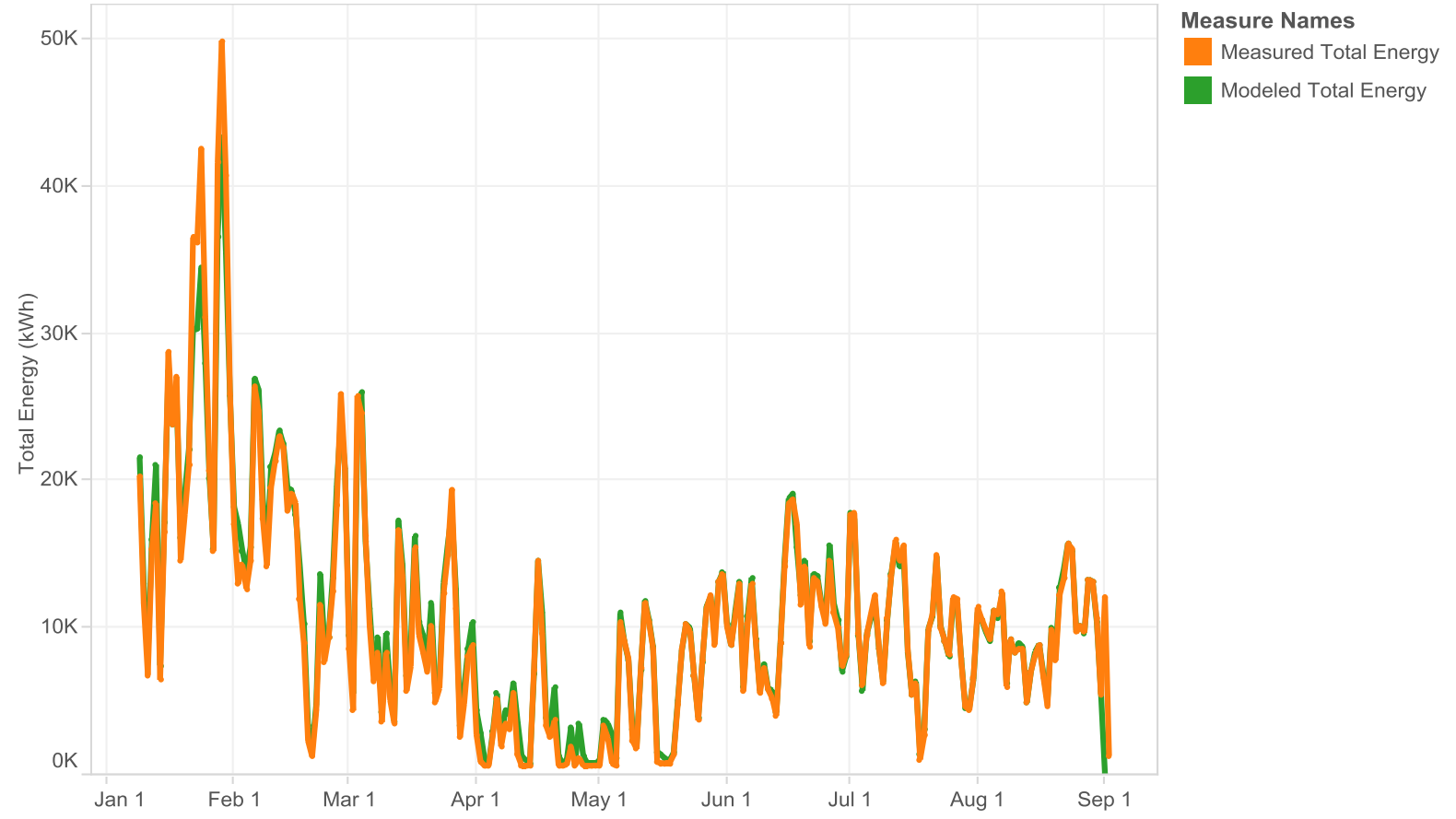

Figure 40: Comparison of heat pump system energy consumption between field test measurements and model verification simulation for 3-ton field test VSHP 
